Florida International University FIU Digital Commons

$11-10-2011$

\title{
Swimming Against the Tide: A Study of a Youth Enrichment Program Seeking to Empower Inner- City Black Youth
}

Jayne A. Klein

Florida International University, martinj@fiu.edu

DOI: $10.25148 /$ etd.FI11120505

Follow this and additional works at: https://digitalcommons.fiu.edu/etd

\section{Recommended Citation}

Klein, Jayne A., "Swimming Against the Tide: A Study of a Youth Enrichment Program Seeking to Empower Inner-City Black Youth" (2011). FIU Electronic Theses and Dissertations. 488.

https://digitalcommons.fiu.edu/etd/488 


\section{FLORIDA INTERNATIONAL UNIVERSITY \\ Miami, Florida}

\section{SWIMMING AGAINST THE TIDE: A STUDY OF A YOUTH ENRICHMENT PROGRAM SEEKING TO EMPOWER INNER-CITY BLACK YOUTH}

A dissertation submitted in partial fulfillment of the

requirements for the degree of

DOCTOR OF EDUCATION

in

HIGHER EDUCATION ADMINISTRATION

by

Jayne A. Klein

2011 
To: $\quad$ Dean Delia Garcia

College of Education

This dissertation, written by Jayne A. Klein, and entitled Swimming Against the Tide: A Study of a Youth Enrichment Program seeking to Empower Inner-City Black Youth, having been approved in respect to style and intellectual content, is referred to you for judgment.

We have read this dissertation and recommend that it be approved.

\section{Roger Geertz Gonzalez}

Glenda D. Musoba

Lesley A. Northup

Benjamin Baez, Major Professor

Date of Defense: November 10, 2011

The dissertation of Jayne A. Klein here is approved.

Dean Delia C. Garcia

College of Education

Dean Lakshmi N. Reddi

University Graduate School

Florida International University, 2011 


\section{DEDICATION}

This work is dedicated, first, to the memory of my mother and father, who I wish could be here to share this accomplishment with me. It is dedicated, next, to my dear friend and colleague Fred Rosario, whose example has lighted the way; and to his wife, Brenda, whose warmth and friendship first led me to him. And finally, it is dedicated to Alonzo Mourning, whose selfless work with the young people in Overtown was and still is my greatest inspiration. 


\section{ACKNOWLEDGMENTS}

There are so many people who need to be acknowledged for the valuable contributions they have made to the completion of this work. First and foremost, I wish to acknowledge everyone on the staff of the Overtown Youth Center for their willingness to share their insights and knowledge about the Center with me. Next, the true depth and scope of this work would never have been possible without the input of the very special young people who attend the Center, all of whom shared the stories of their lives with me so openly and honestly. I have come to know, respect, and love every one of them very much. My deepest appreciation, special thanks, and a world of hugs go out, especially, to Deborah, Reginald, Jonathan, DeAndre, Lorenzo, and Khiry. I also wish to make special mention of Carla Penn, who facilitated this experience for me by sharing her insight on the Center and providing me with such open access to it.

I wish to acknowledge, also, Dr. Benjamin Baez, the chairperson of my dissertation committee, for the breadth of his knowledge and his encouragement, understanding, patience, sense of humor, and often revolutionary thinking. Thank you, too, to Dr. Linda Bliss, for her invaluable input; the members of my dissertation committee for being there for me; and Caprila Almeida, for always being available to direct my steps as I navigated through the seemingly interminable dissertation forms and other paperwork.

Last but certainly not least, my deepest appreciation goes out to my friends Tasha, Libby, Sallie, Peter, Dori, Roberta, and Dwight. You all stood by me, encouraged me, and helped motivate me to keep on writing, even when I was feeling ready to give up. 


\section{ABSTRACT OF THE DISSERTATION \\ SWIMMING AGAINST THE TIDE: A STUDY OF A YOUTH ENRICHMENT \\ PROGRAM SEEKING TO EMPOWER INNER-CITY BLACK YOUTH}

by

Jayne A. Klein

Florida International University, 2011

Miami, Florida

Professor Benjamin Baez, Major Professor

Serious inequities in our K-12 public education system, particularly in regard to the quality of education in predominately Black inner-city schools, are well-documented in the literature (Freeman, 1998; Ross, 1998). Moreover, there is general agreement that the most effective means of ameliorating that situation is through well-thought-out afterschool programs and partnership initiatives (Beck, 1993; Gardner et al., 2001).

The purpose of this qualitative study was to examine the programmatic interventions of a youth enrichment program for inner-city Black youth currently in place at the Overtown Youth Center (OYC) in Miami, Florida, in order to: (a) discern those factors that support its claim that it is making a difference in students' lives, (b) explore how any such factors are implemented, and (c) determine whether its interventions have served to equalize the playing field for these youth.

Two primary methods of data collection were used for this study. The first was participant observation conducted over the course of two years through a partnership initiative established and led by this author. The second was through in-depth interviews 
of the Center's founder, staff, and students. Secondary methods used were the recording of informal conversations and the analysis of written documents.

Analysis of the data yielded four features of the Center that are indispensible to the students' growth. The center provides the youth with (a) physical and psychological safety, (b) supportive relationships, (c) exposure to cultural and educational opportunities, and (d) assistance in building self-esteem.

The most significant finding of the study was that OYC has been successful at making a difference in students' lives and at increasing their aspirations to attend college. By addressing the full spectrum of their needs, the Center has given them many of the necessary tools with which to compete and thereby helped equalize their opportunities to succeed in school and in life.

The study also noted a number of challenges for the Center to examine. The main issues that need to be addressed more seriously are staff turnover, staff indifference, nepotism, inconsistent student attendance, and insufficient focus on racial issues and African-American-centered education. Meeting those challenges would engender even greater positive outcomes. 


\section{TABLE OF CONTENTS}

CHAPTER

PAGE

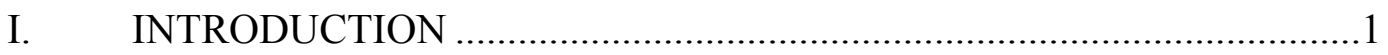

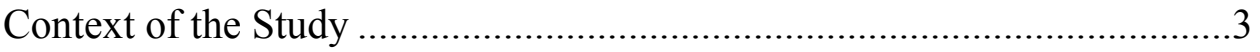

Research Questions .............................................................................15

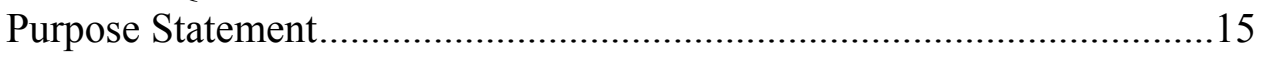

Assumptions and Delimitations of the Study...........................................16

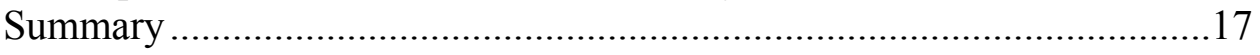

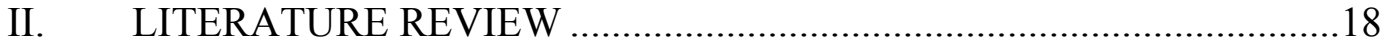

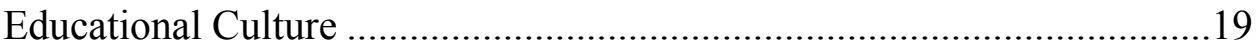

At-Risk Students and At-Risk Behaviors .............................................23

Prevention and Intervention Initiatives: After-School Programs................28

University/Community Partnerships........................................................38

Critical Race Theory as a Framework in Educational Research..................42

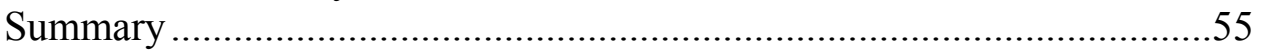

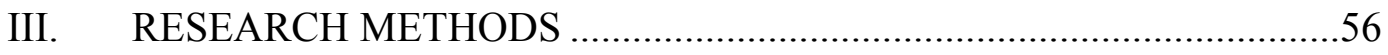

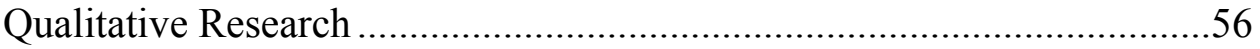

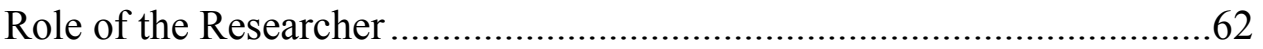

Site and Participant Selection .................................................................66

Data Collection Procedures..................................................................... 70

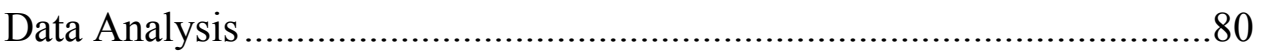

Credibility and Integrity of the Study ...................................................8 84

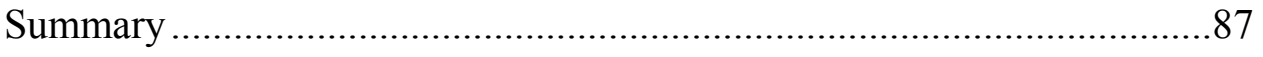

IV. OVERTOWN YOUTH CENTER: HISTORY AND STRUCTURE.........89

The Founding of the Overtown Youth Center ...........................................90

Self-Enhancement Incorporated.............................................................94

Replicating the SEI Program at OYC ......................................................97

The SEI/OYC Program Model....................................................................98

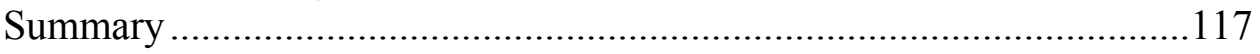

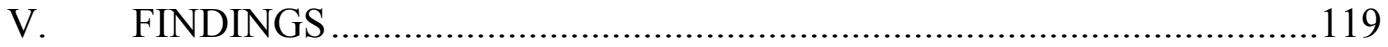

Growing up in Overtown ................................................................120

Relationships With Adults and Peers.....................................................125

Exposure to Cultural and Educational Experiences ..................................140

Physical and Psychological Safety........................................................165

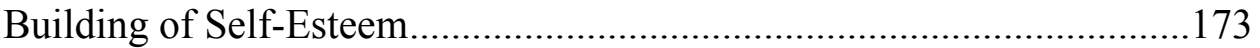

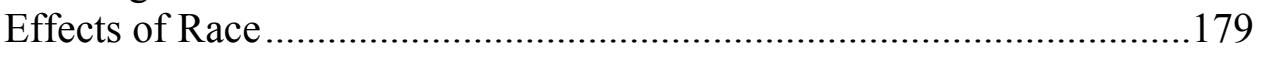

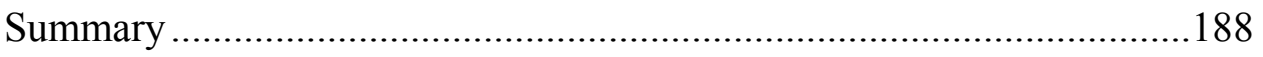


VI. DISCUSSION AND RECOMMENDATIONS..................... 191

Review of the Study............................................191

Discussion of Findings........................................... 199

Implications for Further Research and Study......................211

Limitations of the Study.......................................223

Some Final Thoughts............................................224

LIST OF REFERENCES..............................................227

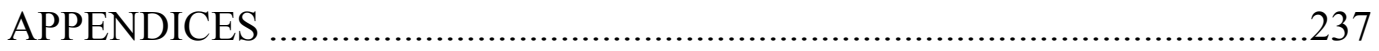

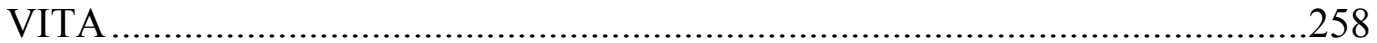




\section{CHAPTER I}

\section{INTRODUCTION}

Education has always played a central role in the determination of the life circumstances of Blacks in the United States (Allen, 1998; Freeman, 1998; Ross, 1998). It is their access to education, or the lack thereof, which has always been the most significant determinant of their unequal economic, cultural, political, and social status (Allen, 1998; Allen \& Jewel, 1995).

The inequities and inadequacies of the K-12 public educational system, and the vast discrepancy that exists between the quality of education in inner-city schools, which serve predominately Black and minority students from low socioeconomic backgrounds; and suburban schools, which serve predominately White, middle-class students, have been well documented in the literature (Freeman, 1998; Wilson, 1998). It is largely because of their awareness of this discrepancy that Blacks in America have historically struggled to gain equal access to the nation's schools and to exert some degree of control over the content of the schooling process as it relates to them (Allen, 1998).

The primary focus of the present study is on addressing the overwhelming need to find innovative ways in which to level the playing field in education, particularly for atrisk, inner-city Black youth. For my purposes here, I use the term "risk" as it has been used by Kopp (1983), who defined it as referring to "a wide range of biological and environmental conditions that are associated with an increased probability for cognitive, social, affective, and physical problems" (p. 1086). From an educational perspective, students at-risk have been identified as those who appear to be predisposed to 
experiencing the kinds of difficulties in typical school programs that greatly limit their ability to succeed (Henderson-Sparks, 2002).

One factor that researchers have associated most consistently with students being at risk or under achieving in school is poverty (Henderson-Sparks, 2002; McWhirter, 1998; Natriello, McDill, \& Pallas, 1990). Students who come from low-socioeconomic, low-skill, and/or low-education family backgrounds, a large percentage of whom are Black males, disproportionately attend large inner-city schools, in which the academic achievement levels and graduation rates are very low in comparison to national averages (Baker, 2005; Noguera, 2003). These students are about twice as likely to drop out of school as students from affluent families (Noguera, 2003). Furthermore, research has identified Black adolescent males, in particular, as being excessively represented in almost every category of academic failure (Martin, D., Martin, M., Gibson, S. S., \& Wilkins, J., 2007).

The object of my research is a youth enrichment program currently in place at the Overtown Youth Center (OYC) in Miami, Florida, which claims to be having measurable success in empowering the young people participating in its programs. The Center is a privately run, not-for-profit, comprehensive program. It works both in conjunction with the public elementary, middle, and high schools attended by the Center's students and with other groups and individuals operating outside and beyond the purview of the public school system.

By thoroughly examining the perspectives, attitudes, and experiences of the Center's administrators, staff, and students, I have sought to discover if and in what ways participating in the Center's activities has helped to bring about noticeable changes in 
those aspects of the students' lives that the Center is trying to address, particularly their attitudes toward school and education in general, their aspirations in regard to attending college, their academic performance, their patterns of behavior, their levels of selfesteem, and other related issues.

In this chapter, I provide an overview of the research project I conducted. I detail its context, discuss the need for the study and its importance to the field, outline my major objectives, present my research questions, and discuss the study's assumptions and delimitations.

\section{Context of the Study}

How we have arrived at the present state of affairs can be understood only by studying the forces effective in the development of Negro education since it was systematically undertaken immediately after emancipation. To point out merely the defects as they appear today will be of little benefit to the present and future generations. These things must be viewed in their historical setting. The conditions of today have been determined by what has taken place in the past, and in a careful study of this history, we may see more clearly the great theater of events in which the Negro has played a part. We may understand better what his role has been and how well he has functioned in it. (Woodson, 1933, p. 9)

The words of the notable African-American scholar, Dr. Carter G. Woodson, hold the same truth today as when they were written almost 80 years ago. In order to fully understand the breadth and depth of the issues faced by Blacks in their quest to attain educational equity in America, we must first examine the nature of their struggle and the history of their journey. It would be almost impossible to understand the totality of the Black educational experience without an awareness of its historical and cultural context. Thus, only by looking at the historical events that set the stage so long ago as well as at the current conditions affecting their educational experiences can we truly appreciate the strength of character that obtaining greater educational opportunity has always demanded 
of them and the dedication it has taken - and will still take - for them to continue to engage in that struggle today.

What has come to be known as "the American dream" is something that lies at the very heart of our American cultural ethos. At the center of that dream is the conviction that, at least in this society, education is the thing that can open the door to success and upward mobility. As such, education can be viewed as one of the essential foundations of democracy. The belief that even the poorest American can achieve greatness as a result of his or her talent (or, more specifically, his or her educational attainment) coupled, of course, with hard work, has always been one of this society's most cherished cultural ideals (Allen \& Jewell, 2002). The extent to which individuals are afforded the opportunity to obtain knowledge in a society, then, speaks volumes about the openness (or lack thereof) of that society and about the power relations that function within it.

\section{Critical Race Theory}

One of the central themes of critical race theory (CRT), a theory that I will discuss in greater detail in Chapter 2, is the contention that the persistent struggle for liberation in the history of the education of Blacks in America needs to be illuminated (Saddler, 2005). Once illuminated, what critical theorists describe as "the American colonial education system," which harbors an ideology of cultural monism and elitism, must be deconstructed through careful analysis and a variety of somewhat unconventional research methods, such as story telling and the use of narratives.

Critical race theory points out that, in our society, White culture has come to be representative of the norm: that is, it is the dominant culture against which all other comparisons are made. As such, the views it holds - whether right or wrong - have been 
adopted and accepted by the majority of White Americans, who then perceive those views as universal. When looked at from that perspective, the entire concept of race can be seen as nothing more than a social label; and the meaning we have applied to that label as being based upon and justified by an ideology of racial superiority and White privilege (Solorzano \& Yosso, 2001).

Many critical race scholars in the field of education today express the belief that racism and racist policies are embedded not only in the American educational system but also in just about every other institution in our society (Artiles, 1998; DeCuir \& Dixson, 2004; Lintner, 2004; Morris, 2002; Solorzano \& Yosso, 2001; Stovall, 2004). The first theme of critical race theory, then, posits that racism is a normal part of American society, that it has become a normal daily fact of life in society, and that its dogmatic assumptions are so deeply ingrained in our political and legal structures as to be almost unrecognizable (Delgado, 1995). Critical race theorists also contend that racial stereotyping runs rampant in our media as well as in our educational and professional environments; and that it is used, among many other things, to blame unequal outcomes on Blacks themselves rather than on society and its institutions - which is where the blame belongs (Solorzano \& Yosso, 2001).

\section{Historical Overview of Education in the United States}

The harshest reality about our educational system in the United States is found in its long history of discrimination against minority groups - and Blacks, in particular. This has been evidenced, first, in the systematic resistance to providing them with any kind of education at all; and second, in the frequently violent resistance, particularly in the southern states, to school desegregation. The need for legal pressures and extended 
litigation to require educational institutions to accept their obligation to serve equitably a more diverse group of students has conveyed not only the message of institutional resistance but also, in many cases, outright hostility toward people of diverse backgrounds (Rossides, 2004).

There have, of course, been many attempts to assuage the problem. For example, the federal government has passed legislation designed to put an end to racial discrimination in education (as well as in other areas). Our federal judicial system, too, most notably the Supreme Court of the United States, has played a major role in attempting to uphold and promote our nation's stated goal of equality of opportunity for all of its citizens. Unfortunately, however, many of those attempts have been halfhearted and only partially successful, at best (Williams, 1988).

Prior to and during the Civil War, there were virtually no educational opportunities for Blacks in the southern states. Black slaves were forbidden to learn to read or write under threat of physical harm or death. The only education any of them was ever permitted to receive was occasional industrial arts training on the plantation under the apprenticeship system (Brown, 1999). Those few educational venues for Blacks that did exist during that time consisted of a smattering of progressive liberal arts institutions in the northeast and the so-called "normal" schools, which were established by abolitionists for non-slaves.

In the years immediately following the Civil War, the experience of forced ignorance under slavery inspired Blacks to seek formal education as a means of distancing themselves from the indignities of slavery and their subordinate status in society. Formal education represented a vital means for them to achieve some degree of 
social mobility as well as to maintain their newly gained rights as citizens. In spite of the seemingly insurmountable limitations they faced, a large number of Blacks embraced the American dream as gospel and invested education with qualities of almost mythic proportions, seeing it as their only hope and salvation for the future (DeCuir \& Dixson, 2004).

During the decade following the Emancipation Proclamation (1863), it became evident to many Americans that a system of formal education had to be established to meet the needs and conditions of its newly freed Black citizens. However, great debates soon arose as to the type of education these newly freed slaves should be given access to.

At one extreme, there was a small cadre of educational leaders and policy makers who felt strongly that providing a liberal education to the freed slaves would be a cornerstone in the efforts to integrate Blacks into the mainstream of American activities (Bullock, 1967). For the more liberal and dominant segments in this group, most of whom were missionary philanthropists, the intention of education was "to prepare a college-bred Black leadership to uplift the Black masses from the legacy of slavery and the restraints of the post bellum caste system ... for participation in the political economy of the New South" (Anderson, 1988, pp. 240-241).

At the opposite extreme, there was a group with equally strong convictions on the issue who felt that the newly freed slaves were not capable of appreciating or even understanding a liberal arts education. Thus, rather than supporting a liberal arts education for them, this group favored providing them with a strictly industrial education, which, they believed, was all the newly freed slaves needed to prepare them to participate in the American work force. 
Regardless of the amount or type of education Blacks in America managed to obtain, however, they continued to be subject to discrimination based solely on the color of their skin. Nevertheless, in spite of that; and in spite of the negative societal stereotypes of Blacks that arose; and even in spite of the fact that, more often than not, their concerted efforts to obtain an education continually sparked threatening responses from White southerners, who continued to feel that educating Blacks would undermine both the South's agricultural economy and its power base, Blacks in America continued to crave and to embrace education as a key solution to all of their economic and social problems. And, even as America developed history's most elaborate institutional barriers to deny them equal access to learning and knowledge, Blacks continued to view and pursue education as their primary means of salvation, freedom, and independence (Allen \& Jewell, 2002).

\section{Historically Black Colleges and Universities (HBCUs)}

The founding of the first Historically Black Colleges and Universities (HBCUs) filled an important gap in the educational terrain of Black America. Founded primarily between the 1860s and the 1930s, HBCUs were a direct outgrowth of the desire of Blacks - and their White supporters - to build a system of higher education that would facilitate their social, economic, and political uplifting, thus representing the first rung in the ladder of freedom and success for them. As such, HBCUs became the very embodiment of the Black quest for education and the embodiment of all of the hopes and frustrations of "a people seeking the Promised Land" (Bullock, 1967).

At the same time, however, for a very long period in American history, HBCUs were, with a few exceptions, such as Oberlin College in Ohio, virtually the only 
educational option available in higher education for Blacks. Thus, by extension, HBCUs must also be seen as historical by-products of systematic social discrimination against Blacks in the United States (Bullock, 1967).

In spite of the difficulties they have had to face throughout their history, most significant among them being strong opposition to their very existence on the part of many of the southern states, a critical lack of funding, and an insufficient number of qualified teachers, HBCUs have still managed to function as multifaceted institutions. They have provided not only education for Blacks in America, but also social, political, and religious leadership for the Black community (Allen \& Jewell, 2002).

For the purposes of this study, the most significant aspect of HBCUs is their educational climate, or culture. That is because the majority of the research on HBCUs has demonstrated unequivocally that it is their culture, more than any other factor, which is responsible for the success in college of Black students, as measured by such things as academic achievement, retention, and persistence to graduation (Kim, 2002; Outcault \& Skewes-Cox, 2002; Rhoads, Saenz, \& Carducci, 2004; Seifert, Drummond, \& Pascarella, 2006; Watson, 1998).

One of the things I have attempted to determine in this study is whether we could expect to have the same positive results with the Black youth attending our inner-city public schools if we were to replicate the educational culture of the HBCUs in those schools. Doing so would, of course, require a complete overhauling of our entire public school system, which at this point in time may be too lofty a goal. Nevertheless, there is something we can begin - and are beginning - to do now that will pave the way and set the stage for such a transformation. The establishing of comprehensive youth enrichment 
programs in our inner-city neighborhoods that concentrate on fostering the same type of social and educational culture as that of the HBCUs would certainly be one of the things that would move us closer to that goal.

\section{Federal Involvement in Educational Policy}

While it is not within the purview of this study to go into detail about the myriad court cases and legislation that formed a part of the history of the period from the end of the $19^{\text {th }}$ century to the end of the $20^{\text {th }}$ century, I will provide a brief overview of two of the most significant efforts on the part of the federal government to put an end to segregation in education (and in other areas of American society as well).

In 1954, the Supreme Court of the United States issued a landmark decision in the case of Brown v. Board of Education of Topeka, Kansas. There is no doubt that the Court's decision, which challenged segregation in public schools, was instrumental in initiating monumental changes in the way public schools in America operated. However, while the decision did pave the way for the establishment of equal opportunity in education, the work the Court envisioned ended up being only half done, primarily because the Court did not include in its decision any specific measures for enforcing school desegregation. That unfortunate omission left the door wide open for the states to devise any number of strategies to prevent desegregation from taking place. Therefore, in order to get the rest of the job done, it would take a great deal more effort, particularly in the area of combating southern White resistance.

In the years following 1954, due in large part to the decision in Brown - and to the strong opposition it engendered - a powerful civil rights movement began to form. Black clergy who favored a non-violent approach to the issue led the first proponents of 
the movement. Later on, however, a more radical, separatist movement among Blacks, which was supported by Whites from growing progressive and New Left groups, formed and achieved a major victory with the passage of the Civil Rights Act of 1964 (Rhoads et al., 2004). In spite of strong opposition, the Civil Rights Act of 1964, which was the very first piece of legislation to provide the statutory strength to enforce the ban on race- and gender-based discrimination in all programs at public and private institutions that received federal funds, was signed into law by President Lyndon B. Johnson (Rhoads, Saenz, \& Carducci, 2004).

The Act contained two sections, Title VI and Title VII, which were meant to provide the means to implement and enforce it. Those two sections also eventually came to define affirmative action and lay the groundwork for the affirmative action policies enacted in the late 1960s and early 1970s (Rhoads, Saenz, \& Carducci, 2004). The purpose of Title VI was to expedite the desegregation of public schools and postsecondary institutions by asserting that no further federal funds would be given to any school, unless it provided equal educational opportunities for everyone, without regard to race, national origin, or gender. The purpose of Title VII was to assure (or hope to assure) equal employment opportunity and an end to all types of job discrimination for all minorities in America.

However, while Title VI specifically outlaws discrimination and mandates diversity efforts, it stops short of defining exactly what is meant by the phrase "discrimination based on race or national origin," and thus the door was left wide open, once again, for any state to interpret its meaning in a way that would benefit its own interests. And many of the states, particularly those in the South, did just that. 
While the Civil Rights Act of 1964 did increase the opportunities for Blacks to attend predominately White institutions (PWIs), it was not until the 1970s that more Blacks began to choose to attend them. And, although in the 1980s, more Blacks were electing to attend PWIs, in the 1990s, the trend reversed itself. Studies of Black student experiences (Bullock, 1967; Kim, 2002; Outcault \& Skewes-Cox, 2002; Ross, 1998; Seifert, Drummond, \& Pascarella, 2006) suggest that this reversal took place largely because many Black students had negative experiences at PWIs and suffered lower achievement and higher attrition rates than their White counterparts. In contrast, Black students who attended HBCUs were found to have experienced greater intellectual gains as well as more favorable psychosocial adjustment, more positive self-images, a stronger sense of racial pride, and higher aspirations (Rhoads, Saenz, \& Carducci, 2004).

In sum, in spite of all of the efforts made to equalize educational opportunity in the last 150 years or so, it still remains well beyond our grasp. One would like to believe that today, particularly in light of the 2009 election of the first African-American president, we have come that much closer to the goal of racial equality, and that the finish line is finally in sight. However, the veracity of that belief is still very much in question.

\section{Problem Statement}

In presenting such subjects as the history of education and the legal and policy issues involved in it, the literature is full of examples of the many ways in which the American educational system has produced and continues to reproduce a social system characterized by an inequitable distribution of educational capital (Bourdieu, 1977; Demaine, 2003; Freeman, 1998). While the literature abounds with information detailing the many shortfalls of the American public school system, it is only on occasion that it 
discusses both the inequities faced by inner-city Black youth and suggests any viable means of combating those inequities by equalizing the field for them. When this issue does find its way into the literature at all, it is, more often than not, approached by researching the students from a deficit point of view. That is, the academic underachievement and behavioral difficulties that characterize many of these students is blamed on inadequacies of the students themselves - on their intellectual and/or social inferiority - rather than on a system that reproduces unequal societal conditions, which is the real cause of the problem (Allen \& Jewel, 1995; Artiles, 1998; Baker, 2005; DeCuir \& Dixson, 2004; Freeman, 1999; Noguera, 2003; Ross, 1998).

Again, while many inner-city Black students are labeled at risk for failure in school - and at risk for failure in their lives overall - there is almost nothing in the literature that offers any viable means of combating their at-risk status by, for example, suggesting fundamental changes in the system. This obvious void in the literature makes it clear that there is truly a need for the scholarly examination I present here, one aimed at heightening an awareness of the needs and experiences of this largely overlooked and forgotten group of young people in our society.

In the study I conducted, I examined a program for Black youth, which can be best described as a comprehensive youth enrichment program. It is located in Overtown, which is one of the most disadvantaged neighborhoods in Miami, Florida. During school hours, coordinators from the Center oversee the academic and behavioral progress of its students by working directly with the elementary, middle, and high schools they attend in the Overtown neighborhood. After school hours, on weekends, and throughout the 
summer, the Center provides regular programming for the youth, which is offered at the Center itself as well as at selected academic and cultural locations outside the Center.

The statistical information that follows is meant to give the reader a sense of the overall educational and economic conditions of Overtown's population. According to the United States Census for the year 2010, $61.9 \%$ of Overtown's population is Black. Of its total of 2,651 family households, $26.9 \%$ are headed by a single female (no husband present). In those households, there are 4,113 young people aged 3-years-old and over. Of them, $294(7.1 \%)$ are in nursery school or preschool; 261 (6.3\%) are in kindergarten; $1,870(45.5 \%)$ are in elementary school (grades $1-8) ; 858(20.9 \%)$ are in high school (grades 9-12); and $830(20.2 \%)$ are in college or graduate school.

In looking at the educational attainment of the Overtown population 25-years-old and over, we find that $21.5 \%$ have less than a ninth grade education; $27.2 \%$ have between a ninth and twelfth grade education but no diploma; $25 \%$ are high school graduates (including equivalency); $11.6 \%$ have some college but no degree; $4.3 \%$ have an associate's degree; and $5.6 \%$ have a bachelor's degree. In sum, only $51.3 \%$ of Overtown's 25-year-old and over population are high school graduates.

Finally, in regard to household income, of the 2,651 families living in Overtown, $29.4 \%$ earn less than $\$ 10,000$ annually; $13.5 \%$ earn between $\$ 10,000$ and $\$ 14,999$; and $22.9 \%$ earn between $\$ 15,000$ and $\$ 24,999$.

It is my fervent hope that presenting an in-depth description of an academic and social enrichment program like the one at the Overtown Youth Center will engender an increased understanding of and further dialogue about the problems that Black youth living in impoverished, underserved inner-city areas are faced with on a daily basis. 
Since I have found nothing in the literature that outlines a program equivalent to it, in terms of its holistic focus, its comprehensiveness, and its self-containment, I am confident that this research will contribute something new to the literature, primarily by suggesting an original approach to solving what has been acknowledged as an ongoing, long-term problem. Through an in-depth description of the Overtown Youth Center, which may be seen as a necessary addition to traditional K-12 education capable of making significant improvements in the self-esteem, achievement levels and aspirations to attend college of students in one of the nation's most underserved areas, this research will make an important contribution to the practice and delivery of education in the United States in both the near and more distant future.

\section{Research Questions}

My research sought, first, to ascertain whether the inner-city Black students at the Overtown Youth Center are empowered academically, psychologically, or both, by their participation in the program; and if so, in what ways. The three main questions I have attempted to answer here are as follows:

1. Has the Overtown Youth Center contributed to the aspirations of the youth to attend college, and if so, to what extent?

2. What are the socio-cultural characteristics of the Overtown Youth Center?

3. What are the experiences of the youth at the Center?

\section{Purpose Statement}

Government interventions have been unable to satisfy the educational needs of the severely underserved Black youth living in our nation's inner-city areas. As educators, it 
is essential that we attempt to identify and institute innovative alternatives by which to help empower these at-risk youth both academically and socially.

The purpose of this ethnographic study, then, was to discern those factors that support the Overtown Youth Center's claim that they have been able to make a difference in the lives of at-risk Black youth, particularly in their aspirations to attend college, and then to explore the ways in which any factors that do so are implemented. One of the anticipated outcomes of an examination of this nature was that, by gaining a better understanding of at-risk youth and their needs, we might be able to develop models for programmatic interventions that could be recommended and hopefully instituted in innercity neighborhoods throughout the State of Florida, and perhaps eventually throughout the entire country.

\section{Assumptions and Delimitations of the Study}

I made a number of substantive assumptions in this study, which are based both on my own experiences and biases and on the conclusions reported in the research on the relationship of race and class to the inequities that exist in the American educational system. Briefly, they were as follows: (a) from their earliest years in school, inner-city Black youth face an uphill battle just to keep up with White students from more affluent backgrounds; (b) the system of public education currently in place needs to be supplemented with holistic programs that concentrate on meeting the full spectrum of these students' needs; and (c) their greatest needs are for individuals who care about them, believe in them, and provide a nurturing environment for them, one in which they can learn, grow, and develop a sense of self-esteem and self-efficacy. 
In regard to the research itself, I made two main assumptions. The first was that I have, indeed, learned something valuable from my observations and interviews. The second is that the participants felt comfortable and unthreatened enough to be willing to answer my inquiries truthfully and in depth.

This study, in that it examines a single youth enrichment program located within a particular historical and social context, is limited to the perspectives and experiences of the students, administrators, and staff at this one center. It naturally follows that the findings of studies like this, which only examine participants in a single context, usually cannot be generalized to other settings. However, the study's use of thick description should make it possible to transfer its conclusions to other settings.

\section{Summary}

In this introductory chapter, I have provided an overview of the research project I conducted. I have also presented its historical and theoretical context, provided my research questions, problem statement, purpose statement, and the study's assumptions and delimitations. 


\section{CHAPTER II}

\section{LITERATURE REVIEW}

As stated in Chapter 1, the inequities and inadequacies in the K-12 educational system have been well documented (Freeman, 1998; Guiffrida, 2005; Wilson, 1998). The literature is replete with information detailing the limited resources, substantial discipline issues, low teacher expectations, and prevailing culture of intellectual disengagement present in the schools in our poor, inner-city areas (Allen \& Jewel, 1995; Artiles, 1998; Baker, 2005; DeCuir \& Dixson, 2004; Delpit, 1995; Guiffrida, 2005; Jost \& Jost, 2005; Noguera, 2001). However, while there is an abundance of information in the literature that details the ways in which such conditions serve more to thwart the academic and personal progress of minority students than to encourage it, there is very little in the literature that suggests viable solutions aimed at bettering those conditions (Guiffrida, 2005). And, there is an even greater dearth of literature that deals specifically with the problems faced by inner-city Black youth, so many of whom are considered to be at risk.

The primary goal of this chapter is to help the reader gain an understanding of how badly youth enrichment programs and community-university-school partnerships are needed as an important means of supplementing pre-collegiate education, particularly for at-risk, inner-city Black youth. To accomplish this, I first look briefly at the literature on educational culture, or climate, in order to show the deleterious effects that an institution's culture can have on these youth. I then focus the bulk of the chapter on examining the ways in which educators have attempted to circumvent the negative effects of educational inequity on such students. Short of creating an entirely new educational 
system in which schools would actually educate all students well and equally (which would, of course, be the ideal scenario), researchers agree that the most effective means of assisting at-risk students today is to establish well-thought-out after-school programs and partnership initiatives. Therefore, one of my goals in reviewing the literature was to examine the effectiveness of the prevention and intervention initiatives described therein.

\section{Educational Culture}

The term "educational culture," or climate, as it will be used here, refers to the level of importance that a school, college or university places on teaching and learning within the context of its overall mission. Even more important, it refers to the beliefs held by the faculty in regard to the role they are expected - and they desire - to play in students' lives as educators and mentors, their overall attitudes toward teaching, and their feelings and biases about their students' abilities (Pascarella \& Terenzini, 2005).

The overall culture of an educational institution is concerned with how the various interrelationships within the academic community are perceived and advanced (Kuh \& Whitt, 1988). A strong, dominant culture, particularly one that is essentially different from the culture that certain students are accustomed to, could be an alienating, ethnocentric force, especially for members of such an underrepresented group as Black students. It should be easy to see, then, how the educational culture found in many of our pre-collegiate schools can present the very same problem for Black students living in poor, underserved areas.

Far too often we overlook the inextricable links that connect our universities with our primary and secondary schools. However, the truth is that the learning environments in our colleges and universities are almost mirror images of the culture that is born and 
nurtured in our elementary, middle, and high schools. And, it is those same institutions that train the teachers and administrators who shape the lives of generations of young people (Ruud, 2008). Therefore, we can no longer afford to ignore the fact that the inequities in our school system that have been reproduced from one generation to the next have their beginnings in the K-12 public education system. It is primarily that system and especially its teachers - which has the greatest impact on the formation of students' academic skills as well as on their feelings of self-esteem and self-efficacy. And it is that very system that molds the students who enter - or fail to enter - our universities and community colleges.

Since teaching methods and teacher attitudes and biases have a tremendous effect on students' feelings about themselves, their abilities, and their aspirations for the future, the need to train and/or re-train teachers to be more knowledgeable about their own biases and privileges and about the impact of cultural differences cannot be ignored. Wilson (1998) contends that the failure of our many attempts at school reform is due in large part to the fact that none of the reforms have done enough (if they have done anything at all) to address the issue of teacher attitudes.

Many K-12 teachers (the majority of whom are White females) have biases and negative beliefs about the abilities of inner-city Black students. While some of those teachers are not even aware that they have such biases, they are still very real. Among the most damaging of those biases manifests as low teacher expectations about the intellectual and psychological capabilities of Black students. In general, the result of those low expectations for the students is low self-esteem, which is often accompanied by feelings of isolation, alienation, and hopelessness (Freeman, 1998; Ogbu, 1995; Wilson, 
1998). Feelings of that nature then engender a prevailing culture within the schools of intellectual disengagement, which is accompanied by a plethora of discipline issues. Therefore, if we fail our youth in their pre-collegiate years by not providing them with the nurturing environment they need, a major component of which is teachers who believe in them and encourage them to learn and develop their abilities, it is unlikely that they will ever make it to college.

All of the studies on the impact on Black students of the educational culture of a college or university have found it to be a particularly powerful influence in enhancing or marginalizing - the ability and the desire of these students to learn and to persist to graduation (Allen \& Jewel, 1995, 2002; Bowen \& Bok, 1998; Chang, 1999, 2000, 2002; Freeman, 1998, 1999; Hurtado, 1996; Lee, 2002; Pascarella \& Terenzini, 2005). The one aspect of that culture singled out in the research literature as having the greatest impact on Black students is the attitude of the faculty toward them and the kinds of relationships they form with the students (Guiffrida, 2005; Kim, 2002; Seifert, Drummond, \& Pascarella, 2006).

Douglas Guiffrida (2005) wrote a particularly illuminating qualitative study on the subject, in which he compared the perceptions of the relationships with faculty that Black students attending historically Black colleges and universities had to those of Black students attending predominantly White institutions. While first acknowledging that there is limited research on the qualities of such relationships, Guiffrida's study uncovered two primary factors that seemed to have a significant influence on them. The first is that Black students may experience difficulty connecting with White faculty, because they do not regard them as realistic role models. The second is that Black 
students often perceive faculty at PWIs as being culturally insensitive to them and thus virtually unapproachable.

In regard to the issue of cultural insensitivity, Guiffrida (2005) identified a number of factors that cause students to have that perception. These include (a) the stereotypical comments faculty are often overheard making about Blacks; (b) the ways in which faculty often regard Black students as being less capable than White students; (c) a general lack of interest in Black culture, which is evidenced by the fact that it is rarely if ever incorporated into the curriculum; and (d) the way faculty will often elicit the opinion of a single Black student as being representative of all Black students. It should come as no surprise that those same kinds of behaviors and attitudes are seen in teachers in the pre-collegiate school system as well.

After noting that prior research has firmly documented obstacles to White faculty/Black student relationships at PWIs, Guiffrida (2005) also notes that there has been very little research that has attempted to determine what is needed to transform obstacles into benefits for these students. Thus, the stated purpose of his study was to understand, from the students' perspectives, those faculty characteristics that facilitate meaningful relationships with Black students. The conceptual notion he uses to frame that understanding, which is called "othermothering," is also what he envisions as a means of linking his theory to the actual practice of educating Black students.

Othermothering, which he contends is a long-held tradition of education within the Black community, is a form of mentoring; but it is one that goes far beyond the traditional meaning of that term. Essentially, it prescribes a comprehensive program of career, academic, and personal advising and also encompasses a number of other factors 
that are integral to students' definitions of faculty who are "student-centered." Among the factors Guiffrida identified were (a) being willing to support and advocate for Black students, (b) providing extra tutoring and helping them locate money to stay in school, (c) believing in and having high expectations of students, (d) raising the bar for achievement and pushing them to succeed, and (e) holding students accountable.

Again, all of these practices have been proven to be powerful motivating techniques not only for Black college students but also for Black students at all educational levels. Guiffrida (2005) states that there is an almost total absence of such student-centered teachers in our inner-city schools. That observation points up the desperate need that these students have to find mentors and positive role models in places other than their schools.

\section{At-Risk Students and At-Risk Behaviors}

A review of the literature on the pre-collegiate school system and after-school programs and partnerships that have been formed to enhance its overall effectiveness for at-risk, inner-city Black students in low-socioeconomic income brackets, in particular, leaves little doubt that such programs are essential to the success of these students, both during their school years and in their lives outside of school. As stated in Chapter 1, from an educational perspective, students at risk are those who appear to be predisposed to experiencing difficulties in typical school programs that limit their ability to succeed (Henderson-Sparks, 2002).

These students are at risk largely because of the detrimental effects that the economic and social environments in which they live have on them. In that regard, Natriello, McDill, and Pallas (1990) identified five broad socio-cultural risk factors these 
children are faced with. They are (a) race/ethnicity, (b) poverty, (c) poorly educated mothers, (d) single-parent families, and (e) limited English proficiency.

In an extensive review of predictors of underachievement in urban children, which has been confirmed by experts and practitioners, Arroyo, Rhoad, and Drew (1999) identified ten variables that are considered to be the ones most strongly associated with underachievement in urban settings. They are (a) teachers' lack of demonstrations of caring, respect, and interest in children's growth, (b) teachers' low expectations for children's achievement, (c) lack of relevance in the curriculum, (d) class size, (e) disengagement from school-related activities, (f) students' own lack of confidence in their abilities to achieve, (g) high mobility in school attendance, (h) low parental expectations and involvement, (i) low level of parent's education, and (j) poverty or low income.

As stated earlier, poverty has been identified as one of the major factors associated with students who are considered at-risk or under-achieving. This is true primarily because what generally accompanies poverty is a lack of medical, nutritional, and early learning assistance, all of which results in these children being academically behind their peers from the time they first enter school.

All of the risk factors listed above are then exacerbated by a public school system that, rather than serving their best interests, provides these youth with far less opportunity and encouragement than students living in the more affluent White neighborhoods are afforded (Guiffrida, 2005). For example, when Black students in urban schools are regarded by their teachers as being incapable of learning, that lack of belief in them often causes these students to feel that their teachers expect very little of them and/or that they 
simply do not care about them, especially when the only time their teachers pay attention to them is when they are engaging in inappropriate social behaviors (Gardner et al., 2000). This gives rise to a low self-evaluation on the part of the students in regard to their academic abilities. The negative self-image they develop then causes them to lack motivation to perform and achieve. The denial of access to adequate education due to the paucity of educational resources in poor urban communities, of course, further aggravates the situation.

Factors associated with children's engagement in risk behaviors have been well established in the literature. Among these factors are early school failure; issues associated with social isolation, poverty, and neighborhood influences; a lack of family support; and the absence of authoritative adults (Beck, 1999; Delpit, 1995). When minority status is added to the mix, the potency of these factors is exacerbated (Steele, 1992).

Many researchers contend that of all the risk factors, the most predominant is early school failure, and that Black children are far more likely than White children to experience such failure (Beck, 1999; Bergin et al., 1992; Kagan, 1991). In order to explain early school failure, researchers have suggested a variety of factors. These include such things as the stigma and stress related to attending school in a racist environment (Steele, 1992); the inequitable distribution of resources among schools; the effectiveness (or ineffectiveness) of a school's teaching staff; and the idea that Black children are penalized by a White middle-class hegemony that does not take into account cultural variations in oral and written expression (Brice-Heath, 1983; Delpit, 1995; Ogbu, 1995). 
In arriving at the latter explanation, Brice-Heath (1983), for example, collected data on linguistic differences that affect the ability of Black children to accurately interpret White teachers' nuances. And Delpit (1995) demonstrated the way in which cultural variations in storytelling format and narrative have shrouded the ability of many White teachers to appreciate the richness of stories created by Black children.

There are myriad risk behaviors that result from the risk factors discussed in this section. Among them are such things as violent behavior, violent crime, property crime, gang membership, drug and/or alcohol abuse, teen pregnancy, teen suicide, truancy, and dropping out of school.

\section{The Plight of Black Adolescent Males}

I would be remiss if I were to neglect to discuss the particularly troubling educational situation faced by Black adolescent males. Much of the literature on at-risk youth has shown that a disproportionate number of these males perform poorly in school as compared to their peers of other races, in terms of both the behavioral and academic aspects of their educational experience. Research conducted by Ogbu (2003), for example, showed that when Black male students are compared to other students by gender and race, they consistently rank lowest in academic achievement, have the worst attendance records, are suspended or expelled from school far more frequently, are more likely to drop out of school, and more often fail to graduate from high school or to earn a GED.

Martin et al. (2007) contend that in spite of overwhelming evidence, when assessing the needs of Black adolescent males (as well as younger Black students), the linking of academic achievement with clinical assessment and remediation has not been 
fully examined. One example of this is the fact that the vast majority of research on dropping out of high school before graduation has focused mainly on its correlates, predictors, and consequences; while there are relatively few studies on the phenomenon that have looked at such things as tutoring and counseling as a means of preventing students from dropping out of school, which would prove far more useful.

In a study conducted by Martin et al. (2007), it is reported that in almost every category of academic failure, Black male adolescents are represented excessively. The study points to statistics from the Education Trust showing that $61 \%$ of Black male students performed below basic levels on an eighth-grade measure of math attainment as compared to $21 \%$ of White male students; and that by the end of high school, Black students' math and reading skills were comparable to those of White eighth graders.

The research itself involved 33 Black male students between the ages of 13-17 who participated in an after-school program for two years. Each of the participants had been expelled or suspended from school at least once and had been given at least 20 discipline referrals in the course of one year. The after-school program they attended provided tutoring, group counseling/social-skills training, and various cultural and recreational enrichment activities. At the beginning of the program, the students were assessed for their academic skills. At the end, they were assessed for behavioral changes as well as for improvements in their reading and math skills. The findings were that there was an impressive improvement in both areas: their daily school attendance increased; the students had fewer discipline referrals; they had no suspensions or expulsions; and the average improvement in their basic academic skills was at least two grade levels. 
As mentioned previously, the educational literature abounds with examples of the end results of the tremendous learning disadvantages and lack of opportunity and encouragement that poor inner-city children face. On the other hand, while early school failure is associated with engagement in unhealthy risk behaviors, early school success is associated with the development of healthy individuals, as it promotes self-esteem, motivation, and aspiration. Thus, academic achievement must be viewed as a key element in effective prevention and intervention programming for at-risk students (Bergin et al., 1992). Given that 20-25\% of America's children grow up in environments laden with risk, a critical goal for us, as educators, must be the development of prevention and intervention strategies that mitigate the effects of at least some of those risk factors (Beck, 1999).

\section{Prevention and Intervention Initiatives: After-School Programs}

Formal after-school programs have been shown to be an effective strategy in assisting at-risk youth and reducing the likelihood of their engaging in risk behaviors. They have also been shown to make a difference in the social and emotional development of these children. Therefore, I concur with Beck's (1999) claim that most educational researchers would agree that urban at-risk children, in particular, need a structured afterschool program to improve their academic skills, social behavior, and opportunity for success in life.

Many at-risk students live in households with single, working mothers who earn a low wage, have limited resources, and find it virtually impossible to provide a positive environment for their children after they get out of school. After-school programs provide these youth with a positive, structured environment in which to learn and spend 
their after-school hours. Such programs also help them to avoid the many inherent dangers that they would face, particularly in neighborhoods where there is high crime, drug use, and so on, if they were wandering around alone in the urban streets after school (Halpern, 1992, 1999). The positive impact on the school success of these students is also due, in part, to the fact that they make it possible for concerned and talented individuals, such as professional Black men, who are mostly unavailable during traditional school hours, to work with these students and make valuable contributions to their lives. These men can be particularly helpful as mentors for young Black boys, especially those who come from single parent, female-headed households (Gardner et al., 2001).

Cosden et al. (2001) summarized the outcomes of ten studies on structured afterschool programs that offered students assistance with homework and other academic needs. Most of the studies focused on children considered at risk for school failure as a result of low income, limited familial resources, and/or poor grades. All of the programs they looked at offered a broad range of activities in addition to academic support (Beck, 1999; Halpern, 1992; Posner \& Vandell, 1994). While the nature of the academic support varied, each program provided children with both structure and adult contact. The full impact of these programs on the students' academic performance appeared to be mediated by such factors as increases in the students' self-esteem and changes in teachers' perceptions regarding the efforts and capabilities of the students.

\section{The Federal GEAR UP Grant Program}

In 1998, the federal government established a discretionary partnership grant program entitled Gaining Early Awareness and Readiness for Undergraduate Programs 
(GEAR UP), which is administered by the U.S. Department of Education. It is an early intervention program designed to significantly increase the number of low-income students who graduate from high school and are prepared to enter and succeed in postsecondary education. (Program success here is defined as enrollment in postsecondary education of GEAR UP students immediately after high-school graduation.)

The GEAR UP partnership grants focus on cohorts of low-income students (rather than on individual students), which begin the program no later than the seventh grade and continue in it through high school. They require that services be provided the students through the establishment of partnerships among colleges and universities, schools, and outside organizations.

The program funds such services as tutoring, mentoring, teacher training, curriculum enhancement, after-school and Saturday programs, summer programs, college visits, college counseling, financial counseling, and parental involvement activities. Funding can also be used to provide college scholarships (U.S. Department of Education. Retrieved from http://www.ed.gov/programs/gearup/).

In order to get an idea of the amount of money this grant program distributes on an annual basis, the total estimated amount of funds available for all GEAR UP grants for the fiscal year 2008 was $\$ 303,423,120$, with individual awards ranging from $\$ 100,000$ $\$ 7,000,000$ for partnership grants and $\$ 500,000-\$ 3,000,000$ for state grants. The estimated number of awards for 2008 was 7 state grants and 30 partnership grants (U. S. Department of Education, 2008). 
While two such grants were awarded in 1999 to departments at Florida International University, I have found nothing in the literature pertaining to student assessment or student outcomes of either of the two programs. In fact, the only literature that discusses any of the numerous GEAR UP programs that I found in the course of my research was an article by Mayers and Schnorr (2003). In it, the authors suggest and operationalize their strategies for the facilitation of a school/university partnership aimed at increasing the number of students from five participating middle schools who will attend and successfully matriculate through the university level. The partnership stakeholders in Gear Up Inland Empire (GUIE), as the program was called, consisted of the grant receiving university, five middle schools, the high schools that the middle school students ultimately attend, the local communities, the parents in the communities, and several of the community businesses that serve them.

Unfortunately, however, the article gets bogged down in a discussion of what the authors call the "resistance phenomenon" that exists among the various stakeholders in the partnership and of how that resistance may be eased, rather than dealing with the student outcomes resulting from the actual implementation of the program. The only point of value for my own research in this article was its discussion of the vast cultural differences that existed between the student body in the study, which was largely Black and/or had English as a second language, and the faculty who taught them, who were primarily White and had English as their only language. The authors' recognition of the very real impact of this cultural difference on learning style, along with their recommendations for assuaging it by optimizing service to Hispanic and Black students and their families, provide further evidence of the need for the study I conducted. 


\section{The Mt. Olivet After-School Program}

In their article, Gardner et al. (2001) argue that, because of the variety and complexity of the educational problems that arise in teaching urban at-risk children, educators may be incapable of dealing with them successfully on their own. The authors contend, therefore, that there is a need for school personnel to work in partnerships with community leaders, parents, and professionals in order to help these youth develop the skills they need to be successful in school. While several different types of community programs have been used to accomplish this, the authors identify after-school partnership programs as being the most effective.

The Mt. Olivet Baptist Church Men’s Fellowship (“the Men of the Manna”), members of a large, predominately African-American church, developed a collaborative after-school program with the Columbus public schools, Ohio State University's (OSU's) College of Education, and 15 Black elementary school boys and their parents. The boys were identified by their classroom teachers and the school principal as being academically and socially at risk for school failure. Academically, they were all one or more years behind grade level in reading and math (as determined by pretest assessments); and socially, they were all experiencing a variety of social behavior problems and had a history of in-school suspensions due to disciplinary problems.

The setting for the project, which was implemented and evaluated by faculty and students of OSU and by the men from the Mt. Olivet Baptist Church, consisted of two second-floor classrooms in the church. The collaboration involved primarily peermediated (i.e., peer tutoring) interventions, which included a combination of academic 
instruction (focused on reading skills and math facts), moral/social skill development, and recreation.

While all of the students in the after-school program demonstrated gains in the targeted academic skills, one of the limitations of the results was the small size of the sample group. However, Gardner et al. (2001) contend that this type of improvement is consistent with the results reported by other researchers, all of whom noted that participation in structured after-school programs and implementation of peer-mediated interventions can have important benefits (e.g., improved academic and social progress) for urban at-risk students (Cochran et al., 1993; Greenwood et al., 1989; Halpern, 1992; Marshall et al., 1997; Posner \& Vandell, 1994; as reported in Gardner et al., 2001).

\section{The Manchester Youth Development Center}

Accepting it as a given that thoughtfully developed, formal after-school programs can and do make a difference in the academic performance of schoolchildren, Elizabeth L. Beck (1999) sought to identify those programmatic features that appear to be associated most with successful after-school programming. I will devote a good deal of attention to this article for a number of reasons.

First, it is the only article I have been able to find that discusses an after-school program (i.e., the major programmatic components) and venue (i.e., a center housed in its own building) that is similar to that of the Overtown Youth Center, thus making it particularly germane to my own study. Second, it is one of the few studies in the literature of an after-school program in which the majority of participants are poor, innercity Black youth. Third, like my own study, it is a qualitative study that utilizes naturalistic participant observations and semi-structured interviews of key informants as 
the primary data collection methods. In addition, Beck's study site served youth ranging from kindergarten through $12^{\text {th }}$ grade, which is similar to the age group served by the Overtown Youth Center. And finally, the stated purpose of Beck's study is very similar to the purpose of my own. She states that the purpose of her study is to "discern and describe factors that support the MYDC's ability to make a difference in the lives of children and explore the ways in which these factors are implemented" (Beck, 1999, p. 109).

In order to accomplish her purpose, Beck states that she adapted a methodological orientation based on Bogdan and Biklen's (1982) best-practices model. That model suggests that we can learn a great deal about program and policy development by examining successful programs, and that a thorough examination of such programs will enable us to identify those variables that have contributed to their success and then describe the ways in which those variables were translated into action.

In discussing the place that her study occupies within the literature, Beck states that it is an extension of prior research, in that it explores prevention and intervention programming through the lens of a specific, successful program. She also notes the relative lack of published research on programs of this nature, stating that her study was done, at least in part, in response to Morris's (1992) claim that, "there are virtually no published descriptions of holistic, non-targeted prevention programs aimed at AfricanAmerican youth" (Morris, 1992, p. 110, as reported by Beck, 1999). And, once again, while there is agreement among researchers that prevention and intervention strategies to assist these youth are needed, there is still very little in the literature that explores any sort of successful programming for them. 
While this article was written in 1999, today, more than ten years later, there is still a dearth of research on the subject. In the course of my own research, I have faced the same problem as that noted by Morris, and it is that very gap in the literature that makes research of this nature so essential. I cannot stress enough the fact that the issues facing at-risk Black children and youth are nothing short of profound and that, as educators - and compassionate human beings - we cannot afford to ignore them or to even downplay their significance.

The site used in Beck's study was the Manchester Youth Development Center (MYDC), which was established in 1972. Most of the program's participants, about 90\% of whom were Black, lived in Manchester, New Hampshire, an inner-city neighborhood where all of the youth are considered to be at-risk (Bolvin, 1995, as reported in Beck, 1999). (The make-up of the participants at OYC is virtually the same.)

Manchester, like Overtown, is a city riddled with violence, poverty and drugs; it is isolated from prosperity; and with the exception of the MYDC, it has very limited community resources. According to data collected by the MYDC in 1995, more than $30 \%$ of its participants came from households where the primary caretaker was a known substance abuser; $20 \%$ came from households where there was known gang activity; and 70\%, from single-parent-headed households (Beck, 1999).

The MYDC has its own free-standing building that houses a gym; music, art, dance, and sewing studios; a state-of-the-art computer lab; and nine classrooms. From 3:00-5:45 p.m., participants rotate through activities at 45-minute intervals. In order to participate, a child must be registered, and there is a standard fee of $\$ 25$ a month. (This is different from OYC, where all services are free.) 
The major findings of Beck's study were the identification of six factors salient to the programmatic success of the MYDC. Every one of these factors is also integral to the Overtown Youth Center's programming. The factors are as follows: (a) both structure and autonomous space are provided; (b) academic achievement is supported; (c) the program is culturally consistent; (d) there is a large core of committed adults; (e) the leadership is child-centered; and (f) it is a safe place.

In her description of the academic component of the program, Beck stated that "support for academics is the nucleus of the MYDC, and radiating from and toward that nucleus was support for self-actualization, African-American-centered programming, and a staff that sought to foster the total growth of the child" (Beck, p. 116). In that statement, she focuses on the idea that, in order to enhance their educational skills, these youth need help in developing a sense of self-esteem, which is something that the majority of them lack. Beck contended that, in order to even begin to instill a modicum of self-esteem in these Black inner-city youth, they need to be placed in an environment where they will not "feel the stigma and stress associated with the institutional and behavioral manifestations of racism that are present in the school environment" (Steele, 1992, p. 71, as reported in Beck, 1999), and where they will be able to interact with successful Black adults.

As a part of her discussion of the factor of African-American cultural patterns, Beck talks about the role played by two components: spirituality and extended family and community. In terms of spirituality, although the MYDC is nonsectarian, she tells us that, "the power of faith and transformation are acknowledged within the environment of the center" (Beck, p. 117). In addition, she reports that it is not uncommon to hear people 
make reference to God and talk openly about the churches they attend, which is an aspect of spirituality that I only occasionally witnessed in the course of my research at the Overtown Youth Center.

Outcome data suggest that there were significant differences between the students living in Manchester who participated in the MYDC and those who did not. In 1996 and 1997, for example, the cumulative dropout rate for the general student population in the city school system was $18.7 \%$, and the rate for Black students was 19.5\% (MYDC, 1997, as reported by Beck, 1999). However, the high-school completion rate reported by the MYDC for its participants during those same years was consistently above the regional mean. The MYDC reported that in 1996 and 1997, 100\% of its students graduated from high school. In addition, MYDC participants have experienced higher rates of academic achievement within the school setting than non-participants (Bolvin, 1995, as reported by Beck, 1999.)

In her discussion at the end of the study, Beck reiterates the great importance of finding ways to assist at-risk Black children and youth, because the issues they face in attempting to make a productive life for themselves are so very profound. And, as mentioned earlier, she reiterates that, although there is agreement about the fact that prevention and intervention strategies are needed, there is little in the literature that examines what actually constitutes successful programming.

Although one limitation of Beck's study is that it only reports findings from a single institution, Beck contends that the factors that the research found to be salient are supported in the literature (p. 121). Overall, the findings from this study suggest that 
MYDC has been able to make a difference in the lives of children at risk, because it has served to fill critical gaps in their emotional, social, and academic needs.

\section{University/Community Partnerships}

Thurlow, Ledoux, McHenry, \& Burns (2007) describe the efforts made by Widener University, which is located in the center of Chester, Pennsylvania, to form a partnership with one of the state's worst school districts. (Chester is ranked number 500

of the 501 school districts in Pennsylvania.) Much like Overtown, it is a severely underresourced school district in an economically distressed area. To illustrate the contrast between the area itself and the Widener University campus, the authors make the statement that, "it appears as an oasis or an anachronism" in the area (Thurlow et al., p. $113)$.

At the beginning of the study, the authors state that civic engagement has become an important mandate at a number of our colleges and universities in recent times, and that it has taken shape in a number of ways. They devote a good deal of attention to the general subject of civic engagement, its history in our colleges and universities, and the history of the Widener University Center of Education's many thwarted attempts at forming partnerships with its neighboring school district.

The bulk of the article describes what the authors call a "circle of programs" at the Center of Education, which was designed to serve both the educational needs of the community and the professional development needs of the center's students. That circle revolves around, and relies on, partnerships with numerous groups, including community groups, local foundations, churches, and the local school district. Some of the programs 
are located within the schools, some take place in locations throughout the community, and some involve opening up the university campus to the community.

While this is a much larger-scale partnership than either the one in my own study or those described elsewhere in the literature reviewed here, it lacks the cohesiveness of a relatively autonomous program like the one at MYDC. This autonomy derives mostly from the fact that MYDC's programs are housed primarily in its own building and it has its own autonomous administration. On the other hand, however, this partnership program and the one at MYDC contain many of the same elements.

An integral part of the "circle" reported on by Thurlow et al. (2007) is teacher education. The authors describe one initiative, called the Junior Block, which expanded Widener's teacher candidate curriculum by including an alternative version of its traditional methods courses. Traditionally, teacher candidates at Widener learned methodology and theory almost entirely at the university and were only given a brief opportunity to apply what they learned at the very end of the course. In the alternative version, fieldwork at the district's schools was instituted as an integral part of its teaching methodology course work from the early weeks. It was felt that providing education students with the opportunity to get firsthand, supervised teaching experience enabled them to become more confident and proficient professionals: "Field experiences are the hallmark of the center for education's focus on experiential learning and the university's call for civic engagement" (Thurlow et al., 2007, p. 116). The authors go on to emphasize that in order for this partnership to be truly successful, it must include a longterm commitment between the university and the community schools. As consistency is a key element in the success of such partnerships, school districts must view themselves 
as part of the university's community, developing a sense of trust over time. Having the same programs in place over many semesters and using the input of the teachers, administrators, and students in the community in helping to shape future field experiences will create this sense of trust and will allow for continuous program renewal (Thurlow et al., 2007, p. 117).

Another aspect of the teacher education initiative is bringing the youth to the university campus. One of the oldest and most successful of the university's community outreach programs is its Saturday Academy Program. Twice a year, a four to five-week educational enrichment program is offered to local children in various locations on the university's campus. A local education foundation and a number of after-school church programs contribute to the cost of transporting the students to the campus by bus, and the classes are designed and taught by teacher candidates.

A number of other initiatives of this nature, all of which are housed on the university campus, are described in this article, but rather than detail them, the most important thing I wish to note here is the variety of positive outcomes - for the children and the university students alike - that resulted from such offerings. I am particularly interested in the study's findings that bringing the children to campus allows them to experience the kinds of activities that are associated with university life, helps them to become more comfortable in a university environment, encourages them to want to attend college, and makes them feel more confident about the possibility of their being able to do so. In the partnership initiative I established with FIU and the Overtown Youth Center (which I discuss in chapters 4 and 5 of this dissertation), I found that the types of 
activities described in the study by Thurlow et al. (2007) had the same and/or similar positive outcomes for the Overtown youth as they did for the youth in that study.

In addition to offering programs at the university, the partnership initiated by Widener offers a variety of activities in the community. For example, the Reading and Academic Skills (RAS) Center at Widener provides tutoring and sponsors an after-school program for neighborhood elementary school children, which is held in a local church.

Without the availability of such a program, most of those children would have to return to an empty home at the end of the school day. As has been reported frequently in the literature and elsewhere in this chapter (Beck, 1999; Gardner et al., 2001), these children have little parental support and encouragement, and they live in one of the most dangerous neighborhoods in their city. Thus, without the help of this partnership, which provides the children with a safe and supportive environment, it is likely that there would be no safe haven for them.

The authors conclude this article with the following statement:

It is our belief that with effective community involvement, this circle [of services] can help move members of our community from a circle of poverty and despair to a new model of excellence in education using all of the resources the community has to offer ... One cannot predict the future from current partnerships, but can hope that the involvement of the well meaning will serve as a catalyst for greater civic responsibility from all constituents. (Thurlow et al., p. 121)

Given the interdependence of our K-12 education system and all of our colleges and universities - public and private, community and technical, two-year, four-year, and graduate - the importance of establishing more meaningful and more diverse partnerships among them should be clear. Every university department should reach out and make an effort to help the K-12 programs accomplish what they need to accomplish. If we fail to 
recognize and act on this, not only will we be failing our students in their college education, but we will also be failing those K-12 students whose futures depend on the wisdom and leadership of our college graduates (Ruud, 2008).

In sum, the research on the kind of after-school programs that offer additional learning opportunities for children has provided important insights into the value of such programs, largely by identifying a number of positive outcomes they help facilitate (Schwartz \& Pace, 2008). Most significantly, the research has found that these afterschool programs provide students with potentially powerful opportunities to improve learning and that they help close the achievement gap by fostering cognitive, social, emotional, physical, and moral growth and development (Hollister, 2003; McComb \& Scotts-Little, 2003; Miller, 2001; Schwartz \& Pace, 2008).

As a result of such findings, in recent years these programs have become an increasingly popular format for improving student academic performance. It should be emphasized that the increase in the number of such programs has come less as a result of policy decisions and more as a result of initiatives on the part of a variety of groups, including educators, child development experts, community development groups, and parent groups (Schwartz \& Pace, 2008).

\section{Critical Race Theory as a Framework in Educational Research} The problem of the Twentieth Century is the problem of the color-line ...

$$
\text { W.E.B. DuBois }
$$

Critical race theory is one of the most powerful theoretical constructs that has been used in recent times to study, understand, and attempt to transform the very destructive social force of racism. One of its ultimate goals, then, is a very active one: to 
promote social justice and social change. It acknowledges that there are multiple ways of viewing things and that there is no such thing as a universal Reality or a single Truth applicable to everyone.

As stated earlier, one of the primary goals of my research is to illuminate the ways in which our public education system continually places its inner-city Black youth at a disadvantage rather than providing them with the services they legitimately deserve and so desperately need in order to be successful in school and in life. Another of my main goals - and possibly an even more significant one - is to identify and examine those intervention strategies that will be most likely to help reverse that situation for these students. And finally, my ultimate goal is to promote social justice and social change by helping to transform our educational system. Since, as stated above, my ultimate goal and that of CRT are virtually the same, it is my belief that by utilizing the methods of CRT and looking at my site and sample population through CRT's theoretical lens, my research will help take me in that direction.

\section{The Prevalence of Racism in American Society}

It is a commonly accepted fact among a large number of scholars in the field of education today - and among scholars in many other disciplines as well - that racism is something that is imbedded in just about every aspect of our society, and that the American educational system is certainly no exception. Any close examination of American history will show that people in the United States have always been extremely conscious of skin color (Artiles, 1998; DeCuir \& Dixson, 2004; Lintner, 2004; Morris, 2002; Solorzano \& Yosso, 2001; Stovall, 2004). 
Morris (2002) contends that, in reality, race is really nothing more than a socially constructed category, which was simply created in order to differentiate racial groups from one another for the purpose of showing the superiority or dominance of one group over another. In accordance with his view, then, the social meaning we have applied to race is both based upon and justified by an ideology of racial superiority and White privilege (Solorzano \& Yosso, 2001). In our society and most other Eurocentric societies, White culture represents the norm against which such comparisons are made; and traditionally, minority people have been defined by what they are not rather than by what they are (Artiles, 1998).

In order to effect any kind of change, we must understand, first, that the long-held views of the dominant group in our society have become what we perceive to be natural and even universal. We also need to acknowledge that human difference has always been seen as problematic in our society. And finally, we need to recognize that discrimination, prejudice, and racism are both subtly and openly enacted every single day in our country. According to Artiles (1998), sociological perception research suggests that in the 30 years from 1968-1998, the views held by many White adults in regard to minorities have changed very little, if at all; that is, Whites continue to perceive of minorities as being less intelligent, lazier, and of lower moral character than they are (Artiles, 1998).

Furthermore, racial stereotyping is something that is found in every aspect of our society. It runs rampant in our media as well as in our educational and professional environments, and it is used, among many other things, to blame unequal outcomes on Black people themselves rather than on society and its institutions, which is really where 
most of the blame belongs (Solorzano \& Yosso, 2001). It can be said, then, that all issues related to race in our society are highly contentious.

Historically, social scientists have represented Black people through traditional social science paradigms. They often misrepresent them or they simply ignore them altogether. In addition, many of the theories in the educational literature rely on racial characterizations and stereotypes about Blacks. Moreover, the literature on instructional approaches for Black students often involves some type of remediation, which leads us to perceive at-risk students as being intellectually or otherwise deficient (Noguera, 2001). Freeman (1999) contends that a good deal of that literature is based on cultural deprivation theories, which connect race to low academic performance. Cast in a language of failure, then, these approaches continue to ignore marginalized groups and their concerns about racism (Ross, 1998).

\section{Research Methods in CRT}

Educational researchers need a different tool with which to examine race and racism in education, one that does not proceed from the same old, tired, biased deficit models. A race-based theory like critical race theory is one such tool, as it can provide researchers with a language and a space for people of color to voice their educational experiences (DeCuir \& Dixson, 2004).

Critical race theory attempts to deconstruct oppressive structures in order to reveal the ways in which such structures have served to limit rather than augment the educational opportunities of Black people. Thus, a critical race methodology can help us generate knowledge about, and provide us with insights into, those people in our society who have been marginalized, silenced, ignored, and dis-empowered, and who have thus 
become invisible to the academic discourse (Denzin \& Lincoln, 1994; Freeman, 1998; Ross, 1998).

In addition, CRT researchers seek alternative ways in which to analyze the role of schools for Blacks, such as having them tell their own stories in their own words from their own perspective. This enables them to express their innermost feelings about their experiences, which gives the researcher a far more complete picture of who they are and what they need.

CRT also helps us understand how traditional ways of researching have often served to limit the educational opportunities of Blacks. As Solorzano and Yosso (1998) so aptly put it, as a methodology, CRT can be used to "turn margins into places of transformative resistance" (p. 3).

It is important to emphasize here that the term "critical" in critical race theory is central to understanding both the ultimate purpose of the theory and the mindset of the theorists who utilize it. The term both illuminates the central focus of CRT, which is to expose the deleterious effects of race and racism, and highlights its ultimate activist goal, which is to bring about the kind of change (or total transformation) that will further the cause of implementing social justice.

\section{A Brief History of CRT}

CRT was first used in the legal field during the mid-1970s and was developed initially from the work of legal scholars Derrick Bell, Alan Freeman, and Richard Delgado (DeCuir \& Dixson, 2004). In that field, it represented a response to what has been described as "the failure of Critical Legal Studies (CLS) to adequately address the effects of race and racism in U.S. jurisprudence" (DeCuir \& Dixson, 2004, p. 27). 
Examples of that failure abound in the literature (Hernandez, 2003; Magee-Andrews, 2003; Saddler, 2005). Many CRT scholars make the claim that, essentially, our judicial system has a history of supporting racial oppression. They have also frequently critiqued and reinterpreted civil rights law and dominant legal claims of equality, color blindness, and meritocracy (DeCuir \& Dixson, 2004).

CRT researchers claim that looking at a policy like affirmative action, for example, can serve to highlight and support some of their critiques. They point to the fact that most of our attempts at affirmative action have proved ineffectual, because they have done very little to address the real concerns of disadvantaged people. In addition, in recent years, many people in the public have come to regard affirmative action as "unjustified gifts." It is precisely this point of view that has led to claims of reverse discrimination in education and employment made by many Whites (Magee-Andrews, 2003). It has also led to judicial battles and to anti-affirmative action legislation in many states, including California and Florida. In assessing the position of the courts in regard to affirmative action initiatives, Magee-Andrews (2003) made the following statement:

The justifications for affirmative action - remedying the effects of segregation, discrimination, and related past and present forms of systemic subordination which have undermined educational and other opportunities for traditionally oppressed groups - have curiously received little support from the courts. (p. 710)

Hernandez (2003) suggests that one possible explanation for this lack of support is that judges - even those serving on the U.S. Supreme Court - are influenced to a large extent by their own personal perspectives, biases, and experiences, as well as by certain political considerations. And, as members of society, these judges, just like teachers, administrators, and legislators, are "just as susceptible to internalizing the cultural disdain 
for anything that comes to be identified with the needs of subjugated communities" (p. 3). Therefore, just like other members of society, they could also benefit greatly by receiving some form of social re-training.

As stated previously, CRT was originally used in legal contexts. However, about 16 years ago, in addition to critiquing American legal institutions, it began to be used to examine our educational and other social institutions, which according to critical race theorists are also institutions that perpetuate inequality. Solorzano (2001) stated that no matter what institution it examines, CRT always seeks to "de-cloak the seemingly raceneutral and color-blind ways in which the law and policy are conceptualized, discussed, and formulated, particularly with respect to their impact on poor people and persons of color" (p. 8).

\section{CRT in Educational Research}

In attempting to explain the role that critical race theory plays in educational research, Solorzano and Yosso (2001) state that "CRT challenges the dominant discourse on race and racism as it relates to education by examining how educational theory and practice are used to subordinate certain racial and ethnic groups" (p. 1). In addition to contributing to an understanding of the role of the theory itself, Solorzano and Yosso $(1998,2001)$ have also contributed to an understanding of the overarching exclusionary construct of American society. They enumerated five basic tenets that form the perspectives, research methods, and pedagogy of a critical race theory in education. The same themes they identified have been utilized and defined in similar ways by many other CRT theorists (e.g., DeCuir \& Dixson, 2004; Lintner, 2004; Stovall, 2004). 
They call the first of these tenets the centrality and intersectionality of race and racism (the permanence of racism). Racism here is explained as being endemic, permanent, and central to the experiences of Black people, and as having always played a central role in the structuring of schools and schooling practices. It is also viewed as intersecting with other forms of subordination, such as sexism and classism. CRT, then, reveals how notions of objectivity, neutrality, and meritocracy, as well as such curricular practices as tracking, teacher beliefs, and intelligence testing, have historically been used to subordinate Black students.

The second theme of CRT is its challenge to the dominant ideology. That is, CRT examines the system of education as part of an overall critique of societal inequality and challenges the dominant social and cultural assumptions regarding intelligence, capability, culture, and so on. Critical race theorists argue that traditional claims of objectivity and meritocracy do no more than camouflage the self-interest, power, and privilege of dominant groups in American society.

The third tenet of CRT is its commitment to social justice and its transformative response to the racial, gender, and class oppression that accompanies it. CRT researchers envision the establishment of a social justice research agenda that will lead toward the elimination of racism, sexism, and poverty, and to the empowering of underrepresented minority groups.

The centrality of the experiential knowledge of men and women of color is the fourth tenet of CRT. This is essentially a recognition that the experiences and stories (or the "counter-stories," as they have come to be called) of Black people are critical to understanding, analyzing, and teaching about racial subordination. CRT theorists 
contend that, for the most part, the experiences of Black students have been marginalized or simply silenced, and that it is of extreme importance that these people be given a voice, an opportunity to tell their own stories.

The fifth theme of CRT is its interdisciplinary perspective. That is, CRT challenges what it calls the "a-historicism" and the "uni-disciplinary" focus of most traditional analyses of race and racism. CRT, on the other hand, considers historical as well as contemporary contexts.

DeCuir and Dixson (2004) delineated two additional themes within critical race theory. The first of these is the idea of Whiteness as property. They posit that, because of the history of racism in the United States and the role our judicial system has played in reifying it, Whiteness has come to be considered as property. In a CRT analysis of educational inequity, then, the curriculum, and specifically, access to a high-quality, rigorous curriculum, has been almost exclusively the property of White students. Such things as tracking, honors and/or gifted programs, and Advanced Placement courses are among the many ways in which the school system has essentially been re-segregated. In other words, many White people take it for granted that, simply because they are White, they are entitled to certain privileges and advantages. Of course, this is not always a conscious thought process, because most people do not even recognize that they are thinking in that way (which makes it even more difficult to combat). But, at the same time, it is very unlikely that they would be willing to sacrifice their superior status - even if it would be for the purpose of achieving equity or racial equality (Morris, 2002).

The second additional tenet of CRT introduced by DeCuir and Dixson (2004) is the critique of liberalism. They delineated 3 basic notions in what they call "liberal legal 
ideology" of which CRT scholars are critical: the notions of colorblindness, the neutrality of the law, and incremental change.

In regard to the first, CRT scholars argue that, whether in society or in jurisprudence, color blindness is just not a rational idea. They contend, and rightly so, that there is simply no such thing as color blindness, that it simply does not and cannot exist. Attempting to argue that society is - or should be - color blind totally disregards the fact that inequity and oppression cannot be remedied by simply ignoring their existence.

As to the notion of the neutrality of the law, from the perspective of CRT, the law is decidedly not neutral. Thus, CRT views any and all claims of color blindness in legal cases as nothing more than a justification to ignore the existence of race-based policies and an avoidance of making any legal efforts to dismantle them.

Finally, critical race theorists argue that the notion of incremental change, which is a notion that underlies liberal policies, is just another way to benefit those in power. That is, the idea that gains for marginalized groups should come at a slow pace is beneficial only to those in power - the oppressors - not to the oppressed.

I would like to mention one other researcher whose observations on the subject of gifted programs merit some discussion here. First, in regard to the general lack of placement of Black students in gifted programs, Morris (2002) states that it is very obvious that most of the school processes, such as their over reliance on standardized measures and incomplete identification and nomination processes, are most responsible for impeding the placement of Black students in gifted education programs. He also reiterates a commonly accepted assessment that it is the racism that exists in the broader 
U.S. society that serves as the greatest impediment to the equitable placement of Black students in such programs. And, finally, he points to the presumption of Black intellectual inferiority (which, he states, is born of racism - and it certainly is), coupled with the negation of African culture in schools, as being what contributes, more often than not, to a perceived - or real - lack of academic success on the part of Black students.

\section{Social Reproduction Theory}

In contemporary social and educational theory, social reproduction theory and critical race theory are closely associated with one another (Demaine, 2003). The term "social reproduction" refers to the replacement of people or structures in a society with a new set of people or structures that is similar to the original, such that the status quo is maintained and the social system reproduced from one generation to the next (Demaine, 2003). The term is also used to refer to the reproduction of the society as a whole, which would, of course, include the social structures and social relationships that characterize that society. The social relationships that are reproduced are often conflictual, oppressive, and exploitative, as has been the case with race relations in America, and this is where social reproduction and critical race theories intersect.

While what is conceived as "the social" varies within different theoretical systems, what is reproduced usually involves hierarchies of classes and occupational status (Demaine, 2003). And, although the character of society, the economy, the technical requirements of occupations, and other social roles are recognized as changing over time, the hierarchical character of the social systems remains the same. Because the hierarchies reproduced are said to be related to knowledge, skills understandings, values orientations, ideologies, and so on, all of which are acquired through learning in school 
(as well as in the family and other formal and informal social institutions), education, both in the broadest sense and in the more narrowly school-based sense, is invariably involved in this process (Demaine, 2003, p. 125).

Pierre Bourdieu, a sociologist known for his work in social, class, and cultural reproduction within educational systems, considers education to be one of the most important social and political forces in the process of class reproduction (Freeman, 1998). Bourdieu (1977) contends that, by appearing to be an impartial and neutral "transmitter" of the benefits of a valued culture, schools are able to promote inequality in the name of fairness and objectivity. Thus, schools play a particularly important role in both legitimating and reproducing the dominant culture (especially at the level of higher education), and they embody class interest and ideologies that capitalize on a kind of familiarity and set of skills that only specific students have received, due to their family backgrounds and social class. Bourdieu referred to that inequality as "cultural capital."

The concept of cultural capital, as explained by Bourdieu (1977), refers to the idea that a child inherits from his or her family sets of meanings, modes of thinking, and types of dispositions that are accorded a certain social value and status as a result of what the dominant class or classes in a society label as the most valued qualities. The cultural and social capital that students bring to the secondary school classroom, then, have tremendous implications for how they will be accepted and treated and whether or not they will be provided the information necessary for choosing to participate in postsecondary schooling. Therefore, since it is generally accepted that Blacks do not bring the same kind of social and cultural capital to the classroom as Whites (Freeman, 
1998), it would naturally follow that their cultural and educational interests and needs would be subsumed by those of the dominant group.

One example of the way in which this theory translates into educational policy and practice is the adoption of the scores earned on the Scholastic Aptitude Test (SAT) as a major determining factor for students' acceptance into college (Watson, 1998). The SAT has actually been classified by many educators and theorists as an instrument of cultural capital, because research has shown that SAT test scores are profoundly affected by factors directly related to the reproduction of the dominant culture, such as parental incomes and education, books in the home, quality of schooling, ability to purchase SAT coaching aids, and cultural differences in the knowledge of words and other socially related concepts (Goldsby, 1993, as reported in Watson, 1998). For those reasons, while they continue to be regarded as good measures of academic ability for Whites (because they are reflective of White culture and ideology), SAT scores are relatively poor measures of the academic ability of Black and other minority students (Morris, 2002; Watson, 1998).

In conclusion, the call for hearing the voices of Black students is a call to bring their experiences to the forefront, which is one essential means of empowering them. Not only will doing this provide valuable insights into the reality of racism in our public education system, but it will also help illuminate viable solutions to the problems racism engenders. By actually making Black students a part of the research, and by developing other innovative strategies for exploring educational policy, research, and practice, it is my hope that we can at least lessen the gap between theory and practice and thus make 
some contribution to the ability of these students to succeed in reaching both their educational and their life goals.

It is important for me to stress here that I am not content with producing a study that does no more than contribute to disciplinary knowledge. Although that is tremendously important in its own right, I am equally concerned with engaging in advocacy on the part of the people I have studied and worked with, by conducting research that will address and contribute directly to solving at least some of the practical problems with which they are faced.

\section{Summary}

In this chapter, I have discussed what is lacking in the literature on at-risk Black youth and how my own study might serve to fill in some of those gaps. I began the chapter by looking at the literature on educational culture and its effects on Black students and then discussed the research on at risk-students and at-risk behaviors as they relate to those students in particular. I then discussed the research on a number of prevention and intervention initiatives (after-school programs and university/community partnerships) that were designed to assist those at-risk students with both their academic and social/behavioral needs. I closed the chapter with a discussion of critical race theory and social reproduction theory, which provide the theoretical framework for my study. 


\section{CHAPTER III}

\section{RESEARCH METHODS}

In this chapter, I identify the rationale for my study, delineate the investigative methods I used, and provide justification for the decisions I made. I present, in detail, the key elements in the study's overall design, including the research tradition in which it is grounded; the theoretical framework of the study; my role as researcher; my site and participant selection; my approaches to gathering, managing, and analyzing data; and the ways in which I went about maintaining the credibility and consistency of my findings.

To remind the reader, this study seeks to add to the current knowledge about enrichment programs and partnership initiatives designed to augment the academic, social, and personal skills of inner-city Black youth.

\section{Qualitative Research}

I begin with a discussion of qualitative research, the research tradition in which my study is grounded. By way of defining the term, it is important to state at the outset that qualitative research is a tradition that does not allow for producing any single, allencompassing definition. As Creswell (1998) put it:

I think metaphorically of qualitative research as an intricate fabric composed of minute threads, many colors, different textures, and various blends of material. This fabric is not explained easily or simply. Like the loom on which fabric is woven, general frameworks hold qualitative research together. With the complexity of qualitative research, its terms, and its traditions, what common ground exists for qualitative research? (p. 13)

Taking Creswell's statement as a starting point, I believe that the most effective way in which to define qualitative research, then, is to identify those common elements by which the majority of researchers have agreed to characterize it. One of the most 
salient characteristics of qualitative research is its emphasis on naturalistic inquiry. That is, the qualitative researcher frequents the places where the events and/or people s/he is interested in studying are naturally found and generally remains there for an extensive period of time (Creswell, 1998; Denzin \& Lincoln, 1974; Miles \& Hubermann, 1994; Ross, 1998).

The qualitative research tradition allows for a process to take place that will enable the researcher to uncover peoples' perceptions and reactions and thus gain a clearer understanding of how they feel about themselves, about others, and about their experiences and surroundings. Such a process requires a deeply personal, insightful, and multi-layered investigation (Creswell, 1998; Denzin \& Lincoln, 1974; Ross, 1998).

The emphasis in qualitative research is on the relevance of primary sources, and thus its approach derives from the belief that meaning is embedded in peoples' experiences. As Merriam (1998) explained it, qualitative research seeks to expose the perspective of the insider (the emic) rather than that of the outsider (the etic). Thus, the stories, experiences, and emotions revealed by the participants in a naturalistic study will be relayed, as much as possible, from their point of view rather than from that of the researcher playing the role of the "expert" or as someone who could be viewed as passing judgment on the participants. Thus, my focus here is on exploring the processes by which the participants construct meaning and then on describing, in detail, what that meaning is.

As noted in Chapter 2, relatively little about the actual lived experiences of at-risk Black students in the public school system has been explored in the literature. Because of that gap in understanding, research that goes beyond a mere enumeration of the complex 
problems plaguing them is scarce. This scarcity points up the need for researchers to turn to qualitative methods as the most effective means of exploring this important and understudied subject and thus expanding the knowledge base about it (Bogdan \& Biklen, 2003; Creswell, 1998; Miles \& Huberman, 1974).

In addition to examining the informant's present actions and feelings, the qualitative inquirer looks also at the larger context of his or her personal history and cultural background, elements that have contributed in essential ways to making the person who he or she is today. Understanding the way in which that context relates to the person or event being studied is an integral part of making sense of the person's lifeworld.

Creswell (1998) describes qualitative research as the type of research that provides a "complex, holistic picture of what is being studied and takes the reader into multiple dimensions of a problem or issue, presenting it in all of its complexity" (p. 15). Thus, the questions I posed to the participants in my in-depth interviews were designed to illuminate that larger context and provide as complete (holistic) a picture of each individual as possible.

Most researchers agree that it would be almost impossible to achieve an in-depth understanding of individuals and events by means of a quantitative investigation alone (Creswell, 1998; Denzin \& Lincoln, 1994; Freeman, 1998). That is because, first, qualitative research enables us to look at social phenomena directly, without the insertion of such artificial or predetermined structures as questionnaires (which are among the main tools of quantitative research). Second, while qualitative researchers believe that explanations are generated inductively from the data, quantitative researchers believe that 
they are generated deductively. Third, the goal of qualitative research, unlike that of quantitative research, is not to test an existing theory or formulate and accept a hypothesis, but rather, to "build toward theory from observations and intuitive understandings gained from the field" (Merriam, 1998, p. 7). As Guba (1978) described it, the qualitative researcher "begins as an anthropologist might begin learning about a strange culture, by immersing himself in the investigation with as open a mind as possible, and permitting impressions to emerge" (p. 72).

All qualitative researchers, regardless of their individual goals or the terminology they utilize, have one goal in common. That goal is to provide a better and more complete understanding of the behavior and experiences of a particular group or individual. It is only by means of a qualitative research study, then, that the detailed life stories of at-risk inner-city Black youth - and the most effective means of helping them will be most likely to surface (Creswell, 1998; Denzin \& Lincoln, 1998; Weis \& Fine, 2000). Therefore, I have attempted throughout this study to present as detailed and holistic a view of my topic as possible.

In their discussion of the ethnographic tradition within qualitative research, Denzin and Lincoln (1994) stated that within that overall tradition, there are some authors who espouse a "scientific" stance and others who espouse a stance of "engaged advocacy" (i.e., a critical stance). Critical race and social reproduction theorists are among the latter. That is, they use qualitative research methodologies to highlight the perspectives of the people in society who have been marginalized and systematically silenced; and it cannot be denied that throughout much of our nation's history, Blacks in America have been among the most marginalized and disregarded of all its citizens. 
Many researchers believe this to be among the most valuable tools we have to empower them, to give a voice to the voiceless, and to thereby ultimately give rise to social justice (Bogdan \& Biklen, 2003; Creswell, 1998; Denzin \& Lincoln, 1994).

It is important for me to indicate again that I am not content with producing a study that serves only to contribute to disciplinary knowledge. Although that has its own special importance and value, I am even more concerned with engaging in advocacy on the part of the people I have studied. By making Black students themselves an integral part of this research and addressing the issues they face head-on, I feel I have contributed something valuable to the solution of some of the practical problems they face. And it is my hope that I have also contributed in some way to lessening the gap between theory and practice and thus helped to enhance the ability of these youth to live successful lives.

\section{Ethnography as a Qualitative Methodology}

The specific qualitative methodology I have employed for this research study is that of ethnography. The term ethnography, in a manner similar to the term qualitative research, has come to mean very different things to different researchers (Bogdan \& Biklen, 2003; Creswell, 1998; Denzin \& Lincoln, 1994). I bring this up because I think it is important to recognize that the designation of a study as belonging in one category or another is more often than not a purely subjective choice, as it is based largely on the individual researcher's interpretation of any given terminology. Thus, such terminology may vary from user to user and from time to time (Bogdan \& Biklen, 2003).

According to Denzin and Lincoln (1994), ethnographic methods, which rely substantially on participant observation, "have a long if somewhat checkered career in the 
social sciences" (p.248), and the definition of the term has been subject historically to quite a bit of controversy. As they put it:

For some, it refers to a philosophical paradigm to which one makes a total commitment; for others, it designates a method that one uses as and when appropriate. And, of course, there are positions between theses extremes ... Across the spectrum of the social sciences, the use and justification of ethnography is marked by diversity rather than consensus. (pp. 248-257)

Bogdan and Biklen (2003) state that there are some scholars who consider the approach of qualitative research to be synonymous with the term ethnographic, because ethnography is directed at describing culture (which is what makes it the method most commonly used by anthropologists). Since, as mentioned previously, one of the things I have done in this study is describe a particular culture and a culture-sharing group, my work fits perfectly into that description.

I point, then, to both Creswell's (1998) use of the term and to that of Denzin and Lincoln (1994) as my main justification for choosing ethnography as my research methodology. Creswell (1998) has described ethnography as a study of the behaviors of a culture-sharing group by means of extensive (i.e., conducted over a prolonged period of time) work in the field, during which time the researcher becomes immersed in the dayto-day lives of the people being studied, aimed at drawing an in-depth portrait of that group. Again, the fieldwork includes, primarily, participant observation and in-depth, one-on-one interviewing.

Denzin and Lincoln (1994) add to that description by pointing out that, in formulating conclusions from the study of a group's patterns of behavior, customs, and ways of life, the researcher attempts to discern the emergent themes and the most pervasive patterns of their daily lives. Thus, the final product of ethnography is typically 
a holistic portrait of a culture-sharing social group, which describes the group's cultural system in as much detail as possible. It is, then, a uniquely humanistic, interpretive portrait of the group, as opposed to the kind of "scientific" and "positivist" one that is produced using quantitative methods.

\section{Role of the Researcher}

Another important difference between qualitative and quantitative inquiry is the role played by the researcher. In doing qualitative research, the researcher is the primary instrument for data collection (Denzin \& Lincoln, 1994; Merriam, 1998). As such, he or she gathers data in the form of words or pictures, analyzes them inductively, and focuses on the meaning they hold for participants in order to be able to paint an accurate picture of their lives (Creswell, 1998).

Ideally, the researcher in naturalistic inquiry should enter into the research as a "clean slate," with no a priori assumptions about what he or she will find (Bogdan \& Biklen, 2003; Ross, 1998). However, that degree of clinical detachment is, more often than not, relatively impossible to achieve. That difficulty may be attributed, predominately, to the concept of reflexivity, which is the active acknowledgement that the researcher's social identity, background, and decisions will all have some impact on the meaning and context of the experience under investigation (Creswell, 1998). Regardless of the difficulties involved, however, the researcher must strive to put aside personal bias as much as possible and to become immersed completely in the sphere of his or her respondents.

There is one additional issue in regard to subjectivity and/or bias that I have to be forthcoming as well as particularly cautious about in my research, which is that my role 
in this study was a multiple one. That is, at times, I have functioned solely as a researcher (an outsider); at other times, as a participant (an insider); and at still other times, as both.

A brief history of my connection with the Overtown Youth Center follows. In June 2007, I approached the Center with the idea of establishing a partnership with them and Florida International University's Biscayne Bay Campus and Honors College. My idea was received enthusiastically by the Center's administration, and our association began almost immediately thereafter. Since then, I have been working closely with them and have put in place a number of different initiatives, including luncheons to celebrate the partnership, recognize the Center's students, and bring the students to the campus; college orientation classes and campus tours for the middle and high-school students; and lectures and a variety of other functions, some of which took place on the campus and others, at the Center. I have also volunteered at the Center on a regular weekly basis and have worked with groups of students as well as with individuals one-on-one, assisting them with homework, providing them with tutoring, and so on. In addition, in 2008, I established an SAT and ACT tutoring program for the high-school students, which has been - and continues to be - an on-going weekly program that takes place on the Biscayne Bay Campus.

As a result of the time I have spent at the Center and the work I have done on its behalf, I have become, as its Executive Director kindly put it, "one of the family." (While that is a good thing, and something that makes me feel good, I am aware that there are - and always will be - certain limitations to that characterization.) Nevertheless, along with my acceptance as a member of the family, I have been told that 
I will have "carte blanche" in regard to access to any information I may need and/or any person or people I may need to speak with in the course of my research. I have also formed close personal relationships with a few of the Center's administrators, staff, and students.

While all of this can, of course, be very helpful to a researcher and his or her study, it can also present certain dangers, which could then become limitations of the study. The most significant limitation, particularly for me, as a novice researcher, is that my objectivity could be put in question. If I am regarded as being too close to the subject I am studying, and thus too subjective, the validity of my conclusions could be questioned. If that were to happen, my entire study could be rejected as lacking credibility (Bogdan \& Biklen, 2003; Creswell, 1998; Denzin \& Lincoln, 1998).

Bogdan and Biklen (2003) suggest that new researchers should study something in which they are not directly involved, and that such researchers should, instead, pick a place where they are "more or less strangers" (p. 52). They go on to state that, while having guaranteed access and excellent rapport are compelling reasons to ignore that advice, the reasons not to ignore it are equally compelling.

While I certainly take the advice of such seasoned researchers as Bogdan and Biklen (2003) very seriously, after giving both sides of this particular issue careful consideration, I can state unequivocally that I have succeeded in distancing myself from my personal concerns and opinions sufficiently to be considered a credible, objective researcher. In order to avoid even the appearance of too much subjectivity, I have been extremely diligent about ensuring that my data is analyzed and reported in as objective 
and transparent a manner as possible. (The specific tools and methods I used to accomplish this are detailed later in this chapter.)

Furthermore, although the close association I have developed with the Center may be regarded as a limitation of the study and of the veracity of its findings, it is important for me to stress here that I am not now, nor could I ever be, a true insider. There are a number of reasons for this. First, I am neither a young adult nor am I Black. What I am is a middle-aged, White, Jewish woman. I do not live in the Overtown neighborhood, nor have I ever lived in an area like it, so I am not a part of the culture or the history of the place. Rather, I am from a middle-class family and grew up in a fairly affluent area in Manhattan, where I enjoyed all of the educational, cultural, and other privileges of "whiteness" that the Overtown youth have been deprived of. And finally, as a university administrator and instructor, I could conceivably be regarded by some of the people at the Center as just another White oppressor, as an outsider who is very much a part of the system responsible for disadvantaging them in the first place. (However, considering the work I have done on their behalf, it is fairly unlikely that I would be perceived in that way.) In sum, then, as close as the relationships I have formed may be, there will always be a limit to my being considered an insider.

The work of Bogdan and Biklen (2003) has provided me with another justification for adhering to my decision to study the Overtown Youth Center. In their discussion of the way in which a novice researcher should choose his or her study, they make the following statement:

However a topic comes to you, whatever it is, it should be important to you and excite you. This is particularly true if it is going to be your thesis, dissertation, or other large effort. Self-discipline can only take you so far in research. Without a 
touch of passion you may not have enough to sustain the effort to follow the work through to the end, or to go beyond doing the ordinary. (p. 51)

My resolve to tackle this study, no matter what I had to do to prove the credibility of its conclusions, derived from the fact that I am very passionate about the subject matter in all of its aspects and ramifications. This avenue of research and practice is something that I plan on continuing to pursue long after this dissertation has been completed; and thus, I have made every effort to do it justice.

Finally, I consider it necessary to mention here, once again, the theoretical framework of my study, because its orientation toward critical race theory presents yet another dimension to the question of the objectivity, and by extension, the credibility, of the study. As one who embraces a critical viewpoint of the American educational system, I recognize - and must make it clear - that my natural bias is in support of the individuals and groups that I regard as being oppressed by a system that upholds the existence of prevailing codes that privilege some groups over others. Because of my philosophical position and my endorsement of substantive change, I have gone out of my way to be even more diligent in my efforts to make the results I report accurate reflections of the evidence I examined.

\section{Site and Participant Selection}

The primary setting for this inquiry is the Overtown Youth Center (OYC), which is an 18,000-square-foot freestanding, state-of-the-art facility located in the heart of Overtown, one of Miami's poorest and most crime-ridden inner-city neighborhoods. The facility is made up of two separate buildings, one of which houses a gymnasium with a full-sized indoor basketball court and locker rooms with showers, two classrooms, a 
dance studio, and a large game room containing pinball machines (donated by Alonzo Mourning), which is also used as a classroom/meeting room for the high-school group. The second building contains a large reception area, a computer lab with 25 computers and Internet connection, a multi-purpose community room, a television/lounge area, five more classrooms, and administrative offices.

The Center, which opened in January 2003, was founded by local real estate developer and art collector Martin Z. Margulies and NBA All-Star Alonzo Mourning. In founding the Center, their stated goal was to provide an "anchor of hope" for the Overtown neighborhood and a safe haven for some of the city's most vulnerable youth in which to spend their after-school hours as well as their weekends and summers. The Center works with children, families, and schools from second grade all the way through to high-school graduation - and beyond. It presently serves over 250 youths, offering them in-school, after-school, weekend, and summer programs that include such activities as academic enhancement, physical fitness, health care and nutrition, creative arts, violence and drug prevention, character-building, and family-oriented activities, including parent orientations.

After-school services are provided both at the site and within the Center's partner schools and are coordinated closely with in-school services. During after-school hours, students attend educational enrichment classes focused on such things as homework assistance, skill building, FCAT preparation, and remediation. The importance of education and of higher education, in particular, is always stressed. 
The Center's mission statement is as follows:

The Overtown Youth Center is dedicated to helping inner-city youth realize their full potential by providing comprehensive educational, social, and recreational enrichment programs through collaborative efforts that facilitate individual and community growth, and enhance the quality of life. (Overtown Youth Center)

One of its stated goals is to be an integral part of the community by delivering enrichment services that "foster hope and promote life-long learning and success for inner-city youth and citizens." Another of its primary objectives is "to develop a resilient child who can survive within an environment that is loaded with risk factors and challenges, and grow into a competent and productive member of society." (Overtown Youth Center)

The choice of this setting fits the characteristics of an appropriate site for an ethnographic study as described by Creswell (1998), who states that an ethnographic study requires "a single site where an intact culture-sharing group has developed shared values, beliefs, and assumptions" (p. 114). It also fits the characteristics of a "good site" as described by Marshall and Rossman (1995), who recommend that the choice of site be one that has accessibility, a mix of people that will yield sufficient research participants, an environment conducive to developing trusting relationships, and an opportunity for gathering quality and credible data.

I divided the sample for the study into two groups of key informants. The first group included Alonzo Mourning, the founder of the Center; Carla Penn, the Center's Executive Director; Fred Rosario, the coordinator who works directly with the high and post-high-school students; and Valerie Lomax, the parent coordinator. I interviewed those individuals in order to provide the reader with a complete picture of the Center's 
background and history, the specific ways in which it is works to meet its stated objectives, its record of success, its plans for growth in the future, and so on.

The second group consisted of six of the Center's high-school-age students, each of whom have been consistent participants in the Center's programming; and two of the Center's elementary-school coordinators, Sabrina Jackson and Ilya Williams, who are both also parents whose children attend the Center. The extensive nature of my analysis of each of my informants suggests that this number is appropriate (Silverman, 2000).

In order to select the Overtown Youth Center students that I interviewed, I used purposive sampling (Merriam, 2002). Purposive sampling refers to selecting study participants based on the specified criteria essential for a thorough analysis of a topic. Those criteria include such things as gaining perspective on time spent in the social life of the group, representation of the culture-sharing group in terms of demographics, and the contexts that lead to different forms of behavior. As suggested by Creswell (1998), using my research questions as a barometer, I relied on my best judgment to make my selections.

In order to have some variation within the group of participants to be interviewed, the students I selected either entered the program at different ages or were in different grades and/or at different stages of personal development. The in-depth interviews I conducted were designed to elicit the life story of each of the students from his or her perspective. I attempted to discover what the most pressing challenge(s) each of them has had to deal with in his or her life, and if and how the Center has helped him/her to deal with those challenges, with his/her academic and/or personal empowerment, and with his/her aspirations to attend college. 


\section{Data Collection Procedures}

In conducting this study I utilized a multiple perspective approach, in order to paint as complete a picture as possible of what is a very complex subject. I focused on the data gathering techniques most common to ethnography: participant observation, oneon-one interviewing, and the recording of informal conversations (Creswell, 1998; Denzin \& Lincoln, 1994). My decision to use more than one data gathering technique was made because using a multiple approach in qualitative research has been proven to be one of the most effective ways to limit researcher bias and thus obtain the most accurate information (Bogdan \& Biklen, 2003; Denzin \& Lincoln, 1994).

\section{Participant Observation}

According to Atkinson and Hammersley (1994), while the definition of participant observation is subject to somewhat less controversy than that of ethnography, its meaning is still not easy to pin down. That is due, in part, to the distinction that is often drawn between participant and non-participant observation; and in part, to what Bogdan and Biklen (2003) call the participant/observer continuum (p. 82). That continuum is based on Gold's (1958) classic typology of naturalistic research roles, which is a fourfold spectrum of modes through which observers may gather data (Adler \& Adler, 1994; Bogdan \& Biklen, 2003).

At one extreme of this spectrum, there is the "complete observer," who does not participate in any of the activities at the setting and is fundamentally removed from it. This role most closely approximates the traditional ideal of the "objective" observer. At the other extreme, there is the "complete participant," who attempts to engage fully in the activities of the group, and whose behaviors and actions can at times be almost 
indistinguishable from those of the people being studied. Between the two extremes, there is the observer-as-participant and the participant-as-observer. The observer-asparticipant role describes researchers who primarily observe their subjects for very brief periods of time in the course of conducting structured interviews. In taking on this role, the researcher is attempting to move away from the idea of participation. In the participant-as-observer role, the researcher, who began as a participant, adopts an overt role and makes his or her presence as an observer and researcher known to the group (Denzin \& Lincoln, 1994). That is basically where I see myself, as when I began my association with OYC, it was not my intention to make it the subject of this research project.

Adler and Adler (1994) sum up the wide variety of roles that a researcher can play in the course of participant observation as follows:

Observers can thus take roles that range anywhere from the hidden or disguised voyeur, who watches from outside or with a passive (even electronic) presence, to the active participant, involved in the setting, who acts as a member and not as a researcher so as not to alter the flow of the interaction unnaturally. (p. 380)

The point to remember here is that what makes the term participant observation so difficult to pin down is the fact that exactly what kind of and how much participation is appropriate will vary in accordance with the particulars of the study and with the different stages that the study is in at any given point in time (Bogdan \& Biklen, 2003).

Ostensibly, however, participant observation is a straightforward technique: by immersing oneself in the day-to-day activities of the people one is attempting to understand, usually over a long period of time, it is presumed that the researcher will gain a deeper understanding than could be obtained, for example, from answers to 
questionnaire items. Generally speaking, the researcher engaged in participant observation tries to learn what life is like for an "insider," while remaining inevitably an "outsider."

There are two strands of thought that I consider particularly germane to the role I have played in the course of my research. The first is pragmatism, which is one of the intellectual traditions of the Chicago School of participant observation and research. Pragmatism emphasizes the idea that social life is not fixed but rather dynamic and changing. For that reason, it is important to participate in peoples' social relations and seek to understand their actions within the context of an observed setting, as people act and make sense of their world by taking meanings from their environment. As such, researchers must become part of that environment, for only then can they understand the actions of people who occupy and produce the cultures they wish to understand (Spradley, 1997).

The second is naturalism, which, as discussed earlier in this chapter, proposes that, as far as possible, the social world of a cultural group should be studied in its "natural state," undisturbed by the researcher. According to that view, people are busy interpreting and acting within a social world that is infused with meaning. The process of learning about their behavior is argued to be absent from other forms of research, such as questionnaires, which capture only a static snapshot of peoples' attitudes. In contrast, participant observation is a process in which a researcher establishes a many-sided and long-term relationship with individuals and groups in their natural setting for the purpose of developing a scientific understanding of those individuals and groups (Spradley, 1997). 
In participant observation, the ethnographer is the instrument of data collection. He or she gathers data by actively participating in a particular social world, one in which people are already busy interpreting and understanding their environments. The fact that subjectivity is an inherent part of this form of research, then, cannot be ignored. And, in doing ethnography, engagement is generally viewed as an advantage rather than a disadvantage (Spradley, 1997). In the research process, ethnographers often explicitly draw upon their own biographies or their own feelings and philosophies, which negates the idea that social research is, or can be, carried out in some autonomous realm that is insulated from the wider society and from the particular biography of the researcher.

On the other hand, of course, subjectivity can be and often is pointed to as one of the downsides of participant observation as a data-gathering technique. As such, as was discussed earlier in this chapter, it may be regarded as posing a threat to the objectivity of the researcher. The researcher may be viewed by some as being biased in regard to what data are gathered and how data are assigned meaning. Others may feel that the participant observer, simply by being present, may have some effect on the phenomenon being studied.

One of the main advantages of participant observation is its flexibility. Fieldwork is a continual process of reflection and alteration of the focus of observations in accordance with analytic developments. It permits researchers to witness peoples' actions in different settings and routinely ask themselves myriad questions concerning motivations, beliefs, and actions (Bogdan \& Biklen, 2003; Denzin \& Lincoln, 1998). Another advantage is that the method enables researchers to develop a familiarity with the cultural milieu they are studying, which proves invaluable throughout the project. It 
gives them a nuanced understanding of its context that can only come from personal experience. There is no substitute for witnessing or participating in phenomena of human interaction - interaction with other people, with places, with things, and with states of being. In sum, observing and participating are integral to understanding the breadth and complexities of the human experience.

In addition, through participant observation, researchers can also uncover factors important for a thorough understanding of the research problem that they may not have thought of when they first designed the study. This is one of the greatest advantages of the method, especially because, although we may get truthful answers to the research questions we ask, we may not always ask the right questions (Denzin \& Lincoln, 1994).

Participant observation often employs informal conversations and interactions with members of the study population as a routine part of its practice. Because observation guides researchers to some of the important questions they want to ask the respondents, and such conversations help to interpret the significance of what researchers are observing, the two methods are quite compatible. Whatever occurs during any of these interactions is an important component of the overall method and as such is recorded in field notes in as much detail as possible (Adler \& Adler, 1994).

Participant observation has been an on-going activity throughout the course of this study. I visited the Center to make some of my observations at least once a week for two to three hours each time over a period of approximately 18 months. The main purpose of the observations was to get a sense of the Center's culture and the types of interactions that take place there on a daily basis between students and their peers; students on different grade levels; students and the Center's teachers, staff, tutors, and 
volunteers; and students and the Center's administrative personnel. I observed those interactions while the students were engaged in a variety of activities at the Center, such as doing homework, being tutored, attending classes, participating in discussion groups, and participating in cultural and athletic activities. I also made extensive observations of their behavior outside of the Center, particularly during their visits to FIU to participate in various programs and activities and in the SAT tutoring sessions, most of which were conducted and/or overseen by me.

During my observations, I wrote detailed, descriptive field notes of what I observed, including gestures, facial expressions, and other non-verbal forms of communication. I did not make tape recordings of participant observations, but I always had a tape recorder with me in the event that it was needed.

I kept my field notes in two separate files, one for my actual observations and the other for my personal reflections and thoughts (Creswell, 1998; Merriam, 1998; Seidman, 1998). In regard to the latter file, I recorded as many of my thoughts, impressions, opinions, or biases that surfaced in the course of my observations as I could.

After leaving the site, I recorded the material from my observations as promptly as I could, so that the details were still fresh in my mind and my records could be as accurate as possible. Finally, I converted my field notes into computer text files, which I stored both on the computer and in hard copy (Denzin \& Lincoln, 1998; Silverman, 2000).

\section{In-Depth Interviewing}

A great deal of research has been - and continues to be - done on schooling in the United States. Unfortunately, however, far too little of it is based on studies that 
illuminate the perspectives of students, teachers, and administrators in regard to their experiences in the school environment, or of the meanings that each of them makes of those experiences. That is why the process of in-depth interviewing is so important in this study. According to Seidman (2006), the purpose of in-depth interviewing is:

...not to get answers to questions, nor to test hypotheses, and not to "evaluate" as the term is normally used. At the root of in-depth interviewing is an interest in understanding the lived experience of other people and the meaning they make of that experience. (p. 9)

Interviewing is one of the most basic modes of inquiry into the behaviors and beliefs of human beings (Seidman, 2006). Throughout recorded history, the recounting of experience through the use of narrative has been the predominant way in which humans have attempted to make sense of their experiences in a given context. Thus, "at the very heart of what it means to be human is the ability of people to symbolize their experience through language" (Seidman, 2006, p. 8). It naturally follows that interviewing, which makes use of the participant's own language, is essential to the ability of research to answer questions about human beings and their behavior.

As Kvale (1996) has noted, the interview is a powerful pathway to the comprehension of other peoples' experiences and perspectives. Kvale sees qualitative research interviews as conversations that strive to unfold the story behind peoples' lived experiences and facilitate the pursuit of in-depth information about a particular theme or concern, in order to understand it intellectually.

It must be remembered that the adequacy of any research method depends on the purpose of the research and on the questions that are being asked (Seidman, 2006). Thus, if the researcher's goal is to arrive at a "subjective understanding" of the participants in 
his or her study, then interviewing will probably be the best avenue of inquiry to follow (Seidman, 2006). Subjective understanding, as it has been defined by Schutz (1967), is an understanding of not only a person's actual experience but also of the meaning that person makes out of the experience; for example, what it is like for students to be in an after-school program.

One of the keys to developing a successful interviewing technique is to be genuinely interested in others and to show that interest to them openly. This demands that our actions as interviewers indicate to participants that the stories they are telling are important to us; and this, in turn, requires that we keep our egos in check. It also requires that, in keeping with postmodern ideology, we acknowledge an understanding that there are multiple ways of viewing things, that there is no such thing as one universal Reality or one single Truth applicable to everyone in every situation, and that we do not consider ourselves to be at the center of the world. While we also have to recognize that there are limits to our understanding of others, we can still strive to comprehend them by understanding their actions.

The word interviewing covers a wide range of practices, and there are no absolutes within that range. On one extreme, there are tightly-structured survey interviews that utilize preset, standardized, normally closed questions. On the other extreme, there are open-ended, apparently unstructured, anthropological interviews that more closely resemble "friendly conversations" (Seidman, 2006). Since there has been relatively little research done on the effects of following one procedure over any other, Seidman (2006) suggests that the governing principle in designing interviewing projects 
might well be to strive for a rational process, one that can be both repeated and documented.

Patton (1990) identified three basic types of qualitative interviewing: the informal, conversational interview; the interview guide approach; and the standardized open-ended interview. In the interview guide approach, which is the approach most commonly used, the interviewer has an outline of topics or issues he or she wants to cover but retains a degree of flexibility in the wording and order of the questions. The standardized, open-ended interview is similar but less flexible, in that it adheres to a specific wording and order of questions.

I have utilized a combination of the three types, making my selections according to the needs of each individual being interviewed and the type of information I wanted to elicit from each. However, for the majority of the interviews, my focus has been on the interview guide approach.

In interviewing the students and their parents, I also attempted to utilize a fourth format, which has been outlined by Seidman (2006). This format, which he calls indepth, phenomenologically based interviewing, combines and builds on the other three. In this method, life history interviewing is combined with focused, in-depth interviewing. The researcher uses primarily open-ended questions, with the goal of having the participant reconstruct his or her experience of whatever topic is being studied (Seidman, 2006, p. 15). Since this an ethnographic study, I attempted throughout to put the participants' experiences into a particular cultural context. And, my choice of critical race theory as the theoretical framework of the study shaped the kinds of things I have done. 
Seidman (2006) suggests following Schuman's (1982) interview design, which is considered to be the one most characteristic of the in-depth phenomenological interview approach. This design calls for conducting a series of three separate interviews of 90 minutes each with each participant, and spacing the interviews from three to seven days apart. In order to meet the needs and time constraints of the individuals I interviewed, I decided to modify the design by conducting two separate interviews of 45-60 minutes each (rather than three). I did, however, attempt to follow the time interval between interviews suggested by Schuman (1982).

In the first interviews, which Seidman (2006) calls the "focused life history interview," my main task was to put the participant's experience in context by asking him or her to tell me as much about him or herself up to the present time as possible. Thus, during the first interview, I asked the participants to reconstruct their early experiences in their families, in school, with friends, in their neighborhood, and if appropriate, at work. The goal of this part of the inquiry was to have them place their participation at OYC within the overall context of their lives.

In the second interviews, I sought to have the participants reconstruct and elaborate on the details of their present experience within the context being studied (i.e., the Overtown Youth Center). I asked them to talk about such things as their relationships with their peers, teachers, mentors, and others.

It is obvious that utilizing this design required me to stick to a definite structure. However, I attempted to work within the structure while at the same time guarding against allowing the structure to become too inhibiting. This required that I work hard at maintaining a delicate balance between providing enough openness to allow the 
participants to tell their stories and enough focus to allow the interview structure to work. I accomplished this by keeping the style of the interviews conversational and personal and making the format flexible enough to allow space for a natural exchange to take place. I also tried to remain open at all times to addressing and exploring any unforeseen issues that emerged during the process.

I contacted all of the people I wanted to interview at least one week in advance, either in person or by telephone, in order to determine the times and locations for the interviews that would be most convenient for each of them. I communicated to them that I was open to meeting with them at whatever location would be most comfortable and convenient for them. By doing that, I believe I made them feel at ease in the interview setting and made it as unthreatening an environment as possible. With the permission of the respondents, I recorded all of the interviews using an audio recorder, and after the interviews, I transcribed each of them verbatim to computer text files.

\section{Data Analysis}

Qualitative research generates extremely large volumes of data (Bogdan \& Biklen, 1998; Creswell, 1998; Denzin \& Lincoln, 1998; Merriam, 1998; Miles \& Huberman, 1994; Silverman, 2000). There are dangers inherent in having to analyze what may be viewed as a mountain of information, not the least of which is that of being overloaded with more data than can be processed (Miles \& Huberman, 1994). Making sense of such a large body of data, then, required that I utilize a carefully thought-out analytical scheme (Denzin \& Lincoln, 1998; Miles \& Huberman, 1994). As Miles and Huberman (1994) suggest, the challenge for the researcher is to always remain mindful of 
both the purpose of the study and the conceptual lenses being used to examine it, while at the same time to remain open to the unexpected (p. 56).

Miles and Huberman (1994) describe a design continuum that ranges from what they call "loose" (less structured and emergent) to "tight" (focused and pre-structured) and then locate their recommendations closer to the "tight" end of the continuum, especially for novice qualitative researchers. They also strongly recommend early analysis, which consists of interweaving data collection and analysis from the very beginning of the research process (p. 50). As a novice, I took their advice, keeping in mind my ultimate objective to arrive at a design that would combine the benefits of data manageability with the flexibility of allowing for the unanticipated.

Miles and Huberman (1994) offer a model of qualitative analysis, which I followed as closely as I could. It begins with data reduction, the purpose of which is to "select, focus, simplify, abstract, and transform the data that appear in written-up field notes or transcriptions" (p. 10). After the basic raw data have been collected, much of which, they state, will be in the form of often hastily handwritten field notes, the first step is to convert them into typewritten "write-ups." This is done so that the field notes can be readily understood by just about anyone who tries to read them (the authors point out that raw field notes are usually hard to make sense of for anyone other than the fieldworker).

Once all of the data from both participant observations and interviews have been converted into write-ups, the first thing they suggest that researchers do is to go over in their mind the main concepts, themes, issues, and questions that arose during each individual field contact. After that, they suggest creating a contact summary sheet, which 
should be no longer than one page for each contact, and then separating all of the data pertaining to each respondent into individual files.

The next step in data reduction included the categorizing of all salient information through the use of a coding system. Miles and Huberman (1994) define the term codes as "tags or labels for assigning units of meaning to the descriptive or inferential information compiled during a study" (p. 56). They go on to state that codes are usually attached to "chunks" of varying size - words, phrases, sentences, or whole paragraphs. They suggest using several different levels in coding: first-level coding, second-level or pattern codes, and a process of deriving even more general themes called memoing (p. 51). In suggesting this system, they explain that the researcher has to "accompany each wave of data collection with a corresponding exercise in condensation and analysis [and that] this step is where coding and other forms of ongoing, iterative reflection come in" (p. 56).

Essentially, coding is analysis. It is a means of arranging and reducing the data into manageable units. While there are, of course, many different methods of creating codes, the one that Miles and Huberman suggest using is that of creating a provisional "start list" of codes prior to doing the fieldwork. That list comes from the conceptual framework, the list of research questions, hypotheses, problem areas, and/or key variables that the researcher brings to the study (p. 58). Crabtree and Miller (1992) use the term editing to characterize this process because, as they put it, "the interpreter enters the text much like an editor searching for meaningful segments, cutting, pasting, and rearranging until the reduced summary reveals the interpretive truth in the text" (p. 20). 
The initial coding scheme I used was based, first, on the major concepts discussed in the interviews. Later on, I modified them as themes began to emerge. The following are the major concept categories I used:

- Socio-cultural characteristics

- Family characteristics

- Motivating factors

- Key interactions

- De-motivating factors

- Effects of race

- Attitudes toward attending college

- Students' experiences at OYC in regard to all of the above concepts

I also created additional codes that related specifically to the major themes of critical race theory identified by Solorzano and Yosso (2001) and by DeCuir and Dixson (2004), which I discussed in Chapter 2. These are as follows:

- The centrality and the intersectionality of race and racism (the permanence of racism)

- Dominant ideology - how it manifests and how it is challenged

- How a commitment to social justice is manifested in the data

- The centrality of the experiential knowledge of Black men and women Analysis, then, involved organizing my data into manageable units by coding and synthesizing them and then repeatedly reviewing my interview transcripts and observation notes. By means of this process, which is also referred to as "clustering," 
themes, patterns, and regularities emerged and were then identified in pattern codes (the second level in coding). Pattern codes are codes that identify an emergent theme, configuration, or explanation. They essentially pull together a lot of material into more meaningful units of analysis. Once identified, appropriate categories in which to place them were devised. The categories I developed then generated the major themes from which my conclusions were drawn.

After reviewing the literature about computer use with qualitative data in general and looking at several specific qualitative-data-analysis packages, such as $N U D^{*} I S T$, NVIVO, Ethnograph and Atlas $t i$, I made the decision that I did not need to use one. It seemed to me that the size and scope of the data I collected only warranted the use of a full-featured word-processing program. In addition, I decided that it is likely that the amount of time that it would take for me to learn to use any of the programs efficiently would outweigh the time I might save by using one.

\section{Credibility and Integrity of the Study}

In order to meet the standards of critical research, qualitative studies, like experimental designs, must be scrutinized for credibility or trustworthiness. This involves data collection and analysis methods that are consistent, reliable, and properly communicated (Bogdan \& Biklen, 2003; Creswell, 1998; Silverman, 2000).

Many qualitative researchers disagree with the epistemological assumptions underlying the notions of the terms validity and reliability, as these are terms traditionally used in connection with quantitative research. Lincoln and Guba (1985), for example, argue that there is a need for a new way in which to discuss these issues that, they contend, will adhere more to "naturalistic axioms." Therefore, to establish the 
"trustworthiness" of a study, Lincoln and Guba (1985) use the terms "credibility," "transferability," "dependability" and "confirmability" as the "naturalist's equivalents" to "internal validity," "external validity," "reliability," and "objectivity" (p. 300).

To operationalize the new terms above, Lincoln and Guba (1985) propose such techniques as prolonged engagement in the field and triangulation among different data sources, methods, and investigators to establish credibility. To increase the chance that the findings will be transferable between the researcher and those being studied, they state that thick description is needed. Rather than reliability, one seeks dependability that the results will not be subject to change. Finally, the naturalistic researcher looks to confirmability rather than objectivity in establishing the value of data.

Both dependability and confirmability may be established by means of an auditing of the research process (Creswell, 1998, pp. 197-198). I have undertaken a number of these verification procedures to solidify my findings and minimize bias. (Creswell recommends that qualitative researchers utilize at least two of the above techniques in the course of any given study.)

Since mine is an ethnographic study, I did, of course, have a prolonged engagement in the field and made persistent participant observations over the course of two years. Those activities served to help me build trust with the participants, learn the culture, and check for any misinformation that might have come from distortions introduced by myself or by my informants (Lincoln \& Guba, 1985; Merriam, 1998).

I scrutinized my data collection and analysis methods for consistency and reliability by using the two basic underlying principles in establishing a study's trustworthiness suggested by Merriam (1998), transparency and thoroughness. In order 
for a study to be transparent, the reader should be able to recognize the basic process of the research, so that the researcher's biases, assumptions, and research skills may be assessed with ease. To enhance transparency, I have been diligent in clearly presenting all pertinent information related to my methods, resources, and personal ideology. My methods, procedures, and thoughts have been thoroughly documented in my field journal, interview elaborations, and memos to myself. I have also documented my initial assumptions and expectations and have treated all such speculations, impressions, hunches, and prejudices as data for analysis (Denzin \& Lincoln, 1998). This should serve to clarify for the reader any bias on my part from the outset and enable the reader to understand the things that shaped my approach and interpretation. In addition, as mentioned earlier in this chapter, I have endeavored to remain as aware as possible of any preconceived expectations and/or covert agendas I might have had as well as any ethical issues that could potentially contaminate the data.

I have also conducted member checks, which involve reviewing the data that result from the interviews with the participants as to the accuracy of the findings and interpretations (Denzin \& Lincoln, 1998). That is, I asked many of my respondents to read my transcription of his or her interview and give me feedback on the correctness of the recorded data and my analysis of the data. By means of this method, I now feel relatively certain that the meaning they intended was represented faithfully. This technique is considered by Lincoln and Guba (1985) to be "the most critical technique for establishing credibility" (p. 314).

I would be remiss if I were to leave this subject without at least making mention of the fact that there are many qualitative researchers who criticize the very idea of 
complete objectivity when it comes to a study of this kind. Ferrarotti (1981), for example, argues that the most profound knowledge can be gained only by the deepest subjectivity between the researcher and that which he or she is researching. I would add to Ferrarotti's argument by stating that, from the point of view of a critical researcher, subjectivity is essential, as it is actually an integral part of the research.

In addition to the above, even when every aspect of the structure, process, and practice of qualitative research is directed toward the goal of minimizing the effects that the interviewer and the interviewing situation have on how the participants reconstruct their experiences, we cannot escape the reality that interviewers are inextricably a part of the process. They ask questions, respond to the participants, and sometimes even share their own experiences with them. They also work with the material, select from it, interpret, describe and analyze it. In fact, such interaction is inherent in the very nature of the research. Therefore, there is no escaping the fact that the meaning will be, at least to some degree, a function of the participant's interactions with the interviewer.

Whatever one's position on these issues may be, however, it is still generally considered the duty of the researcher to do as much as possible to gather and present his or her data in as transparent a manner as possible, which I have ventured to do throughout my study.

\section{Summary}

In this chapter I first discussed the major characteristics of the qualitative tradition in research and why it is considered the tradition best-suited to the type of study I have conducted. I then discussed the meaning and research methods of ethnography, the qualitative methodology I have chosen. 
In the remainder of the chapter I discussed my role as the researcher, the site I selected for the study and how I went about choosing the study's participants, the specific data collection procedures I used (primarily participant observation and in-depth interviewing), the data analysis procedures I followed, and finally, what I did to maintain the credibility and integrity of the research. 


\section{CHAPTER IV}

\section{OVERTOWN YOUTH CENTER: HISTORY AND STRUCTURE}

As stated in my introductory chapter, the primary focus of this study was to understand the ways in which one youth enrichment program positions itself as addressing the needs of inner-city Black youth. Toward that end, I chose a program that is currently in place at the Overtown Youth Center in Miami, Florida, as the object of my research, as it claims to be having measurable success in empowering the young people it serves.

In this chapter, I will first provide the reader with detailed information about the history and founding of the Overtown Youth Center and present my findings about the Center's culture and the basis upon which the OYC participants are recruited and selected. The majority of the historical information was gathered from both formal and informal interviews with Alonzo Mourning, the Center's founder. Additional information about the Center's history and its recruitment methodology was provided through interviews with Carla Penn, the Center's Executive Director.

Next, I will describe the role and responsibilities of the Center's coordinators and provide an overview of its post-high and parent-involvement programs, which are two of the more significant programmatic components that make OYC unique. That information was gathered through formal interviews I conducted with Carla Penn, the Executive Director; Fred Rosario, the Center's high and post-high school coordinator; Sabrina Jackson, one of the Center's elementary-school coordinators; Ilya Williams, another of its elementary-school coordinators; and Valerie Lomax, the Center's parent coordinator. 
The review of the literature I presented in Chapter 2 leaves no doubt that growing up in an impoverished inner-city neighborhood like Overtown puts children very much at risk for engaging in any number of negative behaviors, such as violent crime, gang membership, drug and/or alcohol abuse, teen pregnancy, and dropping out of school, to name but a few. Most educational researchers today agree that if we are to have any hope of improving the life chances of these children, we need to provide them with additional assistance in the form of structured, holistic enrichment programs that focus on improving their self-esteem, academic skills, and social behavior. However, it must be noted here that all programs are not created equal, and I will show in this and the chapter that follows why the Overtown Youth Center is unique and how it is far from being just another average, every day after-school program.

\section{The Founding of the Overtown Youth Center}

Service to others is the rent you pay for your room here on earth.

Muhammad Ali

In 1999, Marty Margulies, a successful Miami real estate developer, art collector, philanthropist, and a Miami Heat season ticket holder, placed a phone call to Alonzo Mourning, an NBA All-Star basketball player for the Miami Heat. During that first phone call, Margulies told Mourning that he was thinking of building a center for disadvantaged youth in one of Miami's most impoverished neighborhoods and that he wanted to meet with him to discuss the idea.

Mourning agreed to the meeting, and when it took place, Margulies told him that he had a vision to establish a center in an area of Miami-Dade County that had a tremendous need for such a facility and that he was willing to donate $\$ 2.5$ million 
through the Margulies Foundation to launch the project. He said that the exact location of the center was not that important to him - it could be in Overtown, Liberty City, Carroll City, Opa-Locka, or any other severely disadvantaged area - as long as it would be serving a population that really needed it. Margulies also told Mourning that, in order for the project to succeed, he felt that he needed "hands-on help" and support from him. He explained to Mourning that, aside from the fact that he knew very little about running a youth center, he strongly believed that its success would be insured by having a celebrity name such as his attached to it. He also said that he knew Mourning was committed to youth in a way that very few other athletes are.

At first, Alonzo said that he was taken aback by Margulies’ proposal. It made him think immediately about how little free time he had and about all the other things going on in his life at the time, including his attempt to win an NBA Championship playing for the Miami Heat and heading his own charitable foundation, Alonzo Mourning Charities (AMC) in Miami.

Since its inception, Mourning's foundation, has organized several major annual fundraising events. The main one, “Zo's Summer Groove," which celebrated its $14^{\text {th }}$ year in July 2010, is actually a series of events that are held over a 5-day-long period. It includes a celebrity golf game, a youth summit, a comedy show, an all-star basketball game, a free block party open to the general public, and a formal charity gala and dinner. Every year, the 5-day event has raised substantial funds for his charity organization. Before the Overtown Youth Center was built, Mourning donated almost all of those funds to two organizations: the Children's Home Society for Abused and Neglected Children, which helps find homes for some of the country's most vulnerable children; and 100 
Black Men of America, a mentorship program for young Black men that helps shape the intellectual development of youth and the economic empowerment of the AfricanAmerican community.

Since the Center opened in 2003, however, the majority of the funds raised have been used to support OYC, which costs about $\$ 2$ million a year to run. To give the reader an idea of the amount of money that comes from AMC's fundraising efforts, here are some figures provided by the Overtown Youth Center, which detail its revenue sources for the fiscal year 2009-2010: $45 \%$ of its revenue derived from grants; $37 \%$, from fundraising; $14 \%$, from in-kind; and $4 \%$, from endowments.

Mourning said that he knew immediately that the project Margulies was proposing would be a life-changing opportunity for him. He also realized that it would be a major undertaking, one that would require a great deal of his time, focus, and concentrated effort. After considering the entire situation, however, he decided that he had to go ahead with it. So he said to Margulies, "Let's do it. Look, if you are willing to come out of your pocket for $\$ 2.5$ million, then I want to help do it, and I want to make sure this center is financially viable for years and years to come and that this community is going to get everything it can out of it."

Once he made his decision, Mourning said that he was determined to make the project work, even if it meant that he would have to use some of his own money to support it and put his reputation on the line for it. He was also willing to put in whatever time it would take to hire the staff, meet the kids, and reach out to the Overtown community to provide credibility for the center and help convince the parents to trust that his center would do the right thing for their children. 
During the time that I have been researching and working with the Center, I have had several opportunities to speak with Mourning and I have also heard him give many impassioned speeches about the Center, the pressing needs of the Overtown youth, and the tremendous importance he places on education. I have also had ample opportunities to observe the degree of commitment and dedication he has to the Center, and particularly, to the young people in the community it serves. I have been very impressed by how much both he and his wife, Tracy Wilson-Mourning, truly care and how they devote so much of their time, talent, and love to the youth there. Mourning is definitely not one of those people who consider it sufficient to hand out a check and then simply disappear or to show an interest only when there are cameras present. He truly does care.

Regarding a site for the center, Mourning told me that the decision to build it in Overtown was probably the easiest of all the decisions he had to make in relation to the project. Aside from the fact that he knew the Overtown neighborhood to be "one of the most blighted and hopeless communities in the country," he had become familiar with the area in the course of the years he played basketball for the Miami Heat.

Overtown is just northwest of downtown Miami and a very short drive from the Miami Arena, where the Heat used to play, and from the American Airlines Arena, where the Heat plays today. Mourning said that he often drove through Overtown on his way to games and always felt very distressed by the decay and poverty he saw there, especially in contrast to the wealth of the areas surrounding it. In fact, he said that you can see Overtown - literally look right down into it - from the balconies of some of the most expensive high-rises in downtown Miami, which "makes one painfully aware of the stark division between wealthy Miami and poor Miami, between power and poverty." 
He was so moved by the impoverished conditions and the people in the community, in fact, that every Thanksgiving he started going door-to-door from one poor apartment complex to the next giving out free turkeys to the families there. He is still doing that today; but in the last several years, up to and including 2010, in addition to going door-to-door himself on Thanksgiving Day, he has been giving out full turkey dinners - complete with potatoes, gravy, stuffing, vegetables, rolls, apple pie, and gallon containers of juice - to over 500 families!

After making the decision to get involved in the creation of the center, one of the first things Mourning did was to get in touch with Andre Napier, a former fraternity brother of his from Georgetown University, who was also one of the people who helped him start Alonzo Mourning Charities. He told Napier that he wanted to make sure that the center's program would be the very best one in the country and that "he could not afford to make any mistakes."

With that in mind, Napier did some research and found out about a nationallyrecognized program that many people consider to be the best out-of-school organization in America. The program is called Self-Enhancement Incorporated (SEI), and it is located in Portland, Oregon. It was founded by a man named Tony Hopson, who is also its Executive Director. After learning about SEI's comprehensive program, which provides in-school, after-school, weekend, and summer services to its youth, Mourning contacted Hopson and asked him if he would be willing to help with the building, the planning, the curriculum, and everything else needed to replicate SEI's program in Miami. When Hopson agreed, Mourning, who wanted to waste no time, flew him down to Miami to get the project started. 


\section{Self-Enhancement Incorporated}

Self-Enhancement Incorporated (SEI) was established in 1981. It was founded initially as a one-week basketball camp for high school boys, but it has since grown into one of the most comprehensive youth development organizations in the country. It currently operates a 62,000 -square-foot facility and serves approximately 2,500 young people (ages 8-25) - and their families - annually in year-round academic, enrichment, and family support programs.

SEI is located in the most disadvantaged, high-risk, predominately Black community in Portland, Oregon, a community that is similar in many ways to Overtown. Over $90 \%$ of its students live in the inner-city areas of north and northeast Portland, and much like the youth in Overtown, these youth come into the program with significant barriers to their success - poverty, absent parents, homelessness, placement in foster care, family substance abuse or gang involvement, academic skills well below grade level, and so on. Over $85 \%$ of them are eligible for free or reduced-price lunch (which indicates that their family is living at or near the poverty level). SEI is dedicated to guiding these underserved youth to realize their full potential, and through its work with schools, families, and community organizations, it provides numerous opportunities for them to achieve personal and academic success.

The statistics on the outcomes of the SEI program provided here are by no means intended to be comprehensive figures. I provide them simply to give the reader a sense of the success its program has pointed to. In 2008, $100 \%$ of its high-school seniors graduated from high school in four years (a figure that surpassed its average high-school graduation rate of 98\%). By way of comparison, the statewide high-school graduation 
rate in Oregon for the year 2007 was only 74\%; and the graduation rate for the high school in the primary area served by SEI, only $64 \%$. Of the 2008 SEI graduates, four distinguished themselves as valedictorians of their class, and one was awarded the Bill and Melinda Gates Millennium Scholarship, which covers full tuition for both the student's bachelor's and master's degree programs. An average of $85 \%$ of SEI's highschool graduates enrolled in college; and very often, these students were the first members of their families to go to college (Self-Enhancement, Incorporated).

The effectiveness of the program is evaluated annually by SEI staff members using a format created for SEI by the Northwest Regional Educational Laboratory. The format monitors changes in grades, school attendance, and behavioral referrals based on report cards, scores on skill tests, values and attitudes, and student interviews.

In one of my interviews with Carla Penn, the Executive Director of OYC, she described her role as that of a "vision carrier" for the SEI program and told me the following about the SEI program model:

I believe it's an excellent model, and it's a proven model. They've been in business for 30 years. They've got the outcomes that will astound anyone. Their graduation rate out of Portland, Oregon, their high school graduation rate is $98 \%$. In the state of Florida it is $47 \%$. I think that speaks for itself. It speaks volumes. And of that $95 \%$ of kids who graduate, $85 \%$ go off to college. The other $15 \%$ are getting not just fair wage jobs, they are getting very good jobs, jobs that can enable them to support their families - and that's what the program is all about.

In 1999, SEI launched a 3-year federal research study to determine the effects of mentoring on substance abuse prevention among 9 to 15 -year-olds. The study was funded by the Center for Disease Control and Prevention, and the results it yielded showed that the SEI program model was highly effective in reducing youth violence, so 
much so that the U.S. Department of Health and Human Services designated it a national model for youth violence prevention.

In 2004, SEI made a substantial addition to its programming and its campus by establishing the SEI Academy, which is a charter school for grades six to eight. The Academy operates in partnership with the Portland Public Schools, the Oregon Department of Education, and concerned parents, community members, and businesses. As of today, OYC does not have any plans to replicate that aspect of SEI, but if sufficient funding were to become available, it would consider doing so, as it would be an invaluable addition to its programming.

\section{Replicating the SEI Program at OYC}

The Overtown Youth Center is currently being overseen and guided by SEI, which has made a commitment to work with the Center over the course of its long-term evolution. Because the ultimate goal of the program at SEI - and OYC - is to produce positive, contributing citizens, the OYC staff and administration receive regular training in various empowerment strategies from the SEI staff. Weeklong trainings are conducted once every other month from 9:00 a.m.-5:00 p.m. every day, Monday through Friday, either at the SEI site in Portland or at the OYC site in Miami.

The majority of the training focuses on instruction on the relationship model, which is at the heart of the Center's culture. The Center believes that, first, the staff must know how to build meaningful relationships with its students before they can teach them how to have positive interactions with others. Thus, the staff is taught, first and foremost, how to develop trusting relationships with the youth, so that they will know what the right resources to offer them are and know how to encourage them and help them to stay 
encouraged. The staff is also taught strategies to teach them how to build relationships with the students' schools, with the community, and with the parents. That training will then enable them to provide the youth with strategies for building solid relationships with the variety of people in their lives. In the end, the program anticipates that by the time the youth have reached the age of 25 , they will have developed into well-rounded, productive adults.

It should be noted here that, while OYC is replicating the SEI program, SEI's center is much larger and more extensive than the one at OYC. Therefore, it cannot replicate every aspect of the SEI model in its entirety. The very difference in the size of the two programs places OYC, by necessity, on a somewhat different operating system from SEI.

\section{The SEI/OYC Program Model}

The main components of the SEI program that are being replicated at OYC are: the age range of the youth it serves; the relationship model, which again, is the basis of its culture; the year-round nature of the programming; the duties and responsibilities of the coordinators, both within the schools the students attend and at the Center during after school hours, weekends, and summers; its post-high-school program; and its parent involvement program.

\section{Age Range}

One of the key features of the SEI program model that OYC is replicating - and the one that does the most to set it apart from almost every other program in place today is the age range of the youth participating in it. Students enter the program during second grade and continue in it, not only until they have graduated from high school, but rather, 
until they are 25-years-old. It is largely due to this kind of consistency and continuity that the Center expects to be able to get these at-risk youth on the right path - and keep them on it - as it guides them through school and well into the world beyond school. (It should be noted that such long-term involvement has been relatively unheard of until very recently, with the advent of the Harlem Children's Zone in New York City and the Promise Neighborhoods Initiative instituted by President Obama, which is intended to replicate the HCZ in twenty cities across the country.)

\section{The Relationship Model and the Culture of the Overtown Youth Center}

Another of its key features is its culture, which is based on the building of relationships (the relationship model) and on the instilling of positive values around which the youth can organize their lives. The relationship model centers on the belief that the building of strong, trusting, loving relationships with peers and adults is the key to the ultimate success of these youth.

The ethical and behavioral components of the relationship model are contained in a set of six values and standards of conduct, which all of the participants in the Center's programs are required to learn, and more importantly, to live their lives by (see Figure 1). Essentially, these values and standards prescribe a set of behavioral expectations for them, expectations that are founded upon principles of personal integrity and respect for self and others. The standards teach these youth how to behave properly, no matter where they are, so that they can co-exist peacefully with others and lead moral and satisfying future lives. All of the programs at OYC are influenced by and implemented according to those standards. 
Each of the OYC standards has a corresponding meaning and corresponding root value(s). For example, the first standard stresses the need for students to establish positive relationships with others; the second emphasizes having verbal respect for others; the third emphasizes having physical respect for others; standard four focuses on the need for honesty, consistency and a sense of responsibility in the students' lives; standard five stresses that they have an understanding of their cultural identity, which should give them a sense of pride and tolerance for others; and standard six stresses the importance of having self-esteem and a sense of belonging. Each of these standards is very important in establishing a set of values, which if learned properly, will become part of the students' moral compass for the rest of their lives.

Figure 1. The OYC Standards

The OYC Standards are founded upon the principles of integrity and respect.

Integrity ... because integrity exemplifies truthfulness, modesty and trustworthiness.

Respect ... because respect exemplifies courtesy, honor, and reverence.

At OYC we greet each other every day with a smile and a handshake to strengthen the relationship between us.

At OYC we honor and respect each other, and so we address one another with proper language and speech.

At OYC, we value our own space and that of others and are careful not to intrude upon or injure each other.

At OYC we are mindful of what is true and strive to be honest with word and deed.

At OYC we treasure our rich culture and we hold the cultures of all people in high regard. 
At OYC we strive to reflect our beauty both inwardly in our understanding and outwardly in our appearance.

\section{The Overtown Youth Center}

By placing a focus on this relationship model, the Center hopes to establish the same type of culture as that of a close-knit family. While there are, of course, numerous obstacles to achieving such a lofty goal, the staff and administration try to instill in the youth there a sense that the Center is their home, and most significantly, that it is a safe home. They constantly reinforce the idea that the Center is also a place of respect and of love, and that if you love a place and respect it, you treat it and the people in it with respect. Fred Rosario, the Center's high and post-high-school coordinator, often tells the youth he works with that, "We're here because we care about you, and if we care about you, we care what happens to you. We can't build a relationship with you if we don't have a genuine connection. There's just no way."

In discussing the culture of the Center with me, Carla Penn, the Executive Director of OYC, told me the following:

The culture is about family, with high morals, high values, integrity, really connecting and being a part of something that is continual. Relationship building is at the heart of the OYC culture. We understand how important it is to form solid relationships with the youth and their parents, because only then will we be able to gain access to every area of their lives. It is, first and foremost, about building trust. And, it's not that we see you only in second grade. We follow you all the way through to $12^{\text {th }}$ grade. And it doesn't just end at $12^{\text {th }}$ grade. We follow you for several years after that to ensure success. The parents, we are with that parent, ensuring that the parent has the right skill sets necessary to financially support their family; educationally, to insure that they are able to get the jobs necessary to be successful as well. So, I would say that the culture of the Center truly is a culture of success, and that's what we promote: individual success. 
It must be kept in mind that, while Penn's statement is a valid description of the ideal culture the Center is trying to establish and maintain, there are certain issues that arise which make it difficult to achieve. Among them is the fact that there is a great deal of turnover in the OYC staff. Therefore, when a student forms a close, trusting relationship with a staff member, $\mathrm{s} /$ he will be very unhappy if that staff member leaves the Center, which is something that happens fairly frequently. Several of the students have spoken to me about the staff turnover problem and have reported that when the person they feel closest to at the Center leaves, they feel abandoned and have a hard time trusting someone new, especially since some of the staff members care about them more than others do. Other students have reported that if /when the coordinator they have gotten closest to leaves the Center, they will stop going there altogether.

Another issue the Center faces in establishing the culture Penn described has to do with the ability and/or the willingness of the parents to become involved with the Center. As Valerie Lomaz, the Center's parent-coordinator told me, while OYC does offer many educational and vocational opportunities to its parents to help them become more successful, many of them do not - or cannot, because of time and work constraints - take full advantage of the types of training the Center offers them. On the other hand, there are many parents who do get involved, and when they do, it truly does make a difference in their children's growth and overall success.

\section{Recruitment Methodology}

Another aspect of the SEI model that the Center has replicated is a classification formula it uses for each student who comes into the Center, which they refer to as "the 10-60-30." It starts with the completion of a form called a Barriers Checklist, which tells 
the coordinators the number of possible barriers to success that each individual child has (i.e., living in a single parent home, having drug or alcohol abuse in the family, having a family member in jail, and so on) at the time s/he first enters the program (see Figure 2). The number of barriers each child has determines whether s/he falls into the $10 \%$ group, the $60 \%$ group, or the $30 \%$ group.

The 10\% group represents what the Center defines as its "leadership youth." Individuals in this group have 0-2 barriers to their success. In addition, these are young people who have already demonstrated leadership characteristics among their peers and are, thus, regarded as potential future leaders, regardless of whether they were to receive support or not. They are considered to be more self-directed than others in their peer group and they are generally relatively successful academically.

The $60 \%$ group is what the Center defines as its "greatest impact youth." These are individuals who have 3-5 barriers to their success and have demonstrated only average academic abilities. The youth in this group are considered to be on the borderline between success and failure. They are considered to be easily influenced and thus could easily yield to negative peer influences. Thus, without the right resources and support, the lives of the youth in this group could easily take a downward spiral.

Finally, the $30 \%$ group is what the Center refers to as its "intensive intervention youth," or its highest impact child. These are the children who are in need of the most intense intervention: they have multiple barriers ( 5 or more) and need multiple forms of support - psychological, social, and educational. In addition, their performance in school is well below academic standards, and they have demonstrated behavioral problems both inside and outside of school. 
Of course, as Carla Penn told me, we have to recognize that the 10-60-30 is not an absolute - it is just a guideline. While most of the kids $d o$ fall into one of those three categories, at any given point in time, whichever category they were placed in originally could change. For example, she explained:

You may have a kid who you did not think was in the highest risk category, but then a circumstance in his or her life may change; and then, all of a sudden, he or she becomes high risk. Or, there may be a kid who does not appear to have a lot of barriers, who is actually very much at risk, and you did not know that, because he or she has been hiding things.

Sometimes, then, the category a student was placed in initially will change because of something unexpected that happens in his/her family or immediate environment; and sometimes, because the Center can know only as much about the child's background as the child and/or the child's parent wishes to divulge.

Each of the Center's in-school coordinators has a caseload of 30-40 students, each of which is made up of those same percentages. That is, $10 \%$ of each coordinator's caseload is composed of students in the leadership group (the 10\%); 60\% is made up of the greatest impact youth (the 60\%); and 30\%, of the intensive youth (the $30 \%$ ).

\section{Figure 2. Barriers Checklist}

Name:

OYC ID\#

School:

Gender

$\mathrm{M} \mathrm{F}$

School ID\#

Coordinator's Name:

Date:

\begin{tabular}{|c|c|}
\hline & Risk Markers (once they are entered, they are static ) \\
\hline School & $\begin{array}{l}\text { - Special Education } \\
\text { - English language learner }\end{array}$ \\
\hline Family & $\begin{array}{l}\text { - } \text { Eligible for free or reduced lunch (poor or poverty) } \\
\text { - Alcohol or drug-abusing parent } \\
\text { - } \quad \text { Criminal parent }\end{array}$ \\
\hline
\end{tabular}




\begin{tabular}{|c|c|}
\hline & $\begin{array}{l}\text { - Domestic violence (police report) } \\
\text { - Single parent (range of family arrangements) }\end{array}$ \\
\hline $\begin{array}{l}\text { Individual } \\
\text { (non- } \\
\text { school) }\end{array}$ & $\begin{array}{ll}\text { - } & \text { JJIS referral (ever) } \\
\text { - } & \text { Mental health diagnosis } \\
\text { - } & \text { History of physical or emotional abuse } \\
\text { - } & \text { Chronic illness }\end{array}$ \\
\hline \multirow[t]{2}{*}{ Peer } & $\begin{array}{l}\text { - Affiliation with deviant peers } \\
\text { - Rejected, neglected or controversial sociometric status }\end{array}$ \\
\hline & Risk Factors (these items need to be updated quarterly) \\
\hline School & $\begin{array}{l}\text { - Late, missing, or failing school work } \\
\text { - } 3 \text { or more absences per quarter } \\
\text { - } \quad \text { Discipline referral (reason) } \\
\text { - } \quad \text { Suspension (reason) } \\
\text { - Expulsion (reason) } \\
\text { - } \quad \text { Motivated to achieve } \\
\text { - } \quad \text { Positive attitude toward school }\end{array}$ \\
\hline Family & $\begin{array}{l}\text { - Low or no family support } \\
\text { - Death in family } \\
\text { - Seriously ill family member } \\
\text { - Low parental monitoring } \\
\text { - Adult moving in or out of home } \\
\text { - Money problems at home } \\
\text { - } \text { Corporal punishment by parents } \\
\end{array}$ \\
\hline $\begin{array}{l}\text { Individual } \\
\text { (non- } \\
\text { school) }\end{array}$ & $\begin{array}{l}\text { - Recent change in residence status (where they are living) } \\
\text { - DYS contact or arrest } \\
\text { - Pregnant or created pregnancy } \\
\text { - Violent video games or media violence exposure } \\
\text { - Poor social skills }\end{array}$ \\
\hline \multirow[t]{3}{*}{ Peer } & $\begin{array}{l}\text { - Affiliation with deviant peers } \\
\text { - Suspected gang affiliation } \\
\text { - School problem with peers } \\
\text { - School problem with teacher or administrator } \\
\text { - Suspected tobacco, drug or alcohol use } \\
\text { - Peers dropping out } \\
\text { - Can't get into a desired program or activity } \\
\text { - Lack of bonding with school }\end{array}$ \\
\hline & Please Check Risk Level: \\
\hline & $\bigcirc$ Low risk $\bigcirc$ Medium risk $\bigcirc$ High risk \\
\hline
\end{tabular}

Overtown Youth Center 


\section{The Role of the In-School Coordinator}

The key to using the relationship model successfully rests in the coordinator's ability to work within three distinct roles in the lives of the youth there, that of parent, teacher, and mentor. Needless to say, that is a very comprehensive role, and the responsibilities these coordinators have can and often do become quite daunting. It is the coordinators who bear the vast majority of the responsibility for helping to make all of the relationships that the students have - with peers, parents, and others - work at an optimal level and for inspiring the youth in their individual caseloads to accept and honor the OYC culture. It can be said, then, that it is the coordinators who have the most significant influence on the lives of the students, particularly because their work is not over at the end of the day or the week: much like a parent, they are expected to be available to the students in their group at all times, 24 hours a day, seven days a week.

The Center has formed partnerships with the elementary, middle, and high schools in the Overtown neighborhood that the students attend, and each coordinator is assigned a caseload of students who attend one of those designated area schools. At the present time, there are five coordinators assigned to case manage the elementary-schoolaged children (the largest number of students attending the Center); three assigned to the middle-school group; and one who coordinates all of the services and activities for the high and post-high-school students.

On week days, the workday of the coordinators is split between their in-school role and their after-school program activities. Their in-school responsibilities include forming positive relationships with the partner-school's principals, guidance counselors, and teachers; providing daily case management of and advocacy for OYC students within 
their schools and within the community; tracking the students' scholastic achievement, attendance, and behavior; and going into the individual student's classrooms to assist in whatever way they are needed. For instance, a coordinator will go into the students' classrooms and talk to their teachers about any academic or behavioral problems they may be having. Each of the coordinators I interviewed said that, for them, the most important aspect of their in-school role is to simply let the kids know that they are there for them every day, no matter what they need or what their issues may be.

Then, at about 2:00 p.m. every day, the coordinators go to the Center to work on whatever projects or paperwork they need to complete and to prepare for the after-school portion of the day, which begins at approximately 3:30 p.m. The after-school programming at the Center is broken down into several periods. During the first period, students work on homework in a classroom setting with their coordinator and receive tutoring help as needed. During the second 2 periods, students may select from a number of activities, such as music, arts and crafts, drama, dance, basketball, computer program enrichment, and so on. If a student is not performing at benchmark levels in math, reading, or another basic academic skill, it is mandatory that $\mathrm{s} / \mathrm{he}$ attend an enrichment class during the second period.

The coordinators also plan and coordinate myriad outside activities for their group that give the students exposure to the kinds of things most of them would never be able to experience otherwise. Both Mourning and the Center's staff and administration believe that exposure is the most significant way in which to empower youth, and that the more you expose them to new and different places and activities, the more aware they will become of the wide variety of opportunities in life that are available to them. (I will 
discuss the exposure aspect of the OYC program and the kinds of activities offered in depth in Chapter 5.) The basic thinking behind this is that the more resources you can offer these youth, the more life choices they will see that they have.

There are specific outcomes, or goals, that the coordinators are responsible for helping the youth to achieve. However, it is the students, not the coordinators, who are tasked with determining those goals. That is, it is the role of the coordinators to work with each individual student to facilitate his/her goal setting but not to determine the actual goals for them. Part of the rationale behind this process is that it helps to teach youth the importance of setting goals and understand the difference between short-term and long-term goals.

With the help of the coordinators, each student is tasked with preparing an Individual Success Plan, or ISP (see Figure 3), which is reviewed and updated on a quarterly basis. The ISP lists three categories of goals: personal, academic, and social. Each student must set one goal for each category every quarter. The students themselves are responsible not only for determining their own goals but also for designing two concrete strategies that will help them to reach each of those categories of goals successfully.

Once a month, the coordinator meets with the students individually to check, discuss, and document their progress toward meeting the goals they set as well as to strengthen the one-on-one relationship between them. At the end of each quarter, the coordinator will meet with them again and ask them if they have met any or all of their goals. If they have reached the goals they set, they will then be asked to set new goals. If they have not, they will be asked to think about and then explain why they were not 
successful, after which they will be tasked with designing a different strategy to attain that goal in the next quarter. It is believed that involving the students in each step of the ISP development will provide the students with valuable problem-solving skills.

\section{The Post-High-School Program}

In order to help the students make the transition from high school to college or to the next step in their life plan, the post-high coordinator explores colleges and career placement opportunities with the group. When I interviewed Fred Rosario, the high and post-high-school coordinator, he told me that he usually knows whether the individual students in his group will be going to college, to technical school, into the Job Corps, into the Armed Forces, or elsewhere, by the time they are in the $11^{\text {th }}$ grade. At that time, then, he helps get them ready to go in whichever direction is right for them.

Figure 3. Individual Success Plan (ISP)

\begin{tabular}{|c|c|c|c|}
\hline Name: & & Stude & \\
\hline Address: & & ZIP: & \\
\hline Telephone: & Grade: & Age: & Date: \\
\hline
\end{tabular}

Spring FCAT Scores for Previous Year

Math Score: FCAT Reading Score: FCAT

$1 \& 2$ Quarter:

Personal (Home, Relationships with opposite sex, Personal Goals, Athletics)

Goal:

Strategy: 1)

Strategy: 2)

Actual Results/ Points: YES NO \#:

Goal: 
Strategy: 1)

Strategy: 2)

\section{Academic}

Goal:

Strategy: 1)

Strategy: 2)

Actual Results/ Points: YES NO \#:

Goal:

Strategy: 1)

Strategy: (2)

Social (Interactions with peers, being involved in socially appropriate activities, relationships with teachers, citizenship)

Goal:

Strategy: 1)

Strategy: 2)

Actual Results/ Points: YES NO \#:

Goal:

Strategy: 1)

Strategy: 2)

In the early phase of their transition from high school, the students will usually get their first full or part-time job, either at the Center or with an organization that has a partnership with the Center. If the student works for a partner organization, the organization will contact Fred, the post-high coordinator, on a monthly basis regarding 
the student's performance and/or he will check up on the student by contacting his or her supervisor. If the students have gotten jobs on their own, Fred will let their employer know that they are from the Overtown Youth Center, give them his business card, and let them know that he will always be available if they need to speak with him.

If he has students going away to school, Fred will help them prepare and get everything they will need ready before they leave. For example, he will help them get their school supplies together; check their airplane tickets, identification, and so on; and ensure that their financial aid applications, housing, and inoculation records are all in order. Once the students arrive at their respective schools, his main concern will be to ensure that their financial aid is in place, that they have registered for all the classes they are supposed to take, that their tuition payments are made to the school on time, that they are getting their scholarship money promptly, and that they are settled-in satisfactorily.

After the students have completed their first semester, there could still be any number of concerns that have to be addressed, so Fred, in his role as post-high coordinator, will continue to check on them regularly. As Fred told me:

A lot of the kids are not really prepared. They're no different from any other kid that goes to college. It's obviously very different from high school, and they have to get used to that. Nothing is really going to prepare them for that until they're in it. You know what I mean? It can be a smooth transition, but they can also get overwhelmed with all the social aspects of college, and before you know it, within one semester, they're failing. ... They never understood that they can kind of gauge how they're doing in a class, for example.

Many of the scholarships the students receive come directly from the Center, so there are also decision-making and other responsibilities that are part of the post-high coordinator's duties. For example, Fred explained that the amount of scholarship money each student receives from the Center is based on his/her attendance at the Center and on 
when s/he started in the Center's program. In order for the students to keep their scholarship money, they must register for classes and begin school in the fall of the year they graduated from high school. The Center understands that every student has a different financial and family situation, so it allows each one to decide whether s/he will attend school on a part-time or a full-time basis.

Students who fail a class or classes in their first semester will be placed on academic probation, but they will not lose their scholarship money. However, if a student fails consistently or drops a course without notifying the Center, s/he will be considered to have nullified his or her scholarship. When that happens, Fred told me, decisions on the action to be taken will be made on an individual, case-by-case basis. For example, if a student is proactive, which is determined by his/her attendance and participation at the Center, the Center may decide to continue helping the student financially, with the expectation that s/he will make the necessary improvements.

To explain the type of follow-up he engages in, Fred told me a story about a student who had been put on academic probation, and whose school did not process the scholarship money the Center sent it on her behalf. Rather than process the funds, the school contacted OYC to make sure that the Center knew that the student was on probation and that it still wanted the scholarship money to be processed. He then told me:

So, you know, the schools have their policies. But at the end of the day, the child needs to be successful, so even though she's on probation, her tuition still needed to be paid for. I'm not going to prevent her from having a chance. On the other hand, if a kid does not stay in school or his/her grades are consistently low, then I can stop sending them money. But in her case, there was a situation: her grandmother had passed away, and she was dealing with a lot of issues. It was her second semester; so she fell through the cracks. So, we built her back up, and 
now she's doing fine. I'm not going to prohibit the student financially when I know that she needs to go.

In saying that, Fred made it very clear to me that his decisions are made in a very thoughtful manner, primarily because the most important thing for him is to be understanding and to do everything he can to help the student to be successful.

For those students attending school in the local Miami area, Fred is also available when they need him. For example, if one of them calls him and tells him s/he needs assistance, Fred will go to the school to see what he can do to help. In lieu of that, any students who have graduated from OYC are always welcome to go to the Center at any time for any reason; for example, if they need school supplies, if they are missing a USB drive, if they need to talk or get advice. Fred will do whatever he can to see that they have their needs met.

After high school, some of the students at the Center who are either not qualified or not interested in attending college participate in a Job Corps program located in Homestead, Florida, with which OYC has a partnership. The Job Corps is a federal program of the United States Department of Labor. Essentially an alternative high school, it offers students the opportunity to earn a GED or a high-school diploma and a certificate of completion in a specific trade. The program may also serve some students as an alternative pathway to getting into college.

The Job Corps is a fully residential program for which the Department of Labor pays $\$ 25,000$ per student, which is obviously a huge commitment on the part of the federal government. At the end of the program, each student is awarded $\$ 1,500$ and is sent out into the world having learned the kinds of skills s/he will need to get a good job 
and become a productive citizen. Depending mostly on what a student's academic standing is, the program will usually take a year to a year and a half to complete.

The trades the students are taught usually involve manual labor of some kind, but there are also a limited number of health care positions they can train for. When they first enter the program, the students are tested to determine what kind of trade they are best suited for and most interested in. Based on the testing, they will choose three trades which will then be placed in a rotation: that is, they will spend one week learning each trade, after which they will determine the one they will focus on. After that, and for the remainder of the program, they will spend a week on academics followed by a week of training for the trade.

Largely because the Center wanted to enable the kids to experience living in an environment completely different from that of the Overtown neighborhood, where many did not have a stable home environment, the Center chose to participate in the program in Homestead rather than one of its locations closer to Overtown. The Homestead Job Corps program is very structured and has very specific rules and regulations for all its participants. It has zero tolerance for anyone who breaks the rules. Although it is a bit more relaxed than the military, it does have somewhat of a military undertone. All of the students must wear uniforms; they must share a dorm room with three other kids; they must keep their rooms clean; and they are allowed passes to go off campus but are given strict curfews. According to Fred, it is a good program, especially for those students who do not want to follow a traditional path or who never had much structure in their lives. It helps them to refocus and enables them to complete their commitments to the program successfully. 
Fred currently has four students in the Job Corps, all but one of whom is on the high-school-diploma track. (The difference between this track and the GED track is that the former requires the students to pass the FCAT, while the GED track does not.) Fred goes to Homestead monthly to monitor his students' progress and make sure they are doing well and have everything they need.

Overall, the post-high portion of the OYC program, which is another of the most unique aspects of the Overtown Youth Center's programmatic components, involves a great deal of mentoring, particularly during the students' first two years after graduating from high school. Once they have passed that mark, Fred told me, he does a lot less for them, “not because I don't want to, but because if they’ve been working for two years and staying consistent and doing well - I know that things are good by only doing a monthly check-in." Finally, if the students' locations are too distant to visit regularly, he relies on texting, Face book, and e-mail to keep in touch with them.

\section{The Parent Involvement Program}

The significance of the role played by the parents in the overall picture of empowering their children cannot be understated. Therefore, another extremely important aspect of the Center's empowerment initiative is its parent involvement program.

The parent program focuses on empowering the parents in both their roles within the home and within the schools. Its goal is to help them to be positive role models for their children and foment a degree of stability within the household. As Valerie Lomax, the parent coordinator, explained to me, 
There are a lot of different things we do to try to help the family, because we consider OYC as a family, as a whole, so we try to put the tools in the parent's hands that they need to be able to be successful in their lives and in the lives of their children.

The parent program also has a parent's support group to assist with difficult problems parents may be facing, regardless of their nature or their source.

Once a month, the Center holds a meeting for the parents during which they will have an opportunity to discuss a wide variety of pertinent issues. For some of those meetings the Center will bring in outside experts to conduct trainings and workshops on such subjects as effective parenting, effective communication skills, health and nutrition, home safety, quick meal preparation, first time home-buying programs, financial literacy, credit repair, and more. The Center will also help the parents with such things as improving their computer skills and resume building. For those parents who do not have a high school diploma (which many of them do not), the parent coordinator can help them enroll in GED classes. For those parents who have graduated from high school and are interested in attending college, she can help them with things like applying for financial aid.

In order to get the parents more involved with the educational aspect of their children's lives, the Center encourages them to become advocates for them at the children's school sites. It encourages them to attend PTA meetings and teacher conferences and to just get involved with the schools in any way they can.

Lomax explained to me that while the Center is very concerned about getting the parents involved, its primary focus is on helping the children to succeed. While the children do need the parents to be there to support them, many of their parents are simply 
unable to be there for them, due to drug or alcohol abuse or other problems they may

have. In that case, she told me,

The Center just tries to empower the kids, help them to stay focused, and let them know that we're here for them, even if their parent isn't. We can be mom, or we can be dad. That's why we build relationships with the kids, just in case they don't have a relationship in the house. They can always reach out to us. That's why we do the hugs and the love touches and things like that. You know what I'm saying? That is all just to let them know that we're here for them, so they feel good when they come to the Center and they know they have support.

It is really true that something as small and seemingly insignificant as a hug or a kind word can - and often does - make a big difference to these youth. I, myself, have witnessed its power on more than one occasion.

\section{Summary}

In this chapter, I have provided the reader with detailed information about the history and founding of the Overtown Youth Center and the program model it is replicating. I then discussed the relationship model, which is at the heart of the Center's culture. In examining that culture I found that while, idealistically, it is extremely effective, in practice, implementing it successfully does have certain problems. I will discuss that issue further in my final chapter, but for now, suffice it to say that the degree to which the culture is adopted by the students as well as their parents is dependent in part on the degree of staff turnover, and even more significantly, on the dedication of the individual coordinators and the Center's administrators.

Taking that thought to the next step, in describing the role and responsibilities of the Center's coordinators, I noted the tremendous responsibility that playing the role of parent, teacher, and mentor for every child in his or her caseload is. Responsibility of that magnitude is not easy to take on. It requires a very special kind of person, the kind 
who truly cares, which is certainly not easy to find. People can be trained to do any number of things, but they cannot be taught to care. In the course of my observations at the Center, I found that there are some staff members who do not care about the students at all, who are there solely for a paycheck. Since the culture at OYC is based on the relationship model, on building respect and trust, when those ideals are not embraced by everyone, problems definitely arise.

Next, I discussed the basis upon which the students are placed into one of three categories based on the number of barriers to success each one has, which the Center designates as the "10-60-30." I find that to be a viable system, particularly because it allows for some flexibility. That is, the Center allows for the possibility that a student's status can change, either positively or negatively, depending on his or her individual circumstances at any given time.

Finally, I spoke about the comprehensiveness of the program and about those elements that contribute to making OYC unique. They include the age range of the participants; the continuity of its programming (i.e., in-school, after-school, weekends, and summers); the range of exposure opportunities it provides; its post-high-school follow-up program; and its parent-involvement program.

As I will discuss in my concluding chapter, OYC provides its students with all the tools they will need to succeed in life. However, it is ultimately up to the students as individuals to appreciate the opportunities they are given and take full advantage of them, and it is up to the Center as a whole to ensure that its staff has what it takes to move the students in the right direction. 


\section{CHAPTER V}

\section{FINDINGS}

Analysis of the data I gathered from my interviews and observations at the Overtown Youth Center uncovered four features of the Center that the youth (as well as the staff) identified as particularly valuable to their growth, and as qualities the students perceived of as being most important to them: supportive relationships with adults and peers; physical and psychological safety; exposure to cultural and educational opportunities, and building of self-esteem. A fifth theme, which I consider to be one that underlies all the others, is that of race. Race is a significant indicator of the students' attitudes toward themselves and others as well as of their levels of self-esteem and selfefficacy. The results I present highlight the meaning and significance that the young people themselves ascribed to each of those features and the qualities of the Center that invited their sustained participation in its programming.

Before proceeding, it is important to remind the reader that, in keeping with the methodology of Critical Race Theory (CRT) - and building on research that has established structured after-school programs as significant contexts for youth development - the main focus of my research is on highlighting and exploring the meaning and significance ascribed to each of those features by the youth themselves. Both their individual life experiences and the ways in which they each experience OYC's developmental supports and benefits are, for this researcher, one of the most significant means of determining how much, and in what ways, the Center has succeeded in helping them make positive changes in their lives. In addition, it is the basic assumption of this methodological approach that this type of research enables the voices of young people to 
not only be heard but also to inform policy discussions and future research on the quality and value of programs of this sort.

\section{Growing up in Overtown}

When it comes to their home life and the overall environment in which they have grown up, all of the young people I interviewed share many things in common, whether growing up in a broken home; having a parent in jail; being exposed to drugs, violence, and crime; or all of those. Before delving into the specifics of each of the themes I identified, I would like to first introduce to the reader the three students who became my primary informants and share some of what they told me about their lives growing up. While those three became the main sources for my findings about the youth at the Center, they were certainly not the only ones. Throughout the chapter I have also included the thoughts and experiences of several of the other students I interviewed, observed, and/or engaged in informal conversations with. As with my main informants, whenever I present a quote from or tell a story about one of those others, I identify each of them by name.

\section{Reginald}

Reginald is probably the most impressive young person I have met since starting my work with OYC. He graduated from the Center in June 2010 and is now going into his sophomore year at the University of Florida, where he is an accounting major and is on the Dean's list. Fred, the high-school coordinator, jokingly told me that he sometimes calls him "the President," because he said, "there is nothing that kid cannot do when he puts his mind to it. He is an extremely special young man." From what I have seen, that 
statement is absolutely true. This is what Reginald told me about his home life growing

up:

I have one little brother and one little sister. My sister is seven, and my brother is four, and we all live with my mom. For several years, we lived with her and my stepfather, but they got divorced about three years ago, so we are now totally dependent on my mom ... My biological father was in jail when I was born all the way up until I was about 16-years-old. That's when he got out. I didn't actually see him until I was about 13 - at the visiting place in the jail. But when I was 16, I was already accustomed to my stepfather, and I called my stepfather "dad" and everything, so I just didn't want to ... I thought it would bring more problems ... I'm not saying I didn't want to give him a chance, but ... When he got out of jail, some of the things he was doing still weren't right ... So I felt like, just because you're my biological father - because I didn't really consider him my father, he wasn't there for 16 years. So, I wasn't really planning on dealing with him at all, because, still, that could put my life in danger, because of the things he was doing. So, I just chose to leave that situation alone, and to this day, we don't even have contact.

From that description, one can see that Reginald is, in some ways, typical of the other kids at the Center: he grew up in the same kind of environment as them; he is poor; he is Black; he and his siblings were raised most of their lives by a single mother; and his biological father spent substantial time in jail, and it seems like he continued to pursue some kind of criminal activities once he was released from jail.

In many other ways, however, he is not typical at all. He has a very strong mother (Sabrina Jackson, one of my OYC staff informants) who raised him to have high morals, a love for education, a strong drive to set and accomplish goals, and an understanding of the fact that he has to work even harder than most, because, as she put it, "from the getgo, he already has two strikes against him - he is poor and he is Black." He also definitely fits into OYC's 10\% category, which again, sets him apart from the majority of the other youth, as he has strong leadership qualities and he probably would have succeeded in life even without the assistance of the Center. While he has a good 
understanding of the limitations of his environment and his socioeconomic status, rather than allowing them to hold him back, he utilizes them to make his strong drive to succeed even stronger.

\section{Jonathan}

Jonathan also graduated from the Center in June 2010. His dream has always been to become a professional basketball player, although he seems to realize it may not come to be. Since graduation, he has been in the Job Corps program in Homestead. In addition to completing the work toward getting his high-school diploma there, he is preparing for a career in Sports Management. The following is some of what he told me about his home life growing up:

I was born in Miami and have lived my entire life in Overtown. For most of my life, I've lived with my grandmother, who's raised me and my younger sister she's 16 and I'm 18. My father, he was a dope dealer, and he split when I was about three. I grew up around guns, to tell you the truth. My folks are still married, but they're split. She [his mother] has a boyfriend, but her boyfriend recently died; and my dad, he has a girlfriend, and he lives in Opa Locka. I talk to my ma, but I don't talk to her often. She calls every once in a while just to make sure I'm alright. My dad only comes by to see me every once in a while.

Jonathan has obviously had a very unstable home life: neither one of his parents seems to have taken an interest in his upbringing, his grandmother being his only stable influence.

As the following will show, he has a very strong love for his grandmother who, as the reader will see, has lived a difficult and violent life herself.

If I had to give my life for anything, I would give my life for my grandmother, so she could start all over again. It's like, if she died, I'd be so heart- broken that I wouldn't be able to do anything. If it weren't for her, I wouldn't even be in school. She was there when I got my bumps and bruises and to kiss them and make them better. She was there to beat me when I messed up. My grandmother is a warrior at heart. Her life story is way harder than mine. She left home when she was 16. She got married when she was 16 . Now she's 76 . She's been a maid 
for I think 50 years or so. My grandfather used to be with her; but she shot him, and he died.

Jonathan told me about his grandmother's having shot her husband in such a nonchalant, completely matter-of-fact manner that I did not know what to say. I was simply shocked that he could talk about something so violent without displaying even a hint of emotion. Then he finished his story by telling me, "She's been married three times, I think. The first one she shot, and he died. The second one had a nervous breakdown, and his girlfriend is taking care of him now. And the other one, I don't know anything about."

Jonathan is definitely more typical of his peers at the Center than Reginald. He, too, is Black and poor, and while the influence of his grandmother is similar in some ways to that of Reginald's mother, his grandmother is definitely not as stable. Unlike Reginald, he does not have a strong drive or any clear cut, realistic life goals. He is much more of a dreamer and often tends to get lost in his daydreams about what he wants to be when he grows up rather than working diligently toward making them a reality. He is a big talker and is actually much more of a talker than a doer. He is, however, a very good, caring, bright young man, and according to Fred as well as my own observations, he has made a lot of positive changes in his attitude and behavior in the course of the years that he has been attending the center.

\section{Deborah}

Deborah just graduated from the Center in June 2011. She will be going to Bethune-Cookman University in the fall and will be majoring in Pre-Law. This young woman is another astounding person, especially considering the tremendous adversity that she faced when she was a young child. She was born with a serious birth defect, 
which placed her in a wheelchair for many years. Although the doctors told her and her family that she would probably never walk, she refused to give up, and today, she is, indeed, walking, dancing, and more. Her intelligence and drive are matched only by her resilience. In regard to her home life, she told me,

I knew my mother, and I stayed with her at first, because she used to stay across the street from us in an apartment building. And then she moved with my brother's side of the family. So my grandmamma didn't want me staying over there, so she had me staying with her. Then my mother died when I was five. The last time I saw my daddy was when I was nine. He was living up in Kansas before he got back on drugs. But I see his dad, but we don't speak. I might see him in a store, because he works right here as a wrestling trainer, but we don't communicate. I get mad. Every time I see him I get mad.

Like Jonathan, Deborah, too, was raised by her grandmother, with whom she has lived since she was one-year-old; and like Reginald, although her biological father is alive, he is a drug addict, and she has not had any relationship at all with him her entire life.

The material above should provide an idea of what these children have had to deal with in their formative years, and that is precisely why the Center places so much emphasis on building relationships with them - just in case they do not have a relationship in the home, which the majority of them do not have. There is always someone at the Center who the kids can reach out to for reassurance, to talk with about a personal or family problem, or to simply get some badly needed affection from. As Valerie Lomax, the parent coordinator, so aptly put it: "That's why we do the hugs and the love touches and things like that. That is all just to let them know that we're here for them. They know they have support, and that draws them to the Center." 


\section{Relationships with Adults and Peers}

At the moment that adolescents, in particular, need supportive relationships, opportunities for autonomy and choice, and a sense of competence in their dealings with the world, the secondary schools, especially those in inner-city areas like Overtown, offer them precisely the opposite. The research has shown that academic efficacy and achievement suffer when students lack supportive relationships with teachers and other adults, and urban schools are severely lacking in opportunities for any meaningful connections of that nature to be formed.

\section{Relationships with Adults}

Research has documented the critical role of a non-familial, caring adult mentor in the lives of low-income youth. As discussed in Chapter 4, relationships and relationship-building are at the heart of the culture OYC is attempting to create; and thus, the main focus of all its programming is on providing its students with the kinds of loving, supportive relationships and role models they need to develop into successful adults. In addition, supportive relationships with adults - and with peers - contribute to their having a sense of safety, which in turn, cultivates a caring, motivating space in which they can express emotions, try on identities, and learn new skills.

Alonzo Mourning expressed his philosophy in regard to the need for positive role models, particularly in inner-city Black communities like Overtown, in the following way:

I think for all children, especially for Black children, it is so important to find the proper role model to help you make the right decisions and be a productive citizen. We lack role models and mentors in so many of our communities, and as a result we let so much great talent just fall by the wayside. If you can mentor a young man to a productive life, then society no longer has to carry him along. 
As Mourning indicated, without a proper role model to help these youth grow into productive citizens, most of them would likely become a drain on society, which to say the least, is a terrible waste of a potentially fruitful life.

In my literature review (Chapter 2), I devoted some attention to the conceptual notion of "othermothering" discussed by Douglas Guiffrida (2005). The research study he wrote discusses the kinds of relationships Black students have with teachers and other adults that tend to have the strongest positive influence on them. To refresh the reader's memory, "othermothering," which Guiffrida states is a long-held tradition of education within the Black community, is a form of mentoring; but it is one that goes far beyond the traditional meaning of the term, in that it is far more comprehensive. That is, along with a traditional mentoring program of career, academic, and personal advising, othermothering brings in a number of other factors that are integral to students' definitions of faculty who are "student-centered." Among those factors are (a) being willing to support and advocate for the students, (b) providing extra tutoring for them and helping them locate money to stay in school, (c) believing in and having high expectations of students, (d) raising the bar for achievement and pushing them to succeed, and (e) holding students accountable.

Although OYC is not set up as a conventional mentoring program, many features of the relationships that the youth described to me at the Center were of that nature. For example, many of the students told me that Fred Rosario, the high-school coordinator, was always available to listen to and help them with their personal problems, and that he helped them stay on track in their academics and motivated them to participate in the activities offered at the Center. 
The kind of relationships that Fred has established with his group provides a quintessential example of the tremendous impact that a caring adult who gives them affection, guidance and support, who holds them accountable for their actions, and who is also a positive role model for them, has on them. They all place a high value on the openness, trust, and affection they share with him as well as on the generally informal nature of their interactions with him. Those things combine to make their relationship with him very different from those with the teachers in their schools - or, for that matter, with some of the other adults at the Center. In addition, almost every one of them has told me that s/he considers Fred to be a father figure as well as a mentor and confidant. However, while Fred is, in every way, the best possible example of a staff person who really cares, he is not a typical staff member. That is, there are very few at the Center who I would characterize as fitting into the othermothering model put forth by Guiffrida. Unfortunately, people like Fred are few and far between.

When I was talking to Fred one day, he told me a story about Lorenzo, one of the boys in his group (which I will relay later on in this chapter). This boy used to be very cold and unreachable and had many behavioral problems both in and outside of school; but remarkably, after attending the Center regularly for several years, he has made a complete turnaround. This is what Fred told me about how Lorenzo had changed:

It's weird, because he's become very receptive. He wasn't before. He told me that after all that happened, his mother told him that she loved him, and he said to me, "You know Fred, I haven't had my mother tell me that since I was little." It's crazy. So, there's times he'll just tell me, "Fred, I love you." And I tell him, "I love you, too." I can't deny him that. I look at him and I think, that's part of the problem, because a lot of us don't do that. But the kid is looking for that [love and show of affection]. 
In talking about Alonzo Mourning and the way he is with the kids, Sabrina Jackson told

me,

He's got a really big heart. He shares a lot of his time with kids that really need it. He doesn't mind hugging a kid and asking them how their day went or helping a kid who isn't dressed up to par, you know. And he's trying to spread the love ... A lot of the time, when he comes here, he'll sit down with them and talk to them or he'll hug them. And a lot of these kids don't get any kind of affection at home, and they really need that hug. And he'll say to them, "I love you, keep on doing your best ..." And when you see that kid and how happy it makes them ... I really respect him and his wife to the utmost. It's a beautiful thing to see someone like that giving so much back.

I have also witnessed the way Mourning is around the kids on many occasions and have marveled at and been very touched by the way he interacts with them, really listens to what they have to say, and sincerely tries to help them in any way he can.

In discussing the nature of the relationship she has with some of the staff at the Center - and with Fred, in particular - Deborah told me the following:

There's people here I have a strong bond with, who I feel I can go to whenever I need something or I really just need to talk, and they will be there for me. No matter what they're doing, they're there. The ones I feel a bond with, I know they really care. The ones I do talk to, they have given me a reason to trust them, and I know that I could always go to them whenever I need something. I know that I can talk to them about anything, no matter what it is. I know that they will always accept me for me, no matter what decision I make about anything.

In that statement, Deborah touched on the very essence of what the relationship model is all about, the establishing of a trust that enables true communication, sharing, and personal growth. Moreover, she continued that line of thought by describing the way in which people at the Center have helped her deal with a problem she might be having by saying,

If they think I'm wrong about something, they won't just say that I'm wrong, they'll tell me why I'm wrong. They'll give me the negative as well as the positive. First, they'll ask me what happened, or what did I do, or what I want to 
talk to them about. And if I don't have an answer, they'll ask me, "What do you think is the solution to what you're going through?" And, if I can't tell them, they'll make me try to find some reason, and then they'll tell me if I'm right or wrong. Because they have more knowledge than I do, all I have to do is listen and try to use what they're telling me to try to get the situation resolved.

What Deborah was saying there is that not only do the people at the Center she trusts listen to her but they also try to help her resolve an issue or problem by helping her to use her own reasoning power. And finally, she is aware enough to understand that while everybody cannot trust the same person, "everyone has someone they can trust here, and we can all tell when people really care and when they don't." That statement underscores the reason why it is so important to have staff members who genuinely care, because the students there always recognize those who are sincere and those who are only faking it.

During an interview with DeAndre, I asked him if he thought that everybody working at OYC has a caring attitude, and he told me the following:

The last teacher who didn't care is not here anymore, so it's kind of, the people have to care. The kids here have all gone through a lot, and they don't respect just anybody. Fred ... we all have a lot of respect for Fred and Miss Stephanie [a Broward County school teacher who works at the Center with Fred and the highschool group on weekday afternoons.] They are like our second parents, our parents away from home. Fred is the best. I think of him like a father.

It is amazing how almost every one of the students I spoke with looks at Fred in the same way, that is, like a father. They are all aware of the fact that Fred (as well two or three of the other adult staff at the Center) provides them with mentorship in multiple areas of their lives. They know that they can look to him for advice in making critical decisions about their future, in working through any day to day issues that might arise, for emotional support, and so on. 
Reginald told me the following about his history with the Center:

I first heard about the Center the summer before I entered the sixth grade, and my mom started working here. She called me up and ... I guess in the summer, they section everything off in groups. At that time, I was interested in being in a band, and they had a drum program, so I wanted to go. So she signed me up, and that was my first time hearing about the Center. And I've been coming to the Center ever since. Then, all through Middle School, I was really into it. In ninth grade, I kind of strayed off a little, but I was still coming here, checking in from time to time. But when I started in tenth grade, because there was a lot of change in the staff, I wasn't really comfortable with everyone, so I hardly came at all. But at the end of tenth grade, Fred came to work here, and that's when I started coming more often. When I met him, that's when I started coming back all the time.

Many of the other students I spoke with told me the same thing as Reginald, that is, that they either began attending the Center or returned to it because of Fred, which is further proof of how important it is to have the right people working with these youth.

During one of my interviews with Fred, he told me a story about an incident that took place between Lorenzo and him. To me, the story is an excellent example of the depth of the relationships encouraged by the Center, which again, Fred, especially, has formed with almost every one of the youth in his group. Before recounting the story, however, I feel it is important to first share my own perceptions and experiences with Lorenzo, as he is someone I have known - and watched grow - over the course of the last $4 \frac{1}{2}$ years, ever since I first started working with the Center.

When I first encountered Lorenzo, the one word I used to describe him and his attitude (in my thoughts only) was "dark." When he came into a room, I could almost feel a dark cloud enter the room with him. He almost always wore a hooded sweatshirt with the hood up (covering his head and most of his face, in spite of how hot it was); he never looked me - or anyone else - in the eye; he rarely if ever smiled; he never greeted 
me with so much as a "hello;" and he was generally sullen, unfriendly, and disrespectful with everyone. He rarely said a word, but when he did, it was almost always a sarcastic comment directed at one of the other students or at Fred. It never seemed as if he wanted to be with us, to learn anything, or to be a part of the group, no matter what it was we were doing. While his negative attitude and poor behavior continued for at least the first 2 years that I knew him, he would still, inexplicably, be present at every meeting we had and every activity we did together.

Then, seemingly all of a sudden, about a year or so ago, he appeared to have gone through a total metamorphosis, which to this day, has completely amazed me. Now, whenever he comes to FIU for SAT tutoring (a program I will discuss later in this chapter), he not only greets me but he gives me a hug when he comes into the classroom. He is cordial to everyone, volunteers to read aloud, shares his opinions openly, talks about his success in school, about where he is going to college, how he did on the SAT exams he has taken, and so on. In sum, he has become, in my mind, the very embodiment of what the warmth, understanding, and one-on-one attention the Center provides can do to completely transform the life of a youth who most people would have considered to be a lost cause.

So, one day a few months ago, I spoke to Fred about how much Lorenzo had changed in the last few years, and I asked him about it. Before going into the story he told me, he said, "Everything makes sense about why he is what he is, because he's come from such chaos." He then told me that one day, a couple of weeks before our interview, Lorenzo did not go to school, because he found out that his stepfather had murdered his mother's boyfriend, and as soon as he heard about it, he called Fred to tell him. At first, 
Fred was dumbfounded and did not know what to say, but he could tell that Lorenzo was hanging onto every word he said. The first thing Fred could think of to say to him was, "I don't want you to think that that's how you handle things, because it's not. You can't make someone want to be with you. If they don't want to be with you, they're not going to be with you. But that doesn't take away who he was for you."

At that point, I asked Fred if Lorenzo had a close relationship with his step-father, and he said:

Yes. He is the only father he's ever known. He doesn't speak to his biological father. All of his siblings - there's four of them - they all come from different fathers, and their mother is only a year older than me. [Fred is about 33-years-old, and Lorenzo is 18.] And, he's the oldest, so now all of a sudden he has to be treated like the man of the family.

Fred went on to tell me that a few days after he found out about the murder, Lorenzo went to the courthouse, and the people he spoke with there made it pretty clear to him that the prosecution was going to ask for life in prison for his father. When he heard that, Lorenzo got hysterical, and the first thing he thought of to do was to go to the Center to look for Fred.

It was pretty late in the day when Lorenzo arrived at the Center, and there was no one else around but Fred, who seeing how distraught he was, took him into his office, sat down with him, and asked him what was wrong. Lorenzo told him, “They're going to give him life. It's bad." On hearing that, at first, Fred was taken aback and did not know what to say. After a few moments of thought, however, Fred decided that he would share some things with Lorenzo about his own life experiences growing up, things he had never shared with any of the other kids. Fred then explained to me that, "I told him those things because I wanted him to know that everything that's happening to him right now is what 
is going to make him stronger and make him the man that he has to be." He also said that he wanted Lorenzo to know that when you see a person today, you cannot always know what kind of circumstances that person has come from, what led up to what that person is today. Fred ended this story by telling me,

Jayne, we were like two little crybabies. He has already told me that I'm his godfather - he didn't even ask me, he just told me. But that doesn't mean that I'm going to be easy on him, because there's a lot of things that I see, like he's lazy, and it infuriates me. But I have to always remember that as much as I want to do things to fix it, I can't always fix it for him. He has to do a lot of it on his own. I can be there to guide him, but I can't make him do things. So sometimes he makes mistakes, and it wouldn't be me if I didn't point out his mistakes to him. I feel like that's what I have to do, that's the least I can do. He looks for that from me, and I'm not going to deny him that.

Fred's perspective on and understanding about what he, as a mentor and father-figure, needs to do in a situation like that is an excellent example of what someone who truly cares can do in a traumatic situation to help a young person like Lorenzo mature and grow into, in Fred's words, "the man he has to be." Finally, Fred ended our conversation by saying,

He's a great kid, super smart and he has natural leadership qualities. He does have some deficiencies, and I understand that, but he wants to do the best he can to help his family. And I will do whatever I can to help him. I just need him to feel successful, so that even though there is chaos in his everyday life, he will have some normalcy.

The final installment in this particular chapter in Lorenzo's life is that he graduated from high school in June 2011, was accepted at Bethune-Cookman University (an HCBU in Daytona Beach, Florida), and will be attending school there in the fall. Then, in spite of all the obstacles he has faced on the road to success, he will begin to prepare himself for the rest of what will hopefully be a very productive life. 
Again, this story illustrates several very significant things about the Center. First, it shows the depth of the relationships that are built between some of the Center's adults and its youth, and the degree of caring - which is absolutely palpable - that goes into those relationships. Second, to use Fred's words, it shows that, "obviously, what we do here is making a difference." And finally, and perhaps even more importantly, it shows that there is something worth saving in every single young person who is willing to make the effort to change.

In building successful relationships with the students at OYC, there is one other aspect that necessitates discussion, which is the element of consistency. Consistency is one of the most significant factors in building trust between adults and youth, especially when dealing with youth who have become accustomed to having those adults who are closest to them coming in and out of their lives. Fred put it very well when he explained,

If I think about some of my kids, if I look at their backgrounds, and I see that mom and dad are in and out of the life, if I'm somebody that doesn't have consistency in my life, and I don't expect you to last here, my guard is up. If I see that you're sticking around two or three years later, I may not like what you've got to say sometimes, but I respect it. I know you well enough to know that you're coming up with something because you care. And I think that's where I'm at three years in. A lot of my kids know that I'm not doing this for anything; I'm doing this because I care. If I didn't care, I wouldn't say anything. So ... that's the difference.

Essentially, what Fred is saying is that, when you are dealing with youth who have had little or no consistency in regard to the significant others in their lives, it is difficult and sometimes close to impossible for them to be able to trust. However, if they see that someone truly cares and is a consistent presence, most of them will ultimately come around and begin to trust; and that is one of the things the Center hopes its relationship model will accomplish. Moreover, Fred went on to say, 
The relationship is everything. I don't know about the other kids, but I do know that high-school kids would not be coming here if they didn't have a relationship with me and with each other. In high school, no one can make you come to a program. There's got to be something solid that gets you to come here... And, I honestly believe that commitment and the consistency of having the same coordinator every year, the same expectations every year, and saying, you know what, I expect this because I've seen what you can do and not wavering from that ... I think consistency is the key for the relationship to stay genuine, and to be honest all the time. Because, if you're not honest, you're not truthful, you don't give respect, what do you have? And that's true in every relationship, really.

In that statement, Fred was speaking not only about the importance of honesty and respect in establishing the kinds of trusting relationships that will produce positive results, but he was also alluding to two related issues that I brought up earlier: the degree of commitment and caring on the part of the staff and the consistency of the staff, or the amount of staff turnover, both of which are extremely important to the establishing and maintaining of trusting relationships.

Unfortunately, consistency is one of the relational constraints at OYC. Many of the youth I spoke with expressed concern and confusion over adults leaving the Center. In fact, turnover seemed to undermine some of the security and stability they valued there. In addition, staff leaving also conveyed a lack of commitment on the part of adults. In that regard, youth sometimes described feeling abandoned, sad, and discouraged when staff members left the Center.

For example, when I asked Reginald if there was anything at the Center that he would change to make it better, this is what he told me:

Hmmm ... if I could change anything ... I would say, the staff here is good, but, like I said, when I first started, there were a lot of changes in the staff, so once you get attached to someone and then they're gone, it makes you feel uncomfortable. With a new person you have to start all over from the beginning, and sometimes it makes you not want to come here anymore. There's a lot of changes in the staff here. There's a lot of people in and out. If they could just 
have those people stick around a little more, just work on it. It seems like, every time you come in, there's a new person or someone you just spoke to is not here anymore. There's a lot of good people who aren't here anymore. If the staff stayed around longer, I guess it would be better.

Reginald's statement makes it obvious that such inconsistency is very disconcerting and off-putting to the students and is, thus, something that the Center definitely needs to address.

\section{Relationships with Peers}

Peer relationships at the Center were another significant theme in some of my informal interview discussions and my observations, and thus they also merit examination here. Most students talked about the Center as being a supportive place for friendships to develop and flourish as well as being a safe place for them to work through any problems that might arise with friends there. In addition, they talked about relationships that were not necessarily based on friendship, but rather on collaborative interactions with peers as well as youth of varying ages.

With regard to friendships, many of the youth said that they appreciated the value of being able to just "hang out" with friends at the Center and to have a chance to be where other kids their age are. For example, the high-school group meets in a large room every day, which is not just a classroom but also a place to relax. The room has a few tables and chairs, two comfortable couches, a flat-screen TV, five or six pinball machines, and a number of board games, including a Scrabble game, which they play fairly frequently. Many of the students have told me that the Center provides a muchneeded place for them to spend time with each other, especially since Overtown is a neighborhood that lacks things for them to do and safe places for them to congregate. As 
Taren, one of the high-school boys told me, "At OYC we all talk to one another. It's like one big family. When we come here, we can get together with our friends, do our homework together, and all that really motivates me."

While there will always be times when conflicts and tensions arise among friends, the students appreciate the fact that when they are at the Center, there are resources available to them that can help them deal with the occasional argument or issue. Whether that means finding an adult who can provide comforting words or simply a quiet place to sit, think, and "calm down," they all described the Center as a place that helped them cope with the occasional stress of adolescent friendship and other issues.

In comparison to their relationships with peers at school, youth described interactions among peers at $\mathrm{OYC}$ in far more positive terms. For example, at OYC, peers were described as "less cliquey," "more friendly," and "more caring." They were also described as being not only more accepting but also far more supportive of the desire expressed by their peers to do well in school. While many of them experienced being put down in school for caring about academics, which frequently caused them to "dumb themselves down" in order to be accepted, the opposite is true of their peers at OYC. As Deborah said, "With my teachers, they noticed that I had a potential but I wasn't bringing it out, because I was afraid that other people would say, 'Oh, she's trying to be smarter than us or she's trying to act like she's all that."' So, rather than being insulted for having superior academic abilities, the youth at OYC are looked up to in that regard by their peers and by those in other age groups as well. The ones who are regarded as being more intelligent and better students are the ones who become the leaders at OYC. 
As a result of the more mature relationships she formed with her peers at OYC,

Deborah described her relationships with peers at school as having changed significantly.

When I asked her to describe how her schoolmates' attitudes toward her had changed and what she thought the reasons for those changes were, she told me the following:

Now, I hear people say, "Oh, she's smart. Can you help me do this, or what's this answer?" It makes me feel good. I feel confident. And then they'll see me in class, they'll see how I ask questions, and how I keep asking them over and over again if I still don't understand something. And even though they get mad, they see that I don't care, and they finally get tired of picking on me. And now, they look up to me for answers. I feel smart, like I'm a genius, I feel real good. I showed them that they can say whatever they want to say, but I know that I have the potential. So I guess they say that, ok, she's independent, she don't care what we say, and I was ignoring them, so they say to themselves, "I'm going to leave her alone and go bother someone else."

From that statement, it is obvious that Deborah gained a great deal of self-confidence and self-esteem as a result of recognizing her intelligence and being unafraid of showing it to her classmates. Realizing that not only changed her attitude toward herself, but it also caused the attitude of her peers in school to change toward her. Now, instead of making fun of her for caring about school, her peers are looking up to her and even looking to her for assistance. She went on to say,

Then they start coming to me and ask, "Oh, can you help me with this, or can you stay after school so we can study, or can I get your number so I can have the right answers for the homework for the class tomorrow?" And all that made me feel really good, and even though I felt that they were being very mean to me before, I still don't push them away, because I know that before I started maturing, I used to be that way, too. I used to depend on other people to help me and they used to push me away, and I don't want to be like other people were towards me. I learned from my everyday experience that people can be mean to you, but it takes a bigger and better person to help that person who needs help. So, that's what made me a better person by coming to the Center.

Deborah demonstrates here that she has a great deal of insight into her own and others' motivations and that she is a bigger person than many of her peers, because she is willing 
to treat them well, in spite of the fact that they did not do the same for her in the past.

And those are the kinds of positive attitudes that going to the Center helped her to develop.

All the youth at OYC have numerous opportunities to participate in activities that require them to collaborate as a group to achieve a shared goal. It is in that area, especially, where one can see how well these young people get along with one another, how much respect they have for one another's talents and opinions, and how well they have developed the ability to work together in a mature, caring manner. Those of them who, before going to the Center, did not like working in groups and did not understand the importance of being able to get along with and work cooperatively with their peers began to see why it mattered. As Alexis, one of the high-school girls told me,

I liked working independently, on my own. I didn't like working with other people or sharing my answers. But when I started coming to the Center, and we had service projects, and they started putting us in groups, I noticed that if you want to get the job done, there wasn't any way of getting around it.

I was fortunate to be able to witness and play a small part in two relatively largescale student collaborations at the Center. The first was the production of an original Hip-Hop play by the high-school students, which I will describe in some detail later in this chapter. The second was the production and publication of a professional magazine, which was put together by the middle and high-school students in the summer of 2009 .

Working in the offices and under the mentorship of a team of professionals at “South Beach Magazine," the group produced a 70-page, full color, slick, professional magazine entitled IE2, which stands for "Inspire, Enrich, and Empower." With the exception of some of the photographs, the entire magazine was produced by the students. 
They conducted and wrote interviews of Alonzo Mourning, Dwyane Wade, Tracy Mourning, Jim Jonsin, and others; selected and modeled the clothing, shoes, and accessories featured; and wrote and edited the articles. It took an incredible amount of work and an entire summer to complete the project, but when the first copies of IE2 were printed and in the hands of the students, they were proud of their efforts and knew that all the time they had put in had been well worth it. As the magazine's Editor-in-Chief, DeAndre Holton said, "Being here [at OYC] is a big resume booster. I'm only 16, and my resume is packed. I edited a magazine; I was on the magazine's cover; etcetera, etcetera. I want to do it again next summer."

\section{Exposure to Cultural and Educational Experiences}

Without exception, every single person I interviewed and/or observed during the entire course of this research project agreed that the exposure to the kinds of experiences and learning opportunities it provides for the youth is the element of its programming that has had the most meaning for them and the greatest positive influence on their lives. The extraordinary variety of opportunities the Center affords them has served to widen their perspectives on the world and on themselves tremendously.

Sabrina Jackson, who is the mother of one of the Center's high-school students (and two of its elementary school students as well) and an elementary school coordinator at the Center, told me that before Reginald, her oldest son, started attending the Center, he used to be out on the streets all day; and one of the main reasons she encouraged him to go to the Center was to keep him safe and out of trouble. She also said that she thinks the Center helped to make him a better person and to have a more positive outlook on other people and on life. She told me that, "It expanded his horizons and widened his 
point of view of where he wants to be as a person. It helped him to ask the question,

'How can I make my life a little better?’”

When I asked her what she considered to be the greatest benefit of the Center for her children, this is what she told me:

Exposure is a big one. They have been exposed to places I know I could not have afforded to take them. That helped my son to become more aware of what he wanted to do in life and where he wanted to go. It helped him to know what he has to do to get to point $\mathrm{A}$, and once he gets to $\mathrm{A}$, what he needs to do to get to point B. I know the support system they provide at the Center is wonderful and has helped him a great deal to grow. Even with my daughter, she was able to go to a Montessori school, which is very expensive and for very bright kids, and she has learned how to live in two worlds and how to weigh them both against one another.

Ilya Williams, another of OYC's coordinators, and two of whose children also

attend the Center, agreed that the exposure they receive to all manner of experiences is

the greatest benefit for all the children. She told me,

I mean, oh my God, these kids get to go places ... Since I've been here, I've been to places I never thought I would go. I mean, imagine, living in Overtown, and everybody looks at us like we're so poor, and we're going to an opera! And, you know, people already have this perception about us before we go to a place, because we're Black and we're from Overtown. But, I promise you, Miss Jayne, I promise you, there isn't a place we don't take our children. I mean, I just love it. And the kids love it.

Along with agreeing that the exposure they get at OYC is so expansive, Williams pointed out that some of the things the Center exposes the children to are even more meaningful, because they are the kinds of things that the majority of poor, Black kids would never get to experience if they did not have the Center.

There are also some experiences that are very simple, yet profoundly important, that OYC exposes these youth to, such as going to the beach and experiencing the ocean. At first glance, that kind of exposure might seem relatively insignificant, but some further 
analysis will reveal its deeper meaning. For example, just think about the fact that all these kids live in Miami, just a couple of miles across the bridge from Miami Beach; yet, before the Center was built, the vast majority of them had never been there. They had never once seen the ocean. Why? The answer is simple, because no one had ever taken them there. It is almost as if there was an invisible fence up around their community, making it seem as if nothing outside of their neighborhood even existed. As Alonzo Mourning has said on many occasions,

Such simple experiences could help to expand their horizons and inspire their minds. If they can't see Miami Beach, they can't dream of moving there one day. I want to provide as much exposure as I can for these kids so they can grow, flourish and find their potential.

Many people do not fully understand the obstacles that these children face in their everyday lives. However, what most of us would view as relatively small, insignificant details can pile up and result in major problems for these youth. As Mourning said to me, for example, "Some of these kids don't get breakfast in the morning, so their attention span isn't great at school. So we try to get them some food, because just providing some food in the morning can make a huge difference." He also told me that they have locker rooms with showers at the Center, and that they also wash clothes for the kids, because, as he said,

They [the kids] may not have the money for a coin machine to wash their clothes. Or the water in their apartment might be turned off. Some of these kids have real hygiene issues that affect their participation in school. Think about if you are in junior high and you don't have clean clothes or you can't shower and be clean, think about how you would have approached a day at school. Eventually you would stop going. Or, if you did go to school, you'd sit in the back and not draw attention to yourself, hope no one noticed you and made fun of your situation. 
Some of these kids will drop out of school or fall way behind for reasons that are so simple and basic. Therefore, for some of them, just a having a hot shower and clean clothes can make a world of difference, and as Mourning said, "as we know, if a kid can't compete in a classroom environment, then their first reaction is to rebel. And that's where the trouble starts. We lose kids in this country over little things like that."

When President Obama was elected, Mourning thought that it would be a great experience for the kids at the Center to attend his inauguration in Washington, D.C. So, he proceeded to rent a bus large enough to take 60 students and staff there and also arranged for them to stay overnight in D.C. for the ceremony. The only thing the students had to pay for the entire trip was $\$ 15.00$. The rest was paid for by Mourning's charity organization. Carlos, one of the students who went on the trip, told me,

I love Obama. It was so exciting to be there and see him get inaugurated. I know what a big deal it is for a Black man to become President. My grandma said she never thought she would live to see a day like this. And here we are, in Washington, D.C., getting the chance of a lifetime. And we even got a place to stay. We stayed in this beautiful Black church, down in the basement. They cooked for us and everything. That trip is something I never will forget!

A trip like that is meaningful in so many ways. It enabled those 50 plus inner-city Black kids to have a totally unique experience, one that they would never have even dreamed of having were it not for OYC. It gave them an opportunity to celebrate their Black roots and learn something important about their history, which resulted in their having an enhanced sense of self-esteem.

The Center's enrichment activities range from such things as visits to art galleries, museums and other cultural venues within Miami; to college tours both within and outside the State of Florida; to academic support and tutoring on a college campus (FIU); 
to highly collaborative, complex, project-oriented activities, such as the writing and performing of original dramas, the production of a slick, professional magazine, public dance performances, and grant writing and project planning. By exposing the students to such a wide range of cultural, intellectual, and other experiences, the Center hopes to make each one of them better equipped to identify the things that are most meaningful to them and most relevant to their futures.

DeAndre, who was in the ninth grade when I first interviewed him, told me that he and his two siblings had been going to the Center since second grade, which is also when the Center first opened its doors. In terms of their home life and upbringing, they are not typical of the majority of the youth at the Center. For one thing, their home life is far more stable; and for another, they have a mother who always placed a high value on education for herself - she graduated from college and graduate school - and for her children. She was actually the first person in her family to go to college, and so she fully expected all of her children to follow in her footsteps. Thus, DeAndre always knew that, for him, college was not a choice but an obligation. In spite of that, he told me, he still had many uncertainties in regard to what he wanted to study in college, especially since, he told me, he was not as good a student as his sister (who always got straight A's) or as artistic as his brother (who was studying art at DASH high school). In regard to what the exposure he got at OYC did for him, he told me the following:

It took a while for me to actually find out what it was that I wanted to do. OYC was just one of the greatest outlets for that, because they expose you to so many different things to help you find out what you're good at and what you're passionate about. It was at OYC that I found out I'm good at creative writing and poetry. At OYC, I also found out that I love to act. I'm a performer. I love the attention. So, anything to do with performance at OYC, I try to do it. I love being in everything. I want to become a radio host or a TV host. 
By being exposed to the wide variety of experiences that OYC affords, then, DeAndre as well as many of the other students I have spoken with - was able to discover what he was truly passionate about. In a subsequent interview with him, he explained more about the ways in which the Center helps the students find the direction in life best suited for them. He said,

There are certain things here that we do have to do: you have to apply for college, and if you don't, you have to have a back-up plan. That's one of the things that Fred does. He tries to find other options besides college for those kids who don't want to - or can't - go to college. The main thing about OYC is we have to want to do something. You have to have a goal. You have to. You have to have something that you want to do. If you don't know what you're good at, you can just tell Fred, and Fred will find something for you. In the end, you have to try to achieve your goal in any way possible.

The following statement made by Alonzo Mourning sums up both powerfully and succinctly the Center's rationale for the emphasis it places on exposing the Center's youth to so many different experiences and learning opportunities. He said:

What happens if no one invests in that kid who may be easy to miss but has the cure for cancer in him, or who has a great business mind, or who can be a great musician or teacher or community leader? We'll never know if we don't give them the chance, if we don't invest in them. I believe that our exposure and our experiences dictate our destiny. The reason why I am where I am is because of exposure. If you expose these kids to the right things, synapses are going to fire ... That's why it's so important for us as a people to create better experiences for our children, all our children.

I could not agree more with his statement that a person's exposure and experiences are what dictate his/her destiny, and that if we don't give our children the chance to be successful in life by guiding them in the right direction, we will never know what they are capable of achieving. 
In the remainder of this section, I will share what the students told me about two of the most significant categories of activities that the center exposes them to, and what their overall feelings about their exposure to those experiences are. Those categories are: community service and educational opportunities.

\section{Community Service}

As part of becoming a productive citizen, one of the things the Center stresses for its young people is the importance of giving something back to the community and to the people who helped them. It teaches the youth there that it is never too late to try to make a difference in their own lives, or for that matter, in the lives of others. Mourning - and the staff at the Center - constantly reminds them that one of the responsibilities they have as recipients of the opportunities the Center and its supporters provide them with is to try to uplift those around them who have not been as fortunate as they. I have heard Mourning say, over and over again, that no one can succeed in life entirely on their own; that no one - not himself, not his wife, not any of the athletes he knows - could have gotten to where they did without having the help and support of someone else. Thus, every one of the young people I have spoken with at the Center has expressed a desire to give back to his/her community or his/her family in one way or another.

One day I asked Deborah to tell me what her favorite activities at the Center were, and this is what she said to me,

We get so many different opportunities, but the ones that I like the best are the different community service projects we do to help our community. Those are great opportunities. For instance, last summer we worked with Hands on Miami, and this year, we're doing some community service projects and working with certain organizations. We went to Vizcaya Museum one day and helped them clean up after a hurricane. We also went to an old folk's home to show them that people really do care about them, even though they hardly ever get out. We've 
been to the Pelican Harbor picking up all the trash to help out the environment, so that the animals wouldn't be harmed. We picked up the trash out of the trees and by the water. Across the street, where it says "Overtown" by the highway, we cleaned up over there and planted different plants, so that people passing by here would see it was clean and wouldn't be able to say, "Oh that's dirty, why don't they clean it up?"

It is rather amazing that a young girl like Deborah would be so enthusiastic about doing those kinds of things, but the Center helped her to discover that giving back is one of her passions, a passion that will probably be an integral part of her life as she continues to grow and mature. Moreover, her point of view on the needs and problems in the Overtown community demonstrates a depth of thought and concern uncommon for a girl her age. She stated:

As I look around my community, I am constantly reminded of the needs not being met. Overtown is plagued with drugs, violence, poverty and crime. There are rundown apartments and homes that must be rebuilt, drugs and violence that need to be removed from the area, and homeless people who need attention. The Overtown Youth Center has provided mentoring and fostered hope to many youth. Their staff has helped me find my potential, fulfill my dreams and understand the value of an education.

In December 2010, one of the Center's donors, who was extremely impressed with the work being done there, created a grant competition for the high-school students. He challenged those who were interested in participating to create a service project that they believed would do something valuable to help their community in some significant way. At the end of the competition, whichever project the donor deemed most worthy would be awarded a $\$ 10,000$ grant to fund it. Deborah was one of the students who took the initiative to develop such a project. It was her project that was chosen, and she described her idea and its genesis to me as follows:

While I pondered on an idea, the memory of my grandmother feeding the homeless inspired me, and thus the "Help Every Last Person Project" was 
subsequently born. The purpose of this project was to make a difference by providing food, hygiene products, clothing, and a caring heart to individuals who may need a helping hand. With this idea I believe that I can realize my full potential, plus follow through on my grandmother's dream as well. Even though the project's inception was a tremendous amount of work, I was able to complete the task. This experience has not only opened my eyes to doing more community-based work, but it also taught me the value of working and creating clubs/organizations that are making the world a better place.

Hearing those words made me think that we, as a society, could not ask for a gift of anything greater from any organization than the fostering of such a compassionate heart and such a strong drive to help others in our youth as that evidenced by Deborah, who some would regard as just another Black face in a dark and hopeless situation. And that is why the work being done at OYC is so important for all of our futures. One day, in regard to Deborah, Fred said to me, "I look at her and I think that she could do anything that she wants to do ... I definitely see that there's a big part of her that likes community organizing and likes wanting to go back into communities and kind of help rebuild them. I could see her being influential in that way."

While a grant opportunity like that presents itself only on rare occasions, I have frequently heard many other young people at the Center express a desire to do something with their lives to give back. For some of the older students, one way they have of doing that is to work with the younger children at the Center as mentors and/or coordinators during the summer after graduating from school.

Opportunities like those often bring out some unexpected qualities in some of the Center's youth. As Fred told me one day:

I've seen some kids who can't get along with their peers, but if I put them with younger kids, they genuinely love being with them. That's their passion. Even the kids sometimes that you think wouldn't want to do that will surprise you. It may be that their level of thinking or their conflict resolution skills are on a lower 
level, which makes them able to identify more with the younger kids. I'm not sure what it is, but I can see a difference when I put a kid to assist and they do well in that environment. They seem to be feeling their leadership skills, they're taking the initiative, they're taking ownership.

It appears that a particular skill or passion is not always evident in a student's everyday interactions with his/her peers. Sometimes simply placing him or her in a completely different role will bring out a hidden talent or ability s/he has.

When I was talking with Jonathan one day, he started telling me how much of an inspiration Alonzo Mourning has been to him, and then he told me what he envisions his role in "society" to be when he gets older. He said,

Where am I going to fit into society? Then you say to yourself, okay, where am I going to lay my landmark? You wanna be one of those big names people look at? No. Not just like someone with millions of dollars. You wanna be like one of those people who are known for what you give to others, someone like Alonzo. Alonzo is known for being a family man, for being a risk-taker, and mostly for giving back. To build a center like this for all these kids ... That's a really big thing, giving back. That's what Alonzo is known for. That's a miracle. That's what I want to be known for.

That may be a lofty goal, but it is precisely the kind of attitude the Center works at instilling in every single one of the young people who walk through its doors every day the desire to do something worthy and give back to others.

In addition to giving back to one's community, these students also think about being able to give back to their families. While it is very admirable for young people to want to use the benefits they receive at the Center to do whatever they can to help uplift those closest to them, it can also put them under a great deal of pressure and be quite stressful for them. As Fred told me,

Some of my kids, their success, their whole family is riding on. They're hoping that if they do well, they will be able to get the whole family out of here. That's a lot of responsibility for an $11^{\text {th- }}$ grade student. A lot of them are put in that 
position. If you do well, if you're a good student, you're going to be the "good one," you're going to be the one to help us all out. Because if I don't make it this time, or if my grades aren't the greatest, you're looking at me like you're not just letting yourself down, you're letting your whole family down. That's a lot for a 16 or 17-year-old kid to deal with!

Jonathan is one of those who feel a strong responsibility for helping his family, and he explained his reasoning to me in the following way: "If I succeed in life, we all [his family] succeed; if I fail, we all fail. My life is not just about me, it's about all of us. When I win, we all win. That's just how it is."

\section{Educational Opportunities}

I have already mentioned several times the fact that Alonzo Mourning is a strong proponent of education as a means of providing youth in underserved Black neighborhoods, especially, with the opportunity to attain "the American Dream." Mourning always stresses that without a good education, it is extremely unlikely that young people, particularly young Black men living in poverty in the inner cities, will ever be able to reach their potential and be successful, contributing citizens.

Because of his strong convictions, the culture of the Center is imbued with a love of learning. In discussing the significance of education in peoples' lives, Mourning made the following statement: "Seventy-five percent of the prison population doesn't have a high-school diploma or a GED. People who have even just a high school diploma are less likely to wind up in prison." He then went on to say,

If you get a kid to graduate from high school, you greatly decrease the chances he will be a convicted felon. As a nation, if we invested in education up front, it could cut the crime rate, cut the money we spend on incarceration. We spend $\$ 35,000$ a year on each prison inmate. It doesn't cost that much to get a kid through high school and send them to community college or even all but the most elite universities. The numbers don't add up. If we focused on education, we'd also be focusing on crime prevention, prison costs, and improving the economy. 
There is ample evidence in the literature that Mourning is right to point out the correlation between lack of education and incarceration rates, and to state that investing in education for our youth rather than paying to keep our prisons filled (especially with Black men, the way they are today) would be a far greater service to society (Brown, 2002; Delpit, 1995; Dyson, 2005, 2008; Ross, 1998).

The Center, therefore, does a great many things to imbue a love of education in its youth and increase their aspirations to go to college. As Carla Penn stated:

It [the Center] brings some of the universities inside the State of Florida in to provide volunteer work. Of course, our long-term partnership with FIU; exposing them to college life; bringing in speakers to talk about career exploration. I mean, the list goes on as to what we do to expose them to further education or education exploration, to help them figure out what they want to be when they grow up. And the wonderful thing is to see the students dreaming about what they want to be past high school, which is very new and very different for most of them.

Unfortunately, however, in spite of all the efforts the Center makes to bring a love of education to the forefront, the academic aspect of its programming is still one of its weaker ones. While the exposure to college campuses is an excellent way in which to help them "dream about what they want to do," it does not succeed in getting many of the youth to truly appreciate the assistance they are getting and the importance of focusing on the opportunities for learning they are provided with.

By far the most popular program aimed at giving the youth at the Center an idea of what college life is like and thus helping engender in them a desire to go to college, each year the Center plans and organizes a week-long college tour for 10 to 15 of its middle and high-school students. The opportunity to be an intimate part of and actually 
live the college life for an entire week is very exciting to the students, especially since all of their expenses are paid for by the Center.

During the course of the week, the students visit several different college campuses within the State of Florida (and sometimes, in other states as well). In addition to being taken on tours conducted by current college students of each college's campus, the students also have the opportunity to meet with representatives from each college's offices of admissions, financial aid, housing, and others.

In addition to visiting the colleges themselves, the OYC students are also provided cultural and historical experiences during the college tours. For example, during one of the tours, students visited the historical, predominately Black town of Rosewood, Florida, where they learned about the town's history and heard different peoples' views about the horrific massacre that took place there.

In sum, the college tour empowers students and also motivates them to visualize their dreams of reaching higher education goals. As Fred Rosario said, "The college tour puts in perspective everything I have taught OYC students about the expectations of college." It is hoped that by exposing the youth to a variety of colleges and universities they will be able to make the best choices for continuing their academic careers.

When I asked Sabrina Jackson, one of the elementary school coordinators, how much emphasis the Center places on having its students go to college, she said,

Oh, a lot. Even with the help of FIU - the partnership we have - Fred is always talking with them about going to college ... he's not putting down the working world or the technical schools, or things like that, but, you know, he doesn't try to push everyone to go to college. He tries to place the kids where they feel most comfortable, because, you know, not every kid is meant to go to college. Fred does try to get every student in the best place for them. 
Jackson's last statement that "not every kid is meant to go to college" is very true. In fact, it would actually be counterproductive to try to force every student at the Center to aspire to go to college, especially when it is obvious that not all of them have the capability to do well in a college classroom. Being aware of that fact and then working within the parameters of each student's capabilities and passions is one of the more positive things that the Center does. Along those lines, Jackson went on to say that, We try to identify each student's strength(s) and what fits best with those strengths and prepare them the best way we can. We sit down and talk one-onone with every kid to see, for example, how we can find them a decent job, and then eventually, that person may want to go to college or technical school. Fred is always trying different things for each of them. Maybe one of them will want to go into the Army, but he does try to get them interested in going to college.

As noted previously, while the Center does hope to encourage all the youth to strive for and value higher education, it does not force it on them. Instead, as Jackson's statement indicates, it looks to find some way, whatever will work for each individual student, for $\mathrm{him} / \mathrm{her}$ to experience success in life, whatever road s/he chooses to travel.

Reginald, Jackson's son, who as mentioned earlier graduated from the Center in June 2010, is one of those students who always had a strong desire to go to college. He has just completed his first year at Florida State University, where he is majoring in accounting and is planning on attending law school after he graduates. When I asked him how he viewed the kind of assistance he had gotten from the Center in the area of college preparation, he told me,

For as long as I can remember, I always thought that after high school, I'm going to college, but it wasn't a developed thought. It was all pretty unrealistic until I got older and started to understand my goals and look at the pros and cons of different kinds of schools. When I was younger, I didn't know, I would say I'm going to this college, but I didn't know that, OK, this college has my program that I want to study. So coming here [to the Center] didn't have any major influence 
on my desire to go to college, but it did help me to get ready to do what I had to do to prepare myself for it.

Obviously, Reginald is not one of those students who had to be coaxed to aspire to go to college - he already had the desire. As he said, he was always certain that after high school he would go to college. However, the Center's focus on higher education did help him in another, more practical way, as he went on to tell me,

The academic program here is, for me, I guess for kids entering college, it's really good. Because this program really helped me out - more than my CAP advisor at school. And, like today, I'm coming here [to OYC] because I'm finishing up my scholarships and grants, trying to cement those off. All of my college applications were done mostly here, with help. My FAFSA [application for financial aid] and everything, all of that was done here. So ... I'm usually here. It's a really good program to help get you to the next level after you've completed high school. So that part of the program is really good.

As Reginald said, the part of the Center's college prep program that helped him was the guidance it gave him in preparing all of the often cumbersome and confusing paperwork and applications required, including applications for scholarships and financial aid.

\section{Educational Opportunities at FIU.}

In 2008, as one of the facets of the partnership I established with FIU and OYC, I created an SAT and ACT tutoring program for the Center's $9^{\text {th }}$ to $12^{\text {th }}$ graders. I initiated the program to serve three main purposes. First, and most obviously, to help the youth prepare themselves for taking the SAT and/or ACT exams; second, to provide them with continuous exposure to a college environment, so that if they do go to college, they will already feel comfortable in that environment; and third, to expose them to one-on-one interaction with a college professor and college students, who could serve as tutors and as possible mentors and/or role models for them. 
This program has become the most consistent and successful aspect of my partnership with OYC, and it has been ongoing since its inception. The program, which is administered and taught by me and a number of Honors College students on a completely volunteer basis, takes place once a week, year round, including summers. We meet in a classroom on FIU's Biscayne Bay Campus. The tutoring sessions include intensive instruction in math and verbal and reading comprehension skills, utilizing SAT and ACT practice exams from official workbooks and websites.

We also provide a number of other less conventional strategies to keep the youth engaged in learning the kinds of things they need to master in order to do well on those exams. In some of our sessions, for example, we have given the students a list of new vocabulary words to learn and then asked them, individually, to make up a poem using as many of those words as they could. The students became quite engaged in the exercise and it made them truly enthusiastic about not only learning the words but also being able to use them in an original, creative way. Seeing how excited many of them got about challenging themselves in that way was a very rewarding feeling for me, and it opened up an entirely new realm of learning for them.

We also used the game of "Jeopardy" as another way of teaching them some of the math, vocabulary, and reading comprehension skills they need to know for those exams. To do this, we would first randomly divide the students into three or four small groups. Then, in keeping with the method used on the television game show, we took the various skills they had to learn and divided them into categories (i.e., algebra, vocabulary, sentence completion, and so on). We then selected questions (which came directly from actual SAT or ACT exams) and placed them in the appropriate categories arranged in 
order of increasing difficulty. Using the Jeopardy game in this way has proven to be a very valuable learning tool for a number of reasons: it made learning what they viewed as relatively dull material more fun, it satisfied their love of competition, and it helped them learn how to work cooperatively in groups with their peers.

During the school year, the SAT/ACT program at FIU takes place after the students have been in school all day, so there are times when they simply are not ready to focus on academics. Sometimes they may just need to unwind and not talk about anything. At other times, they may prefer to use their time at FIU to talk about things they rarely if ever have a chance to talk about in school. At one time or another, they have all complained to me that what they do in school is driven entirely by the need to prepare for passing the FCAT exams, which leaves them very little time to learn about other things that may interest them.

It is at times like those when, rather than forcing any kind of structured learning on them (which is always counterproductive), I will ask them what they want to talk about or suggest a topic that I think will interest them. On occasions like that, we have talked about such things as current affairs that concern them, like the economy or the earthquake in Haiti; politics; racial issues; and sometimes even things like the latest movie they have seen, their Senior Prom, the Miami Heat, and so on. Whenever we do that, most of the students become genuinely engaged in the conversations and tell me how they never get the chance to talk about those kinds of things at school. Every once in a while, I have done things like bringing in a newspaper article about something I think will interest them, reading it out loud to them, and then having them participate in a casual discussion about it. 
Finally, because I have given a great deal of thought to the fact that exams like the SAT and ACT are very culturally biased, and therefore, are one way in which the system works to set Black students up for failure (Morris, 2002; Watson, 1998), I decided to try a new approach to helping prepare them for the verbal and reading comprehension portions of those two exams.

During the summer of 2009, I attempted my first "experiment" of that nature by using a novel rather than the usual SAT/ACT reading selections to help them improve their vocabulary and reading skills. Each week I would ask the students to read certain pages of the book and have them answer 10 to 15 questions about the passage. I composed the questions myself and formatted them exactly like the questions on the SAT/ACT exams.

The novel I selected for them to read was The Dew Breaker, which was written by the world-renowned Haitian author Edwidge Danticat. Before having them begin to read the book, in order to get them as engaged in reading it - and in reading, in general - as possible and teach them something about a subject I knew they were unaware of, I started by giving a brief lecture on Haiti: its history, the story of the Haitian revolution (which is the main source of pride for every Haitian I ever spoke with about it), its art, its culture, and so on. After that, I provided them with a bit of biographical information about the author and a brief synopsis of the novel.

I purposely selected a book written by a Black Haitian author, because I wanted to give the students material to read that they could relate to. Since I knew from their last names that several of the students in the room were Haitian, I assumed that I had made a good choice. However, when at one point, I asked the Haitians in the room to raise their 
hands, not a single one of them did so. None of them wanted to admit it. It was at that point that I realized my thinking had been somewhat off target. Although the students actually did relate to much of the novel's subject matter, they did not relate to Haitians in general, about whom, I soon learned, they had formed many prejudices. Because of the many negative things they have always heard about Haitians on the streets, they have come to consider Haitians inferior, beneath them.

Fred later told me that, "they tend to classify everything they consider derogatory as 'Haitian,' or less than," which is something I had not thought about before making my book selection. He also said that if I had chosen a book by an African-American author rather than a Haitian, they would have responded very differently to it and "might have been a lot more involved with the reading."

However, after listening to what I had to say about Haiti, about Haitians in general, and about the author herself, and especially, after beginning to read the book, their attitudes did begin to shift quite markedly. They became fascinated by the characters and the stories in the book and actually became very engaged in reading it and in having animated discussions about it. In the end, then, the choice turned out to be more of a learning experience for them than even I could have anticipated. It also served the main purpose I chose it for by helping to expand the students' vocabulary and enhance their reading comprehension. At the end of that summer session, I asked Fred if he thought that the experience had done anything to change the students' attitudes about Haitians, and he said: "Yes, definitely, the mindset has changed. And what I'm hoping is that one of the kids who didn't want to say they were Haitian in the beginning will want to now. That's what they need to see." 
There is an addendum to this story that I would like to share with the reader here, as it demonstrates the length to which I feel it is necessary to go in order to help expand the horizons of these students through education. I believe that we have to utilize everything we have in our arsenals that will contribute to engaging them and immersing them in the whole process of learning.

One day an idea came to me. I thought to myself, "Wouldn't it be phenomenal if I could bring Edwidge Danticat to FIU's Biscayne Bay Campus to meet these students who just finished reading her book?" I knew that Danticat lived in Miami and that she cares very much about empowering young people, especially poor inner-city Black kids, so I knew that my idea was not all that far-fetched. Once the idea took hold in my mind, I found out from a contact at FIU how to get in touch with her and sent her an e-mail. In my e-mail, I explained about the partnership I had formed with OYC, told her that a group of students from the Center had just finished reading one of her books, and asked her if she would be willing to come to FIU to meet them, have an intimate conversation with them, and sign their copies of her book. Much to my surprise, she responded to my e-mail almost right away and said that she would love to do it. After many, many more e-mails back and forth, we were able to arrange a date and time for her visit, and my idea became a reality.

I did not tell the students anything about the arrangements I had made until right before the date at the end of September when she was scheduled to appear. Witnessing their reactions to having the opportunity to actually meet and talk to a famous author, one who they had come to admire over the course of the summer by reading her book, was something beautiful to behold. They could barely conceal their excitement, and they all 
sat wide-eyed as they listened to her speak and answer the questions I had asked them to prepare for her. The questions they asked were about writing, in general, and about the stories and characters in The Dew Breaker, in particular.

When she finished speaking and answering all their questions, Ms. Danticat asked them to come up one-by-one, gave each of them a warm hug, said a few words to each one, and then autographed their books for them. Chantal, one of the young girls who was there, told me,

I was so surprised. At first, like, my mind wasn't right, and I was asking myself, "Who is this?" I didn't start catching on until someone asked her a question about something in her book, and I said to myself, "Her book?" Then, I looked at the book, and I realized that was the author right in front of me. I was shocked. I was so excited. I thought it was, like, wow, she's right in front of me. That was so exciting for me. And when I got to actually meet her, and she gave me a big hug ... I just could not believe it was really happening. It was so great that you got her to come. It was so much fun to meet her.

From what I have been told by OYC students and staff alike, this tutoring program has become not only useful but also popular with the students. When I interviewed Sabrina Jackson and asked her about it, she told me:

In the beginning, when the kids were first going to FIU, they weren't that enthused about it. But, now, the kids are asking Fred, "When are we going to FIU? We really want to go. Don't leave here without us, etc., etc." Now they can't wait to go. It was hard to get them to go at first, but now, they really want to go. When I tell you how much it means to them to go now, you have no idea.

Knowing that the youth themselves recognize the benefits they are getting from the program is extremely gratifying for me. The interest they are showing, along with the feeling they have of being welcomed in our college environment and the level of comfort they now have being here were exactly what I had hoped for when I initiated the partnership program. 
Deborah expressed her appreciation for the ways in which the Center, partly

through the program at FIU, helped her to prepare herself for college and understand the steps she needed to take. She told me the following:

Coming to the Center, it helped me find out what college I want to go to, because we search colleges and build our resumes together, so if we apply for a scholarship, we will have our resume ready. They $[\mathrm{OYC}]$ also give us the foundation to go to college. Like, they take us on college tours, which usually include visits to five different colleges. They also take us to FIU to take part in the SAT prep program you started. If I wasn't coming to the Center, I wouldn't get that opportunity, because I would have to pay for the classes. So, that's what I really like. They build a foundation for us.

Much like Reginald, she, too, understands the significance of the assistance the Center provides when it comes to preparing the students for college. Then, I asked her if she thought that going to FIU once a week helped her feel more comfortable about the idea of being in college, and this is what she said:

Yes, because I have AP classes, and they're very hard, but when I go to SAT prep, it's the same concept, but I still get it, because y'all explain it to us even more, and the words that are there are hard to understand, but when I start to study them, I notice that the same words we learn in SAT prep come up when I'm at school. So, when the teacher asks, "What does this word mean?" I can tell them. And when they ask me where I learned the word, I say, SAT prep, and they ask me "Do you have to pay for that class?" I say, "No. I go to the Overtown Youth Center, and they take us every Wednesday." They say, like, "Wow," they are shocked!

For her, then, aside from the level of comfort she now has with being on a college campus, the SAT prep program at FIU has helped her significantly to understand the things she reads in school as well as to expand her vocabulary. She is well aware that being a part of the Center is why she has been able to get that valuable added exposure. I also asked Jonathan if he felt that the reading comprehension aspect of the SAT tutoring program had helped him, and he explained what it did for him by saying, 
Because you have a wrong understanding of what a word means, you could evaluate the meaning of the whole paragraph wrong. But once you understand what the words mean ... and that's what the SAT tutoring helped me to do. If you get the right clues, like you taught us to do, you can understand what the word means and everything. In high school, they're more worried about the FCAT. Here, you actually teach us something.

In addition to the SAT/ACT prep program, there is a long list of other activities I have organized for the OYC students when they come to the Biscayne Bay Campus to help them understand the importance of higher education and the many possibilities it can open up for them, enhance their self-esteem and self-confidence, get themselves prepared to become college students, and encourage them to feel comfortable in a higher-education environment. For example, in October of 2007, I conceived and hosted a luncheon event called "Possibilities" to inaugurate and celebrate the new partnership between FIU, the Honors College, and OYC. In attendance were about 30 middle and high-school students from OYC; several of the Center's administration and staff; and students, staff, and administrators from FIU. The event included a Caribbean-style lunch, an African dance and drum performance, and dancing to a live band. To conclude the event, a group of Honors College students took the OYC students on a tour of the campus, which culminated in their giving an inspirational talk about the importance of having a college education. The event was very successful and has since become an annual celebration. In June and July of 2009, I conceived and conducted two 3-hour "college orientation" classes for 30 of OYC's middle and high-school students. The sessions dealt with such subjects as the University Core Curriculum, Plans of Study, the University Catalog, procedures for Registration, using Panthersoft, Financial Aid, scholarships, and other topics. At the end of the second session, I gave out Certificates of Completion to 
each student who attended both sessions. In July of the same year, I also arranged for two groups of middle-school students and one group of high-school students to be taken on extended tours of the Biscayne Bay Campus.

In August of 2009, I arranged for the OYC high-school students to give a public performance of an original Hip-Hop play they had been working on for several months in the Wolfe University Center Theater on FIU's Biscayne Bay Campus. The play, entitled "G.A.N.G. UP: The Chronicles of Life," was written, produced, directed and performed entirely by the OYC students. "G.A.N.G. UP" stands for "Good Attitude Never Gives Up," and the following is the poem the students wrote to explain what the play was all about:

The Chronicles of Life, what does that really mean? I guess depending on who you are is how you shape the scene.

Tonight we want to take you on a journey through our world, a world where some are afraid to go in.

Some are afraid to get exposed in And others ... Well ... They just live in it.

The sad thing about it, these people don't even know they're locked in.

You'll see things that are negative;

you'll also witness our strength and triumph. But most importantly, you'll hear our story.

through our own mouths as we GANG UP in OVERTOWN.

The rest of the play consisted of 12 Hip-Hop songs that spoke very powerfully about different aspects of these students' life experiences:

"The Struggle" - the rise and fall of the African-American struggle in America "Stop the Violence Campaign" - an everyday occurrence of Black on Black crime 
"A Day at OYC" - an introduction to the students and their lives at OYC "Mid Evil" - a reflection of two young men who became products of their environment

"My Block" - students' reflections on their community and how they view their block

"Homicide Prevention Campaign" - the facts and statistics that plague the Black community

" 3 rd Degree Puppy Love" - some people don't think that teenage love is true love; this is love from a teenager's point of view

"HIV Prevention Campaign" - the facts and statistics that plague the Black community

"Collateral" - a reality check that young Black women are experiencing all over America

"Soulja" - a chance to look inside the life of a young Black woman

'Divine Thoughts' - a young man and woman's conversation with God

"Graduation" - after the long battle and journey that these young adults have been on, they have finally made it.

Finally, in February 2009, I organized a lecture and round-table discussion on the subject of the election of the first Black President of the United States entitled "Now That We've Made History, Where Do We Go from Here?' The keynote address was delivered by Minister Rasul Muhammad, one of the leaders of the Nation of Islam, and the panel included Minister Muhammad; a non-denominational Christian pastor; a community activist in Liberty City, Overtown, and Coconut Grove; an Honors College student; and Reginald, the high-school student from OYC who was one of my main informants for this research study. Students and staff from OYC and FIU were all invited to attend. The purpose of the event was to share information and opinions about the significance of the election of a Black man as President. More importantly, however, it was organized to give the OYC students an opportunity to participate in the kind of discussion and intellectual exercise that is common on many college campuses nationwide. 


\section{Physical and Psychological Safety}

The theme of safety definitely warrants its own analysis because of how commonly youth mentioned it as a specific feature of their experiences at the Center. Conversations about safety involved both physical and emotional elements in their lives and focused mainly on the influence that the environment in the Overtown neighborhood (and sometimes in their homes) had on them as compared with the safety of the environment at the Center.

Overall, OYC provides youth with an intermediary space in which they can feel safe to experiment, form an identity, make choices, resolve personal crises, and learn to navigate the different worlds of school, family, and neighborhood. Research has shown that a sense of safety and belonging is associated with positive learning and developmental experiences.

\section{Physical Safety}

Living in a neighborhood as fraught with violence, drugs, and other crime as Overtown, it should be obvious that one of the first things these youth need is a safe place where they can go to spend their after-school, weekend, and summer hours and escape from the violence that surrounds them every single day in their neighborhood. The Overtown Youth Center provides just such a safe haven for Overtown's young people, and everyone I have spoken with agrees about the tremendous importance that kind of safety holds for them.

I asked Deborah what she used to do after school before going to the Center, and she told me, "I just used to hang out on the street doing nothing. Coming here keeps me out of trouble. It keeps me from getting into things I'm not supposed to get into." When 
I asked Carla Penn, the Executive Director of OYC, what she considered to be the greatest obstacle for the young people living in Overtown, she told me:

Negativity in the environment is definitely their greatest obstacle. You know, because we have all these wonderful people who are around them, such as yourself, who tell them you can do whatever you want to do and you can become anything you want to be, but then the next thing that happens is somebody's killed ... a teenager is killed. There's a drive-by or something else that just knocks them for a loop, and then they might say, "Can I really do this? Am I going to live long enough to do this?" So, it's that kind of stuff. So it's the environment, it's definitely the environment.

According to Carla, then, their greatest obstacle to living a productive life is the environment in which they live, and particularly, the violence in that environment. It seems that whenever the youth begin to feel that they can rise above where they come from, something awful happens to make them question whether they will even live long enough to accomplish anything. Carla went on to tell me, "If you ask them about a family member who's been killed or murdered, almost $90 \%$ of their hands would go up. So, the majority of them have definitely been exposed to violence."

She then told me about some of the things the Center does to help the youth avoid violent behavior in their own lives:

We look at bullying; we look at the impact of violent behavior, so sometimes during the summer we take them to juvenile detention centers or to the adult prison, which is very scary for them. We also have violence prevention speakers who come in throughout the year. Really, we try to get them to start thinking about different ways to do things in different situations they get themselves into, making better choices, and we've been doing that as well.

Teaching them new ways in which to resolve various conflict situations in their lives, combined with bringing them face to face with the penal system, which is society's way of making people pay for their violent behavior will, at the very least, give them pause to think about avoiding such behavior in their own lives. 
Deborah told me that when they visit a juvenile detention center or prison, they are usually taken to sessions where some of the inmates tell them about the crimes they committed that put them in prison and how they feel about being there. I asked her if she thought that having an experience like that was helpful to her, and she answered:

It probably is; but then, it's sometimes sad, because you're sitting there and listening to someone else's story. They're in there when it could have been prevented. If they had somewhere to go like we have [OYC], maybe they wouldn't have been in there in the first place. And then, all the people in jail are not bad. They probably just made one wrong decision that changed their whole life, and there's nothing they can do about it. I get upset, because you have so many schools around here, but then there are more jails than schools, and that makes me feel like they are just setting our future for us. It makes me really upset.

Deborah has made a number of very astute observations like that throughout my interviews and conversations with her. Sometimes, I have marveled at the intelligence and insight in such a young girl. Not only has she shown herself to be a compassionate person, but she has also demonstrated an understanding of society that is, to me, way beyond her years. Her statement, "there are more jails than schools, and that makes me feel like they are just setting our future for us," is so painfully true, and it also echoes the sentiment Mourning expressed in one of my conversations with him.

In addition to the safe haven that the Center represents for the youth, the adults at the Center are viewed, to a large extent, by them as "guarantors" of their physical safety, as people who protect or "watch over" them and keep potentially dangerous strangers out. As DeAndre told me, "OYC has become like a second home. It's so safe, and a lot of the time when you come here, you feel like you're not even in Overtown.”

I have been told numerous stories about the violence these young people have witnessed in Overtown. What struck me the most about all of the stories is the way in 
which the youth deal with living in that kind of environment. That is, they have shown themselves to be incredibly resilient and they have levels of understanding about it and its consequences that go way beyond their years. They have even thought about and suggested some very credible solutions for dealing with and possibly alleviating some of the violence and crime that surrounds them. The following is what Deborah told me:

The environment in which we're living, there's always drugs and people getting shot, and even if I don't know them myself, it affects all of us, because somebody usually knows that person, and we have to feel the pain that they're feeling. My friend just got shot on Saturday. He got shot in the face, and he died on the scene. And then his friend who was with him got shot in the back and he died Monday in the hospital. It happened at a club that all the teenagers go to on $66^{\text {th }}$ Street and $7^{\text {th }}$ Avenue. It sits right there in a little plaza across from the apartments, and they were coming from the club and they were walking ... there was an altercation at the club, but they got caught up in it, and he [her friend] got shot under the bridge. He was around my age. He just graduated high school last year. I knew him because he went to the same church as me. He was supposed to go to Miami Dade, but he didn't go. He was just at the wrong place at the wrong time. He shouldn't have been there in the first place, especially at 2:00 in the morning.

We hear stories like that in the news almost every day, and the worst part of it is that the two young people she spoke of were innocent bystanders who were shot simply because they were in the wrong place at the wrong time. They had nothing to do with the argument that precipitated the shooting, and at least one of the youth who was killed was someone who would have been on his way to college and to a productive life. Deborah continued the story and brought up an issue that we have also heard a great deal about lately, that of "snitching." Here are some of her observations on that issue:

If a person gets shot around here ... someone knows the person that shot that other person, but they don't want to snitch. But that's not right. If you don't want it to happen again to someone that you know or to one of your loved ones, you have to tell, because it's going to keep on going on, it's not going to stop. And then they have this little gang thing ... it's an altercation between people from what they call "The Swamps" and "The City" [Overtown]... It's just horrible, because we all come from the same place, you know, low income, Black, and lack 
of education .... and yet they are all up there shooting each other, and it's not right. It's really not. And then ... you know who did it, so why don't you tell, so that it doesn't happen to anybody else?

Deborah is saying that it is bad enough that the kind of violence taking place often happens for no real reason, but then what makes it even worse is the fact that those people who could do something to prevent it from happening continue to do nothing to make it stop. Moreover, she said,

Then, later on in life, you're probably going to feel bad, because you know you might have prevented it if you had said something about it. And, now it's too late, and there's another young person who could have been prevented from getting shot. And you didn't say nothing, you didn't speak up, just because you didn't want to snitch ...Yeah. It's not a fairy tale about where we live. It's real. The violence just has to stop. Just because people come from different areas, we're still all going through the same thing. No one's any better than anyone else. We're all living in the same low-income Black families, the same families that go to these African American schools, and they're all out here killing each other, and for what? Nothing at all.

I asked Reginald to describe how it makes him feel to live in Overtown, and this

is what he said:

Overtown - wow - it's a lot - it's crazy. Some people may see it on TV or you hear in the news about people getting killed ... it's dangerous, it's really dangerous, but you have to have that mindset that you don't want to get involved in that. Sometimes you go riding home, and you have to wait down the street because your street is blocked off because there's a chase; or you'll be hanging at home watching TV, and you'll hear gunshots, and you're just like ... it gets to the point where you're just used to it now, and you're like, oh, ok, you're kind of nervous for a while seeing as how close it is. But you hear things every day about things happening in Overtown or in Liberty City, but it's now to the point where it's not even shocking anymore. So it's kind of the norm for the area. It becomes part of like your daily routine, and it's not really shocking to you anymore.

It seems, then, that the way these kids learn to deal with the violence is to make themselves become immune to it, because it comes to be seen as a normal part of living in the neighborhood. "The more we try to make it better," Reginald said, "the more 
people do wrong." He then painted a scenario for me, which, he said, is pretty much of an everyday occurrence.

Like, a kid might just be on the porch playing, or you're walking down the street talking on your cell phone, and someone says, "Hey, I want that, or I want your watch, or I want your ring, or your jewelry ..." And if you even try to defend yourself, that could be your life. So, right now, people are like, if it happens, just give it up, because it's not worth your life, because, nowadays, people will kill you over nothing. Still to this day, walking alone, you're kind of nervous...Say, for instance, I'm walking to the bus stop or something and I see someone walking coming behind me on a bike or something, my initial reaction is to take my ring off and put it in my pocket, or put my cell phone away, just in case someone wants to steal it, because there's always that possibility. It's always in the back of your mind.

Living in that kind of constant fear is certainly not the way most of us would want to see our children growing up; but that is the way it is if you grow up in an area like Overtown.

One day I was at the Center meeting with a few of the high school girls. We were all just sitting around talking about all sorts of things, when Alexis, who I learned has been shuttled around from home to home and is now living with her aunt, started telling us a story about a shooting she had witnessed. Both the content of the story and the nonchalant manner in which she told it were truly frightening to me. She told us about how two of her cousins had been shot right in front of her house and how one of them died in her arms. She also told us that she had been grazed by bullets herself on more than one occasion. She explained about all the gang wars in Overtown and said that her cousins, who were her age (she was 16 at the time) were in a gang and were dealing drugs. Apparently, some of the gang members had something against one (or both) of her cousins. One day they drove by and fired 30 bullets at her cousins while they were standing outside her house. When she heard the bullets fired, she said that she went running out of the door of her house, and that was when her cousin, who had been shot, 
fell down and died in her arms. The last thing he said to her, she told us, was "take care of my kids."

I could not believe the matter-of-fact way in which she relayed such a tragic story. I kept looking at her to see if she would express some kind of emotion or show some sign that she felt something about it, but she did not. She just talked about it as if it was just another everyday occurrence (which, in a way, it was). And that was the part of her story that was the most mind-boggling to me, hearing a 16-year-old girl like her talk about an experience like that with such a total lack of emotion. When I said to her that she has had an awful lot of frightening experiences for someone so young, she replied, “Oh, I've had a lot of experiences like that. I've even had the FBI come to my door a few times." Basically, she said, "there's nothing you can do about the fact that you live in Overtown. You live with your parents or your grandparents or your aunt, and you're not independent, so you just have to get used to it and not let it bother you."

In regard to $\mathrm{OYC}$ being a safe space, Alexis told me that she has been attending OYC since it opened. She has always regarded it as the only means of escape - if only temporarily - from the violence on the streets, the chaos of her home life, and as the only safe place to be in Overtown, which is why she has continued to go there over the years. She also said that, in all the time she's been there, every single kid who's been in the program and graduated from high school has "done something positive with their lives": they have either gone on to college or to getting a good job. She had nothing but tremendous praise for the Center and for the opportunities that it provides those kids who want to take advantage of them. (Alexis just graduated from high school (June 2011), and she will be going into the Air Force Reserve at the end of the summer.) 


\section{Psychological Safety}

Youth also described OYC as an emotionally safe space. It was seen as a place where they could be themselves around both adults and peers who they trusted. As Carlos, another high-school student stated:

It is easy to express myself [at OYC]. Like, I didn't always have to be the funny one. I could be like really serious, if I wanted to, or if I went there one day and, like, I was feeling really sad and ... people would understand that and not give me a hard time. They'd just let me be and leave me alone until I wasn't sad anymore.

The youth also reported feeling comfortable working out many of their personal problems in the context of the Center, because they felt that there were people there who would listen to them and have respect for what they felt and what they had to say. Some of them also mentioned the confidentiality they could count on at the Center, especially when dealing with adults there. That is, they knew that if they told a peer or even an adult at the Center something very personal, he or she would not tell others, unless it was absolutely necessary to protect the child or someone else.

As I have indicated elsewhere in this chapter, many of the Center's youth come from what can best be described as dysfunctional homes. While that does not mean necessarily that there is violence in the home, which the child has to be protected from, the emotional issues that others in the home have could have a negative effect on the behavior of the child. It is an environment such as that which the child might need to find a safe haven from. For example, as Sabrina Jackson told me:

We found out that a lot of our parents can't read, and that's a major problem. A lot of them have emotional issues ... so, now we know why the children have these issues, because the household is dysfunctional. And it's not always a "bad" thing; sometimes there are things that just can't be helped, but a lot of times the parents are too ashamed to try to get help, and the children are the ones who suffer the most. 
What that means for the child is that it is really hard for him or her to develop things like self-esteem, and by extension, any motivation to succeed in school, let alone excel.

In summary, my discussions with youth allowed me to gain a deeper understanding of the meaning of safety for these young people. For most of the youth I spoke with, safety at OYC meant that they were removed from the gangs and other threats that they experienced in their neighborhoods. For others, safety revolved around their feeling comfortable enough to talk about personal problems at home or elsewhere or to let down their guard and just relax. Safety at OYC, then, is not strictly a matter of getting young people off the streets and into a place that is physically safe. There are also the psychological dimensions of safety that were articulated by them.

\section{Building of Self-Esteem}

"At OYC we strive to reflect our beauty both inwardly in our understanding and outwardly in our appearance."

Standard six of the OYC Standards (above), which refers to having self-esteem and a sense of belonging, is another important aspect of the programming at the Center. Without developing a healthy sense of self-esteem, it is doubtful that many of these disadvantaged Black youth would be able to rise above their immediate circumstances to become productive adults. The majority of them have to be taught to believe in themselves and their abilities and taught that they are more than the color of their skin or the environment in which they live.

The Center helps the youth develop self-esteem and self-efficacy either directly, by holding workshops designed specifically for that purpose, or indirectly, by making personal empowerment an integral part of every one of its programs. For example, the 
combination of the many educational and recreational activities offered at OYC, combined with its focus on relationship-building, exposure, and safety all work together to build a strong, resilient character in these youth, which ultimately leads to their feeling empowered and believing in themselves and their abilities. Having that sense of empowerment then enables them to identify and avoid many of the negative influences in their lives and to pursue positive ones instead. In sum, all of those influences combined contribute immeasurably to their feelings of self-esteem and self-efficacy.

Many of these youth take the negative messages they hear every day in their neighborhood, their schools, and sometimes even in their homes, which tell them that they can never accomplish their goals, as a challenge that motivates them to prove their naysayers wrong. For instance, when I asked Deborah if she wanted to return to Overtown after finishing college, and she said, "Yes. I want to show people that I did succeed in life. Everybody who said I couldn't do it, to prove to them that no matter what y'all said, I did it. No matter what obstacles got in my way, I overcame them.” Reginald also expressed that same thought, when he told me that having people tell him that he will never be able to accomplish anything in his life gives him even more motivation to succeed, so he can show them how wrong they were to doubt his abilities. As stated previously, the role that having caring, supportive relationships in their lives is extremely important, as it, too, contributes a great deal to the development of a sense of competence, which then begets feelings of self-esteem and self-efficacy. Sadly, a majority of the youth at OYC get little or no positive input at home. Although one of the goals of the parent program at the Center is to have its culture brought into the home and become a part of the home environment, it is not something that happens quickly or 
easily. Therefore, the youth look to the staff and other adults at the Center to provide them with the positive reinforcement, direction, and sense of self-esteem that they lack.

In the area of academics, before they can hope to succeed in school, they must first believe that they can learn and be successful, and then they have to develop the desire to do so. As Fred has said, "That stuff is the hard part. Once that is taken care of, the academic part will usually just come."

As mentioned earlier, having positive relationships with adults and peers also contributes to the students' feelings of safety. Being in an environment that makes them feel safe makes it far easier for them to then express their emotions freely, try on different identities, and learn new skills. When those things are coupled with the abundant exposure experiences provided by the Center, these students' perspectives on themselves and the world around them is widened exponentially, which, again, adds another dimension to their levels of self-esteem. In sum, knowing who they are and what they are good at is essential to their developing self-esteem. In attempting to drive that message home as often as possible, Alonzo Mourning repeatedly tells the students,

Every one of you here has a talent, and the only way for you to find out what that talent is, is for you to educate yourself. And that's why you were given the tools that you were given to use. You've all got a good brain. You've got a good physical stature. You've got to use all that to your benefit to find out your purpose here. Believe in yourselves and you will succeed.

Many of the students have told me that being at the Center has helped them begin to believe in themselves and their abilities more than anything else in their lives had done before. For example, Jose, one of the high-school boys, said:

At OYC I learned that if you work hard and you push yourself, and you have other people pushing you, you can pretty much do anything you want. And, if I 
can do it, anyone can do it ... Because of OYC, I now feel like I'm on a path to a new horizon.

Following that same train of thought, Reginald said,

Outside in Overtown, it's always negative. People are always telling me I can't do this or I can't do that. But once you step into OYC, it's all positive. They are always telling you that you can do anything you put your mind to.

And Jonathan said, "OYC taught me that whatever I want, I have to go out there and earn. I have to fight for it, no matter what. I learned to not let anyone tell me that I can't do this or I can't do that." Finally, Reginald summed it up perfectly when he said:

They lift you up here. They're always pushing you to go the extra mile. Even if you don't accomplish your goal or you don't win or you don't make it, they'll say, "Well, ok, at least you tried your best," or "What if you didn't try? You wouldn't even have the chance or the opportunity at winning or achieving something." They do so many good things to help with self-esteem here. They make everyone feel worthwhile here. Even if you're not very intelligent, they make everyone see that they have their special talents.

When young people are reminded over and over again that they can do whatever they put their minds to; that even if they did not accomplish a particular goal, they are still winners, because at least they tried; or that there is something special about each and every one of them; they cannot help but feel good about themselves. That feeling will be enough to sustain them and encourage them to keep trying until they succeed.

Many of the parents who participate actively in their children's growth at the Center also recognize the significance of the self-esteem-building aspect of OYC's programming. As Ilya Williams, a parent and an OYC staff member, said to me,

When you're in a positive environment that's full of excitement with nothing but good people surrounding you, like at OYC, your attitude changes ... When you have positive people around you telling you that you can do this, that you can be what you want to be, that you can be like this person you admire, then you have no choice but to believe that's what you can do, to believe in yourself and your abilities. 
In a discussion I had with Fred about the relationship between exposure, the development of self-esteem, and students' aspirations to go to college, he said,

By exposing you to opportunities in and around your city, now all of a sudden, I'm tapping into jobs that I never thought about, I'm tapping into ideas that I never thought about; I'm in places that my mind's never been in; so now my mind is thinking in a completely different way. So, I'm going back home, and now I'm saying, you know what, I do need to graduate. Not only do I need to graduate but I need to go further. I need to go to college or I need to get a trade. I need to do something so that I can get out of this life.

In essence, what he is saying is that you can tell young people that they have to graduate from high school or that they have to go to college, but if they don't know anything about college, or if they have never even really understood the importance of high school, because their parents never graduated from high school, they will probably think, "Why should I care? If I've never known anything other than what's here, why would I want to aspire to anything better?" If they have been conditioned not to care, it is not very likely that they ever will care; on the other hand, if they are conditioned to care, it is far more likely that they will.

Deborah had a great deal to add about the link she perceives between the exposure she has gotten at OYC and the changes she has seen in herself since she started attending the Center. She told me that before she started going to the Center, she really did not care about school or success or much of anything at all. She used to hang around with "the wrong crowd;" she was generally disrespectful and rude, especially to adults; and she took all the negative things that people around her, who she later realized "only wanted to pull her down," told her about how a poor Black kid like her would never amount to anything, completely to heart. But when she started going to the Center, she said that she began to mature. Furthermore, she said that, 
There are people who see that I have so much potential. But I had to learn to see that for myself. I realized that I couldn't keep listening to all the negative things that other people told me. I had to figure out, okay, Deborah, you're smart. Stop listening. Stop hanging around with the wrong crowd, because they're just going to pull you down. You're going to be able to succeed in life. You want to be a lawyer, so get up, and do what you have to do to get there.

Being at the Center, then, helped her to recognize that she was intelligent and that she could, indeed, do whatever she put her mind to. "Whatever I learn," she said, "can't nobody take it away from me. It's in my mind." Furthermore, she said,

OYC taught me that I have to be able to tell myself I can do it. I have to believe in myself. There's not going to be somebody by your side all the time telling you, "You can do it, you can do it, you can do it." You have to have that sense in you that you can do it.

After listening to Deborah's assessment of the need to believe in herself, I

wanted to learn more about what changes, if any, she had seen in her school work and her grades since she started going to OYC. When I asked her about that, she told me:

My grades were usually good, but then, in my ninth grade year, they got pretty bad. I didn't really focus on school. I focused mostly on my friends. I didn't listen in class. I was just talking, and you know, I never did any work, and so my grades dropped. And then when the summer came, when I was in the $10^{\text {th }}$ grade, I started at the Center, and they taught me that you have to take responsibility for yourself, and that if you want to go to college, there are certain things, certain guidelines that you have to follow in school if you want to get there. And then they were giving me all these steps to take so that I could get into college.

Because of the encouragement Deborah got at the Center that summer, when she went back to school the next fall, she said that her grades improved tremendously.

The things that Deborah and the other students told me show what a valuable contribution the Center has made to building self-esteem in these youth as well as how essential self-esteem is to their being successful in school, and by extension, for creating a productive life for themselves once they have finished school. If she had not gotten the 
help she needed to have confidence in her intelligence, Deborah would not have had the resilience necessary to follow her dreams and reach her goals, as she said, no matter what the obstacles might be. No matter how intelligent she or the other youth at the Center might be, without a foundation built on self-esteem, it is likely that they would never be able to reach their true potential.

Of course, not everyone responds to the Center's guidance in the same way that Deborah and some of the other students I interviewed did. In fact, there is not a program in the world that will work with $100 \%$ of the students $100 \%$ of the time. OYC, like every other well-meaning program, will only work for those individuals who truly want it enough to allow it to work.

\section{Effects of Race}

In the first chapter of this research study, I made a number of statements based on ample evidence from the literature in regard to the inequities and inadequacies of the K12 public educational system, particularly when it comes to delivering quality education to Black students living in poor, inner-city neighborhoods like Overtown. I also stated that the harshest reality about our educational system as a whole is evident in its long history of discrimination against Blacks; and that, therefore, there is an overwhelming need to find innovative ways in which to level the playing field in education for these youth. That need is one of the main reasons I chose to make the youth enrichment program at the Overtown Youth Center the object of this research.

While race is certainly not a central focus of OYC's programming, whether OYC's staff or students choose to address it directly or not, it still remains central to 
many of the issues these young people face in their efforts to become better educated and to create successful futures for themselves.

As I stated in Chapter 1 and re-stated in Chapter 2, many critical race scholars in the field of education today believe that racism and racist policies are embedded not only in the American educational system but also in just about every other institution in our society. In many ways, that makes racism an even more subtle and insidious problem for those of us who are socially conscious educators to deal with. Precisely because of what critical race theorists designate as the centrality and intersectionality of race and racism (the permanence of racism), it is, and has always been, central to the experiences of Black people; and thus, it has always played a central role in the structuring of schools and schooling practices for them.

Recognizing that the experiences and stories (or "counter-stories," as they have come to be called) of Blacks have been largely marginalized and silenced, CRT theorists (DeCuir \& Dixson, 2004; Lintner, 2004; Solorzano \& Yosso, 1998, 2001; Stovall, 2004) consider it extremely important to give these people a voice, that is, an opportunity to tell their stories from their own perspectives and in their own words. That is what I have attempted to do throughout this chapter.

One of the questions I asked almost all of my informants in my interviews with them was what they considered to be some of the biggest obstacles to success they faced in their lives. Most of their answers were related to the poverty, crime, and violence in their neighborhood, but there was also always at least an incidental mention of race. For example, Robin, one of the high-school girls at the Center, told me, 
I never accomplished anything before coming here [to OYC]. I always thought I was gonna fail. Everything around me was negative, and I used to think I would never be anything but Overtown - you know, poor and Black. But now I see that I'm way better than the color of my skin or the neighborhood I live in. Now I see that I can go anywhere and I'm not gonna let anything stop me. I'm on the Superior Honor Roll now, and I maintain straight A's and B's ... I never in a million years imagined that I could go to college, but now, I'm doing everything I can to get there.

Malika, one of the girls I have had a number of conversations with, said,

We're always looked down on, you know, because we're Black and because of the neighborhood we live in. I didn't think I could do anything before, but now I believe I can. I love being around kids. I want to be an elementary school teacher one day. I want to be someone who makes a difference in kids' lives.

It is so uplifting to observe young people who were once without much hope for their futures begin to recognize the possibilities available to them. Robin never imagined that she could actually go to college, and Malika found something she was passionate about as well as having gained a desire to do something to help someone else better themselves.

In contrast with many of his peers and most of my other informants, Reginald told me that he always had high self-esteem. He is one of the lucky ones, because he was surrounded with family - his mom, especially - who encouraged him, saw how special he was, and taught him he could do whatever he put his mind to. However, he, too, spoke about some of the negative experiences he has had as a result of racial bias:

But traveling or doing some other things, people often have a pre-judgment about, hey, he's Black, and look where he's come from - Overtown, which equals poor and Black. I know he's not going to be able to do this or that. A lot of people who are Black and grow up in an area like this feel like they will never get out and that they don't really deserve anything more. But I guess I just use this to drive me to succeed, to do something positive, to do the right thing ... you see your friends or you just see people who fall into the poor, Black stereotype, and I know I don't want to fall into that category. So I use the negative things people think and say to prove them wrong or to see the look on their faces when I exceed their expectations. 
While I have rarely heard the majority of the kids at the Center address racial issues directly, as Reginald's and the girls' statements above makes clear, they are aware of the fact that the color of their skin plays a significant role in the opportunities in life - or the lack thereof - afforded them. There are some among them who like Reginald, Deborah, and Robin, to name but a few, use their awareness of the racial prejudice directed at them to drive themselves even harder to realize their dreams.

In the time I have spent working with the students and staff at the Center, it has really surprised me to learn that most of the young people there know virtually nothing about the history of race and racism in the United States or about the ramifications that Black/White relationships in this country have had on their own lives and the lives of their families. While some of them are at least subliminally aware of the bias directed at them because of their skin color, it is not something that they really try to deal with or discuss head-on. I asked both Carla Penn and Fred about my observation, and they both told me that I was right. Carla said,

I find that kids in the inner city, they really don't know much about history. They don't know what happened, where it happened ... They are really always just in the here and now. If you talk to them about anything that happened historically, they are engaged, and they're really interested, but I'm shocked and amazed that they really don't know more. So, that's one of the things that we do at the Center, is we try to teach them, to expose them to more, so they know where they come from and they know the richness of their own culture.

From what I have seen, however, the Center has definitely not done a very good job of accomplishing that. They certainly have not educated them about Black history, and I know that because I have asked the students about it, and whenever I had the chance, I would talk to them about the slave trade or about the Civil Rights movement and so on, 
and they have, indeed been engaged, but they have also told me that they had never been told the things I told them before.

Then Fred explained the following to me,

From the students' perspective, White America doesn't exist in Miami, at least not in the context that they see it. They don't go to school with White kids, not at Booker T., not at Miami Jackson, not at Miami Northwestern, not at Miami High. They go to school with Hispanics that they label "White," so their idea of what is Black and White is what we see here in Miami. They don't know what it's like to go into a school and be really the only person in a particular category. They don't know what that's like.

What I gather from that statement is that the students are so segregated from White society that they do not really know what it is like to be out in a primarily White area or institution and actually stand out because they look different.

Fred went on to say,

It is the job of the Center to educate them about it. They see these films with someone using the "N" word to somebody, and then they get all hyped up. But at the same time, they're calling one another by that word every day. When they're talking to one another and using that kind of language, they're perpetuating that same kind of hatred that people have directed at their ancestors. But I don't think they realize that.

The youth are obviously unaware of the real meaning of racial discrimination or of the "N" word. I have been at the Center when they have shown a group of students a film that portrays racism quite explicitly, but what the Center does not do is engage them in a discussion of the overall meaning of the film after they have seen it. That is something that they really need to do. Perhaps if they were able to analyze those things in a group, they would come to understand what a serious issue racism is and how much it impacts them every day in a very direct way. Once again, it may well be "the job of the Center to educate them about it," but it is one job that they have not done well at all. 
Because I have become painfully aware of that void in their education, in some of my tutoring work with the students, I have attempted to educate them about the history and results of discrimination against Blacks in this country myself. Earlier in this chapter, I discussed the novel by Edwidge Danticat that I used as part of my SAT tutoring program for the OYC students, and the discriminatory feelings that many of them have toward Haitians. I asked Fred to explain that to me, and he told me that prejudice against Haitians or other Blacks whose skin color is lighter or darker than what they recognize as "the norm" is something he always has to deal with them about. Moreover, he told me:

When you say to them, but your last name is Narcisse or something else that identifies them as Haitian, but you don't want anybody to know that, you have to throw that back at them. Instead of looking at it as a negative thing, you could also look at it as a positive. That's another part of who you are. You should want to research it for your own personal understanding. They're around the Haitian culture all the time. Whether they realize it or not, they're being influenced by that culture all the time, but they still feel it's beneath them. And feeling that way, they are losing a part of their identity.

I do not really know how much conversation he has had with the students about their bias against Haitians, but from what I have observed and heard, I would have to say that it has not been enough.

Another question I asked Fred was if he felt that any of the kids thought they were discriminated against because they are Black. He answered,

They might say that they feel discriminated against, but the issues I have heard have been the teacher tends to favor the other students that are of Spanish descent, because the teacher is predominately Spanish-speaking. A lot of the teachers don't speak English that well, so they will automatically favor the Hispanic students. This is the reality. I understand what they're saying. But to go into a school where no one looks like you - they don't know what that's like.

One of the reasons I asked that question is because in the years I have been connected with the Center, I have seen only one or two White people working there; and 
of those, not one was an administrator, coordinator, or teacher. Of the myriad times I have visited the center, $99 \%$ of the time, I have been the only White person there. I mentioned that observation to Sabrina Jackson (Reginald's mother and one of the elementary school coordinators), and she responded, "We should have more White people at the Center here working with the kids. There should be more ... at least three or four more, anyway.” And, Ilya Williams (the other parent and elementary school coordinator I interviewed) said,

It's so important for them to get out into the world and mingle with others so they can understand the diversity that exists in the world. If I could change anything at the Center, that's what I would do ... I'd want to go to more mixed camps or allWhite camps, so we could mix people together, instead of always having them around all Blacks. And even staff - I think we need to have more White staff.

That one-dimensional aspect of the Center is something that has made me wonder what kind of message that sends to the Center's students. Are they being surrounded almost exclusively by Black adults so they will have role models they can relate to most easily? Or, by doing that, is the Center unintentionally teaching them to discriminate against people who do not look like them? Those and other related questions are things that I have not been able to answer for myself satisfactorily, so they remain complex questions that I find bothersome and somewhat frustrating. However, in attempting to give me a degree of perspective on the issue, Fred gave me his take on the mindset of the students themselves: "I think what they [the students] do know is that there are good people all over the world, whether they're Black, White, or purple, that doesn't matter. And when you're looking for good people, the skin tone doesn't really matter. It's a combination of a lot of things." 
In my role as tutor and occasional mentor at the Center, there have been times when I was unsure about how far I should go as a White person when it comes to discussing the subject of race with the students or educating them about it. However, after being reassured that I am right to try to educate them about race and racism, I continue to do so whenever the opportunity arises. I feel that they need to know about their history and their background, where they come from, to prepare them for the time when they go out into the world and encounter a variety of people of different races and cultures. During one of my interviews with Carla (the Center's Executive Director), I expressed my concern over whether or not I was "overstepping my bounds" by trying to expose the youth to those subjects as much as I do. Her reaction was as follows:

I think you're right on target, I think that this generation, for some reason, has missed that very important factor, and I think you're right on target when you continue to expose them to the richness of who they are. I think they are becoming more aware, but I think they definitely need to be exposed to more.

That is something I will continue to do as long as I am affiliated with the Center.

I will close this section with a story that Khiry, a student who was in the first OYC graduating class (June 2007) and is now a student at FIU, told me about what happened to him when he first went off to college. When Khiry was a student at Booker T. Washington high school, he was a very talented athlete, a popular football hero as well as a gifted student. At that time, his lifelong dream was to become a player in the NFL. When he graduated, he received a full football scholarship to William Penn University, a small, private university in Iowa. It seemed to him and his family that his future was set, and he went off to William Penn with high hopes. 
Unfortunately, however, once he arrived at his new school, he found himself faced with some very negative circumstances, which caught him very much off guard. It appeared that, for several years, William Penn University had been granting scholarships to a large number of Black athletes. However, the university had being doing it for only one reason, to satisfy quotas by raising its percentage of Black students.

Khiry had no idea about the real reason for his acceptance into the school, so he fully expected - and rightly so - that his talent would be more than sufficient to earn him a position, possibly as a starter, on the William Penn football team. Most unfortunately, that expectation turned out to be only a pipe dream. The reality was that he found himself sitting on the bench for the entire time he was a student there, constantly being passed over for other athletes who were far less talented than him but who were White.

Needless to say, he had not expected to be faced with the kind of racial discrimination he found on the football team and at the university as a whole, and he was understandably disillusioned, disappointed, and unhappy. He wanted nothing more than to leave the school and return home to Overtown, to his family, and to people who cared about him. Eventually, he did leave but not until he had been at William Penn for an entire year.

When he returned to Miami and found that over one-half of the credits he had taken at that college could not be transferred to Miami-Dade College, the school he planned on attending next, he was beside himself. Nevertheless, he accepted the situation, enrolled at Miami-Dade, and in 2010, earned an A.A. degree.

Khiry is now 22-years-old, and he is a student at FIU. He is still a part of OYC's post-high-school program and still has Fred as a friend and mentor. However, partly 
because of getting a painful, firsthand experience of racial discrimination, and partly because of his relative lack of knowledge about its existence, he has lost a part of himself and his dream, and he now has to totally re-think his options for the future. Playing football, however, is still the only thing he is truly passionate about.

Khiry's story is not entirely negative, however, as he has found a new group of friends and mentors at FIU. At the beginning of the fall 2010 semester, Fred brought him to see me in the hope that I could help him with some difficulties he was having with Admissions and Registration. I spent several hours speaking with him and taking him around the Biscayne Bay Campus to speak with various people who could help resolve those issues for him. To make a long story a bit shorter, although he registered for classes a week late, he did become a full-time FIU student that fall. Then, a month or so after classes started, I introduced him to a friend of mine who offered him a job on the campus. Only time will tell if he will heal completely from the damage his experiences in Iowa did to his hopes for the future and to his psyche, as their imprint on him remains quite palpable to this day.

\section{Summary}

In this chapter I have discussed in detail each of the four features of the OvertownYouth Center that I identified as being particularly valuable to the students' growth: (a) supportive relationships with adults and peers; (b) physical and psychological safety; (c) exposure to cultural and learning experiences; and (d) building of self-esteem. A fifth theme, race, was also identified as a feature closely connected to and underlying the other four. The results I presented in the chapter highlight the meaning and significance that the young people themselves ascribed to each of those 
features as well as the qualities of the Center that invited their sustained participation in its programming. As I will discuss in my final chapter, the need to recognize the absolute interconnection of all five of the elements identified cannot be understated, as improvements in one of those areas will generally bring about improvements in the others.

In regard to the building of relationships with adults at the Center, while it is one of the Center's strengths, there are still a number of problems that, at times, make it difficult to sustain the kind of trusting relationships the Center describes in its vision and mission statements. The main problem in that regard comes from the fact that there is a lot of turnover in the staff, and thus the youth cannot always experience the degree of consistency that is crucial to meeting their needs.

The same thing can be said about the Center's goal of providing supportive, caring adults to mentor the youth. While I had the good fortune to be working with Fred, a person who is the quintessential example of a caring mentor, teacher and father figure, Fred is not typical of the staff at OYC. There are many others working there who do not really seem to care at all.

On the other hand, the Center has been quite successful in the area of peer relationships. These relationships are generally caring, considerate, and respectful; and the students all seem to be very supportive of one another's academic success and drive to succeed.

The kinds of exposure the youth get at the Center are absolutely critical to their growth as individuals and as productive members of society. The experiences the Center 
provides enables the youth to become aware of the vast variety of choices that exist for them and definitely helps them to determine where it is that they belong.

In regard to exposure to educational opportunities, one of the most admirable things about the Center is that it does not try to force education on the students. While it does whatever it can to inspire them to want to go further in their educations, at the same time, it lets each student know that s/he can succeed in other areas, if that is what $\mathrm{s} / \mathrm{he}$ wants.

The other positive aspects of the Center are that, first, it contributes tremendously to the students' sense of physical safety, as it truly is a safe haven, a place where they can go to escape all the chaos that surrounds them; and it also contributes to their psychological safety. Both physical and psychological safety are important components that are associated with positive learning and developmental experiences. Second, it has done an excellent job of building self-esteem and self-efficacy, both of which are essential to success.

Finally, one area that will require a great deal more attention on the part of the Center is its academic component. As noted earlier, it is particularly deficient in the area of educating the youth about their culture and about issues of racial discrimination. 


\section{CHAPTER VI}

\section{DISCUSSION AND RECOMMENDATIONS}

The initial impetus for this research project arose from my understanding of the inequities and inequalities that have existed in the American educational system since its inception. These inequalities are still being experienced today, although far more insidiously, by Black youth living in poor, inner-city areas; and they are still resulting in serious consequences for them. As stated in my introduction (Chapter 1), education has always played a central role in the determination of the life circumstances of Blacks in the United States (Allen, 1998; Freeman, 1998; Ross, 1998). And, it is their access to education, or the lack thereof, which has always been the most significant determinant of their unequal economic, cultural, political, and social status (Allen, 1998; Allen \& Jewel, 1995). It is largely because of their awareness of that fact that Blacks in America have historically struggled to gain equal access to the nation's schools and to exert some degree of control over the content of the schooling process as it relates to them (Allen, 1998).

\section{Review of the Study}

I began this research by examining and placing the educational experiences of today's inner-city Black youth in their historical context. As part of that context, I provided an historical overview of the development of HBCUs and noted that, for the purposes of this study, the most significant element of the HBCUs is their educational climate, or culture. That is because the majority of the research on HBCUs has demonstrated unequivocally that it is their culture, more than any other factor, which is responsible for the success in college of Black students, as measured by such things as 
academic achievement, retention, and persistence to graduation (Kim, 2002; Outcault \& Skewes-Cox, 2002; Rhoads, Saenz, \& Carducci, 2004; Seifert, Drummond, \& Pascarella, 2006; Watson, 1998).

Taking that as a starting point, I then attempted to determine whether we could expect to have the same positive results with the Black youth attending our inner-city public schools if we were to replicate the educational culture of the HBCUs in those schools. While I understand that doing so would likely require a complete overhauling of our entire K-12 public school system, which at this point in time, while most desirable, may be too lofty a goal, I did find that we are at least beginning to recognize the importance of looking at a solution of that magnitude. The establishing of comprehensive youth enrichment programs in our inner-city neighborhoods, such as the Overtown Youth Center, which concentrate on fostering the same type of personal, social, and educational culture as that of the HBCUs, is indeed paving the way and setting the stage for the kind of total transformation I envision as a major part of the ultimate solution to the problem of equalizing the playing field in education and other areas for inner-city Black youth.

After examining the context in which education for Blacks in the United States arose and developed, I noted (in my Purpose Statement) that even such seemingly comprehensive government interventions as the Civil Rights Act of 1964 and the affirmative action policies of the 1960s and 1970s have fallen very short of being able to satisfy the educational needs of the severely underserved Black youth living in our nation's inner-city areas. In addition, I noted that, in the literature (Beck, 1999; Martin et al., 2007), even when attempts to examine the educational needs of these youth have been 
made, the academic underachievement and behavioral difficulties characteristic of many inner-city Black students are blamed, more often than not, on inadequacies of the students themselves - on their intellectual and/or social inferiority, and sometimes even on their biological inferiority - rather than on the social system in which they must live and compete. That is an extremely biased point of view, especially since the real cause of the problem is the system, as it is a system that reproduces unequal societal conditions that lead directly to unequal educational, political, and economic opportunity (Allen \& Jewel, 1995; Artiles, 1998; Baker, 2005; DeCuir \& Dixson, 2004; Freeman, 1999; Noguera, 2003; Ross, 1998).

As educators, it is essential that we attempt to identify and institute innovative alternatives by which to help empower these at-risk youth both academically and psychologically. Youth empowerment programs like the one at OYC, which begins with the premise that we must address the whole person in order to understand the full spectrum of their needs, can and should be used as models for the kind of programmatic interventions we need to enhance public-school education in inner-city neighborhoods throughout the State of Florida, and perhaps eventually, throughout the entire country.

The main focus of my literature review in Chapter 2 was to (a) introduce the reader to the types of youth enrichment programs and community-university-school partnerships currently in place in different parts of the country, and (b) to provide an understanding of how indispensible such programs are as a means of supplementing our public education system, particularly for at-risk, inner-city Black youth.

I began the chapter by looking at the literature on educational culture, paying particular attention to Douglas Guiffrida's (2005) article on the significance of 
othermothering, the mentoring practice he described, which points up the importance of forming close, family-like relationships between students and their teachers and mentors. The kinds of relationships he describes in his article are very similar to both the culture found in HBCUs and the trusting, family-like relationships that form the basis of the relationship model, which is the culture established at the Overtown Youth Center.

It is clear from Guiffrida's (2005) findings and other related findings in the literature (Beck, 1999; Delpit, 1995; Kim, 2002; Martin et al., 2007; Seifert, Drummond \& Pascarella, 2006) that the types of relationships, teaching methods, and biased attitudes about the abilities of Black inner-city youth that are prevalent in many public schools, especially those in our inner cities, have a tremendously negative effect on the way those students feel about themselves, their academic abilities, and their aspirations for the future. Furthermore, many public-school teachers today are completely unaware of the fact that they have biases of that nature; but that lack of awareness is, nevertheless, still reflected in their attitudes toward inner-city Black students, and by extension, in their teaching practices as well.

In the remaining pages of Chapter 2, I examined the effectiveness of the prevention and intervention initiatives described in the literature I reviewed. I found that throughout the literature (Beck, 1999; Cochran et al., 1993; Gardner, et al., 2001; Greenwood et al., 1999; Halpern, 1999) there is unanimous agreement that the most effective means of assisting at-risk Black students today is through the establishment of well-thought-out after-school programs and partnership initiatives. Therefore, one of the things I did in my literature review was to compare the effectiveness of the various programs presented therein with the program model at the Overtown Youth Center, 
which as I stated previously, claims to be having great success in empowering the youth there and in encouraging them to develop a love and respect for education and for giving back to their community.

Chapter 2 concludes with a discussion of critical race theory, which is a powerful theoretical construct that points to the prevalence of racism in every aspect of our society and has been used in recent times to study, understand, and attempt to transform that very destructive social force. I agree completely with the scholars in the field of education today - and scholars in other disciplines as well - who have stated that racism is imbedded in every one of the institutions in America, so much so that it is often invisible, and that our educational system is certainly no exception (Artiles, 1998; DeCuir \& Dixson, 2004; Lintner, 2004; Morris, 2002; Solorzano \& Yosso, 2001; Stovall, 2004).

In that chapter, I stated that one of the ultimate goals of CRT, that of promoting social justice and social change, is also one of the goals of my own work with regard to the American educational system. Critical race theory posits that many of the theories in the educational literature rely for their conclusions on racial characterizations and stereotypes about the inferiority of Blacks. It also posits, as I stated in Chapter 2, that the literature on instructional approaches for Black students often indicates that there is a need for some type of remediation when it comes to these at-risk Black students (BriceHeath, 1993; Delpit, 1995; Martin et al., 2007; Noguera, 2001; Ogbu, 2003; Steele, 1992). Rather than attempting to suggest a solution to the problem, that kind of approach simply leads to a perception on the part of educators that these students are intellectually or otherwise deficient, which, as I have seen firsthand, is more often than not, very far from the truth. 
Therefore, CRT suggests, and I agree, that educational researchers need a different tool with which to examine race and racism in education, one that does not proceed from the same old, tired, biased deficit models. A race-based theory like critical race theory, then, is one such tool, as it provides researchers with a language and a space for people of color to voice their educational experiences from their own points of view (DeCuir \& Dixson, 2004).

Finally, in attempting to explain the role that critical race theory plays in educational research, Solorzano and Yosso (2001) have stated that, "CRT challenges the dominant discourse on race and racism as it relates to education by examining how educational theory and practice are used to subordinate certain racial and ethnic groups" (p. 1). Therefore, I determined that utilizing the methods of CRT in my research and looking at my site and sample population through the theoretical lens of CRT would be the most appropriate research method to follow.

In Chapter 3, I first discussed the major characteristics of the qualitative tradition in research, the tradition in which my study is grounded, and why it is considered the tradition best-suited to the type of study I conducted. To remind the reader, one of the reasons I chose the qualitative research tradition was because it allows for a process to take place that enables the researcher to uncover peoples' perceptions and reactions and thus gain a clearer understanding of how they feel about themselves, about others, and about their experiences and surroundings (Cresswell; 1998; Denzin \& Lincoln, 1994; Miles \& Huberman, 1994; Ross, 1998).

Next, I discussed the meaning and research methods of ethnography, the qualitative methodology used in this research. I explained that the reason for my choice 
of ethnography derived, in large part, from Creswell's (1998) explanation of ethnography as a study of the behaviors of a culture-sharing group by means of extensive (i.e., conducted over a prolonged period of time) work in the field, during which time the researcher becomes immersed in the day-to-day lives of the people being studied, aimed at drawing an in-depth portrait of that group. That is an excellent description of the way in which I conducted my own field work, using primarily participant observation and indepth, one-on-one interviewing as my means of data collection.

In the remainder of the chapter I discussed my role as researcher, the site I selected for the study, how I went about choosing the study's participants, the data analysis procedures I followed, and finally, what I did to maintain the credibility and integrity of the research. In the course of that discussion, I provided justification for all the decisions I made.

In Chapter 4, I provided detailed information about the history and founding of the Overtown Youth Center and the program model it is replicating, that of SelfEnhancement Incorporated in Portland, Oregon. I explained that one of the most significant aspects of that model is the family-like culture it establishes, which is based on the building of relationships (the relationship model) and on the instilling of positive values around which the youth are taught to organize their lives. The relationship model centers on the belief that the building of strong, trusting, loving relationships with peers and adults is the key to the ultimate success of these youth.

I also detailed the ethical and behavioral components of the relationship model, which I found are contained in a set of six values and standards of conduct; and explained that those values and standards prescribe a set of behavioral expectations that are founded 
upon principles of personal integrity and respect for self and others (Overtown Youth Center). That is, the standards are meant to teach the youth the importance of having self-respect as well as respect for others and how to behave in a way that will enable them to co-exist peacefully with others and lead moral and satisfying lives.

Next, I described the role and responsibilities of the Center's coordinators, noting the tremendous responsibility that playing the role of parent, teacher, and mentor for every child in the coordinator's caseload is. I noted also that meeting responsibility of such magnitude requires a very special kind of person, a person who is fully invested in helping these children, a person who really cares, which is not easy to find.

After that, I outlined the basis upon which the students are placed into one of three categories according to the number of barriers to success each one has. I have found that to be a viable system, particularly because it allows for a degree of flexibility. That is, the Center allows for the possibility that a student's status can and often does change, either positively or negatively, depending on his or her individual circumstances at any given time.

Finally, I spoke about the comprehensiveness of the program and the elements that contribute most to making OYC unique. Those include the age range of the participants; the continuity of its programming (i.e., in-school, after-school, weekends, and summers); the wide range of exposure opportunities it provides; its post-high-school follow-up program; and its parent-involvement program.

I began Chapter 5 by sharing the life stories of three of my main student informants, in order to give the reader a sense of the kinds of issues they have had to deal with in their environment and their upbringing. All three of them came from homes in 
which they were raised predominately by a single parent (or grandparent), and they all had very similar experiences with violence and/or drugs in their neighborhood and/or their homes.

I then presented an analysis of the data I gathered from my interviews and observations at the Overtown Youth Center and provided a detailed discussion of the four features of the Center that the youth identified as particularly valuable to their growth, the qualities of the Center they perceived of as being most important to them, and the qualities of the Center that invited their sustained participation in its programming. To refresh the reader's memory, those qualities are: supportive relationships with adults and peers, physical and psychological safety, exposure to cultural and educational opportunities, and the building of self-esteem. In discussing those features, I focused almost exclusively on the meaning and significance that the young people themselves ascribed to each of them. In addition, to provide as full a picture of the Center as possible, I also pointed out the elements of OYC's programming that the students themselves identified as areas that they felt needed improvement.

\section{Discussion of Findings}

In attempting to answer one of my primary research questions, whether or not participating in the program at the Overtown Youth Center contributes to the students' aspirations to attend college, I found that there is no way to answer that question satisfactorily without looking, first, at the variety of other factors that contribute to such aspirations. That is, it is simply not possible to separate a young person's aspirations to attend college from all the other related factors that contribute to creating (or sustaining) those aspirations. For example, such things as developing self-esteem and self-efficacy, 
the formation of positive attitude and behavioral changes, exposure to a wide variety of learning opportunities and cultural experiences, and so on, are all things that steer young people toward increased achievement and adaptive academic and developmental outcomes, without which they would not have realistic aspirations to attain higher education goals.

In Beck's (1999) article about the Manchester Youth Development Center, which I discussed at length in Chapter 2, the author presented a finding very similar to mine (above). That is, in speaking about the academic component of the MYDC program, Beck stated that, "support for academics is the nucleus of the MYDC, and radiating from and toward that nucleus was support for self-actualization, African-American centered programming, and a staff that sought to foster the total growth of the child" (p. 16). In making that statement, Beck was acknowledging the fact that, in order to enhance their educational skills, and hence, their aspirations to go to college and get a good education, these youth need help, first, with developing a sense of self-esteem and a sense of purpose, qualities that the majority of them lacked.

The Overtown Youth Center, while constantly stressing the importance of getting a good education and going to college as one of the main keys to attaining success, focuses, first, on character-building. That is, it recognizes that before the young people it services (inner-city Black youth) can even think or care about academic success, they must first have a sense of self-esteem and self-efficacy. That is, without first developing a positive self-image and a belief that they can transcend the negativity of the environment in which they are growing up, it is very unlikely that these youth would be prone to even consider the importance of education. In other words, it is only after they begin to 
develop a degree of self-respect and self-esteem that they will be ready to think about and understand the importance of education to their overall success in life and be cognizant of its value.

In answer to my research question regarding the experiences of the youth at the Center, I provided a detailed discussion of the wide range of cultural, educational, and other experiences the Center provides, which the participants in my research study unanimously identified as the most significant feature, in terms of expanding their previously severely limited horizons, of the Center's programming. By providing so many varied exposure opportunities for the youth, the Center has definitely helped to enrich their lives and empower them. By awakening them to possibilities in life that many of them had never even imagined before, the Center has made them better equipped to identify those things that are meaningful to them and most relevant to their futures.

In regard to exposure experiences, there were two areas that the students identified as being particularly valuable to them: community service opportunities and educational opportunities. In regard to community service, the students told me that the Center stresses activities that involve giving back to the community in some way, and that those types of activities are the kind that they (the students) feel they get the most out of. Through their participation in OYC's program, they have come to understand that giving something back to their community and to those who have given to them is an essential brick in the road toward their becoming productive citizens. These students have shown me how profoundly they understand that whatever they can do to uplift those around them will make them better human beings in the process. 
A perfect example of that mode of thinking is Deborah's statement about what she wanted to do with the grant money she received for her project. To refresh the reader's memory, she told me that her grandmother used to dream about being able to feed the homeless, and that remembering her grandmother's dream is what inspired her to make that dream a reality. She believed, she said, that she could "realize her full potential by providing a caring heart to people who may need a helping hand." Moreover, she told me that the experience of giving, "not only opened [her] eyes to doing more community-based work, but it also taught [her] the value of working and creating organizations that are [aimed at] making the world a better place." Her obvious dedication to giving back made me think that we, as a society, could not ask for a gift of anything greater from any organization than the fostering in our youth of such a compassionate heart and such a strong drive to help others as that evidenced by Deborah, who many would regard as just another Black face in another dark and hopeless situation.

In regard to the educational opportunities the Center provides, I mentioned several times throughout this study the fact that Alonzo Mourning is a strong proponent of education as a means of providing youth in underserved Black neighborhoods, in particular, with the opportunity to attain "the American Dream." Whenever he addresses the students at the Center, Mourning always stresses the idea that without a good education, it is extremely unlikely that they, as young Blacks living in poverty in the inner city, will ever be able to reach their full potential and be successful, contributing citizens.

In order to follow Mourning's lead, the Center does a great many things to build a love of education in its youth and thus increase their aspirations to go to college. The 
annual college tours, for example, are one important means of empowering the students and motivating them to visualize and then actualize their dreams of reaching highereducation goals. Another source of exposure to educational opportunity that many of the OYC students identified as particularly exciting and motivating for them pertains to their regular visits to FIU's Biscayne Bay Campus. Through my discussions with many of the students as well as some of the staff, I discovered that those visits have definitely increased their interest in education, along with their aspirations to go to college. That is partly because of the assistance with academic skills they receive during their visits, but even more, because of the level of comfort they have attained as a result of getting regular exposure to the university experience.

Thus, an experience that many of them once found off-putting and sometimes even awe-inspiring and frightening is now a very familiar one for them. Through that consistent exposure, then, they have actually become comfortable at FIU and now feel that they could fit in and become a part of any college environment, which is exactly the result I hoped for when I initiated the partnership program. Moreover, it has also helped them to recognize the many possibilities that higher education can open up for them, it has helped to enhance their feelings of self-esteem and self-confidence, and it has helped to prepare them to become college students.

My discussions with the OYC youth also enabled me to gain a deeper understanding of the meaning of safety, both physical and psychological, to these young people (Beck, 1999; Cosden et al., 2001; Gardner, et al., 2001; Halpern, 1992, 1999). All of the participants in the study reported that they view OYC as a safe haven, a safe place that protects them from the violence they face every day on the streets of Overtown. 
They have all told me that being at the Center insulates them to a large extent from the gangs, the drugs, the violence, and all the other threats that exist in abundance on the streets of their neighborhood. Many of them have also reported that they consider it a safe place for them psychologically as well. They have often stated that when they are at the Center they feel comfortable enough to talk about any personal problems they might have at home or elsewhere with staff members and/or with their peers, or to simply let down their guard and just relax.

Overall, then, I have found that the Center has achieved its goals of providing an intermediary space in which these youth can feel physically and psychologically safe enough to experiment; form their own unique identities; make choices; resolve personal crises; and learn to navigate the different worlds of school, family, and neighborhood. Moreover, my own research as well as that of others in the literature (Freeman, 1998; Granger \& Kane, 2004; Halpern, 1999; Hollister, 2003), has identified that overall sense of safety and belonging as being closely associated with positive learning and developmental experiences.

Another area where my findings have shown the Center to be successful is in that of building self-esteem. I have witnessed some amazing transformations in many of the students I have worked with over the years, changes that were due primarily to their having developed greater self-esteem and self-efficacy. In that regard, the Center has helped them both directly, by holding workshops designed specifically for that purpose, and indirectly, by making personal empowerment an integral part of all of its programs.

In sum, I have witnessed how the combination of the many educational and recreational activities offered at OYC, combined with the Center's focus on relationship- 
building, exposure, and safety have all worked together to build a stronger, more resilient character in these youth. The possessing of a resilient character leads ultimately to their empowerment, which then leads to their believing in themselves and their abilities. All of those factors work together to then enable them to identify and avoid many of the negative influences in their lives and to pursue positive ones instead. Furthermore, many of the students have told me that being at the Center has helped them learn to believe in themselves and their abilities more than anything else in their lives had ever done before.

The research I conducted at the Overtown Youth Center has served to both confirm and add to the existing literature on community centers in a number of important ways. First, by sharing in-depth portraits of the life experiences of the high-school students attending OYC and then describing and elucidating on the myriad benefits they, themselves, reported to have attained as a result of their attendance at the Center, my research confirms and supports the contention in the literature that there is a great need for such programs, especially when it comes to inner-city Black youth (Beck, 1999; Cosden et al., 2001; Gardner et al., 2001; Halpern, 1992, 1999; Thurlow et al., 2007).

Second, the most recent outcome figures reported by the Center (2009-2010), which are based on such assessment measures as school attendance, discipline referrals, on-time promotion, high-school graduation, and enrollment in college, show that OYC is having a high degree of success in preparing its students to be successful in school and in their lives after school. For example, the Center's data show the following: $97 \%$ of its students had on-time promotion; $83 \%$ of its third-grade students, and $100 \%$ of its eighthgrade students passed the FCAT; $69 \%$ of its students achieved 95\% school attendance; $67 \%$ of its students received no behavioral/discipline referrals; $100 \%$ of its senior class 
graduated from high school; $100 \%$ of its 2010 graduating class are currently enrolled in college; and $89 \%$ of its post-high students are still attending college.

Those statistics add significantly to the literature, which has been shown to be severely lacking in the area of specific research on ways in which to equalize the playing field for inner-city Black youth (Beck, 1999). In addition, the outcome data above suggest that participating in OYC's programs produced significant differences between those students living in Overtown who participated in OYC and those who did not, thus adding further evidence in support of the need for research such as mine. For example, in spite of the fact that the 2009-2010 FCAT rankings of six of the seven public schools serving Overtown children were graded as "F," with that of the seventh being graded as "C," the vast majority of the OYC students were doing well enough in school to be both promoted on time and graduated from high school on time. And, by way of further comparison, the U.S. Census Bureau statistics (2000) showed that only one out of twelve students in Overtown graduates from high school, and that the high-school graduation rate in the State of Florida is only $47 \%$.

Finally, one of the most significant ways in which this research study will serve to add to the literature lies in the fact that it presents a program that is completely unique to the field. That is, I have found nothing in the literature that outlines a program equivalent to it, in terms of its holistic focus, its comprehensiveness, and its self-containment. Therefore, I am confident that this research will contribute something new to the literature, primarily by suggesting an original and holistic approach to solving what has been acknowledged in the literature and elsewhere as an ongoing, long-term problem. 
Moreover, by means of my in-depth description of the programmatic components of the Overtown Youth Center, I have shown that such programming is needed as a means of supplementing the traditional K-12 education, especially for inner-city Blacks. In addition, the many stories told by my informants have demonstrated that OYC's program is capable of making significant improvements in the self-esteem, academic achievement levels, and aspirations to attend college of these students, who live in one of the nation's poorest and most underserved areas. Overall, then, I contend that this research will make an important contribution to the practice and delivery of education in Florida, and hopefully, in the United States in both the near and more distant future.

As stated previously, while there are a number of programs that provide some of the same services and/or take some of the same approaches to assisting inner-city Black youth as OYC, I have not found a single one that contains all of the elements it does. For example, OYC is the only center with a post-high-school program: no other program follows its students from the time they are in second grade until they reach the age of 25 . Both the GEAR UP grant programs (where the youth come into the program no later than seventh grade) and the Manchester Youth Development Center (which has the children beginning in its program in kindergarten) still only follow them through high school. Another aspect of OYC that makes its program unique is the fact that it is the only program that provides the kind of extensive exposure to educational and cultural opportunities that it does, and it is also the only one that encourages its young people to engage in community service activities - and even provides them with the venues in which to do so. 
Finally, while the other community centers I have looked at often do provide young people with caring adults who can serve as teachers, and possibly, as mentors, OYC is the only program with a culture based on the relationship model. That model, which is centered on the belief that the building of strong, trusting, family-like, relationships with peers and adults is the key to the ultimate success of these youth, is another unique feature of the Overtown Youth Center. In addition to focusing on the building of relationships, the model also contains ethical and behavioral components that serve to instill positive values around which these youth can build their lives. That is, the values and standards of the relationship model prescribe a set of behavioral expectations for the youth that are founded on principles of personal integrity and respect for self and others.

\section{Where Does Critical Race Theory Fit into all This?}

In order to further the discussion of my findings, it is necessary at this point for me to bring into the picture an examination of those findings as they relate to my theoretical framework, which is that of Critical Race Theory (CRT). At several times in the course of this research, I have pointed to the contention of CRT theorists that racism is not an aberration but rather a normal part of American society, that it has become a normal daily fact of life in our society, and that its dogmatic assumptions are so deeply ingrained in our political and legal structures as to be almost unrecognizable (Delgado, 1995; Ladson-Billings, 1996, 1998). The mere fact that enrichment programs like the Overtown Youth Center are necessary as a means of fostering greater equality of opportunity in the education field (and in many other fields as well) for inner-city Black youth bears further witness to the validity of CRT's initial premise. 
In attempting to explain the insidious influence of racism on the everyday lives of the Black youth I have been working with, I must admit that I have at times found it very difficult to be able to verbalize the ways in which they - and I - perceive how deeply their lives have been - and continue to be - impacted by racism. I have also found it difficult to understand just why, when I (and so many of the researchers whose work I have examined here) am so certain of the existence of racism as a constant, underlying detrimental influence on the quality of their lives, have been unable to articulate it clearly.

As a result of agonizing over that very question for some time now, I believe I have finally arrived at, at least a few preliminary explanations with which to better unravel that enigma. First, race, which is a social construct with such powerful social and political implications, has been, in the words of Gloria Ladson-Billings (1996), "so muted (emphasis is mine) in the current multicultural paradigm or so pitted against other subjectivities - particularly class and gender - to render it 'un-discussable' as a difference or a site of struggle" (page 248). Once the veracity of that concept is recognized, one can then see how racism has become even more embedded in our society than at any time in the past.

During the days of slavery, for example, Blacks did not have to wonder what most White people (especially those in our southern states) thought of them. It was generally accepted as "fact" that, by virtue of their supposed lack of intelligence and motivation and their general lack of human qualities, they could essentially be regarded as property and nothing more (and they were generally regarded that way). In the days after the emancipation of the slaves, the venom that was hurled at them every day by southern 
Whites, who did not want them to have any of the liberties that belonged naturally to anyone whose skin color was white, made racism a very obvious fact of life. In the early days of school desegregation, it was quite obvious, once again, that Whites were not about to share their property - their Whiteness - with Blacks, without a fight. In the heyday of the Ku Klux Klan, with its lynching of Blacks, its burning of crosses and of Black people's homes, Black people in America had no trouble identifying their enemy. He was right there in front of them, his hatred completely out in the open. Today, however, racism is far more insidious, far more veiled and hidden, far more embedded within the very heart and soul of the American social, educational, political, and economic systems. As Gloria Ladson-Billings explains it,

That embeddedness or "fixed-ness" has required new language and constructions of race, so that racial denotations are submerged and hidden in ways that are offensive without identification. Thus, when we talk about "gang members," "welfare cheats," "rappers," "basketball players," "drug dealers," we have particular images [in our minds] that are more than stereotypes. Rather, they are coded language for the "threat" we see as Blackness (page 250).

It is no wonder, then, that neither the OYC students nor its staff were able to explain to me, despite my persistent questioning, how they experienced the effects of racism in their everyday lives: it is simply too much a part of them - and of America's understanding of them and of itself - to be readily separated out or easily explained. And, what makes matters even worse for the youth I have spoken with at OYC, is their almost total lack of education about Black history or Black culture or about questions of race and racism in general. That is a topic that I will discuss a bit more later in this chapter.

While in the course of telling me their stories, the OYC students have often expressed their recognition of the fact that the color of their skin is a mitigating force for 
them in this society, they do not seem to have given the problem much serious thought. That has led me to believe that either they do not know how racism manifests itself in their day-to-day lives or they do not know how to explain it, especially since they are exposed only rarely to a predominately White society in their day-to-day lives.

By emphasizing the fact that there is a real need in inner-city Black areas for places like the Overtown Youth Center, and by stressing the fact that such venues are needed precisely because of the deleterious effects that racism has on their everyday lives, this research has attempted to unmask and expose racism in some of its more insidious permutations. I believe that all of the students' stories I have shared with the reader (in Chapter 5) have provided the necessary context for understanding, feeling, and interpreting the role that racism plays in their lives. Whether the students understand it intellectually or not, their experiential knowledge of racism - the ways in which they have been silenced and marginalized solely because of the color of their skin - has been conveyed clearly enough in many of the comments they made to me and the stories they told. Unmasking, through the students' own words, the ways in which our society is so deeply structured by racism will, I hope, be enough to reveal the truth of the contention of CRT theorists that Black people in America share a common history of oppression, which has become inseparable from the American landscape.

\section{Implications for Further Research and Study}

As one way of counteracting the deleterious effects of racism, it has become clear to me, both from my examination of the CRT literature and from my own observations and discussions with the youth at OYC, that there is a tremendous need to provide a different type of training for future educators in our K-12 schools as well as those at OYC 
than that which is currently provided them. Let me speak briefly, first, about the schools attended by the Overtown Youth Center's students. From what many of the OYC students have told me (in both formal interviews and informal conversations), I have learned that there is little or no focus on issues of race in the classroom, nor is there much if any discussion of African-American history or culture there. To ignore an examination of such subjects in our public education system is to deprive all of our students - both Black and White - of a full understanding of their world, which is both unjust and unjustifiable.

When we look at the way that public education is currently configured, it is possible to see the ways that CRT can be a powerful explanatory tool for the sustained inequity that Blacks experience. In regard to curriculum, for example, critical race theory sees the official school curriculum as "a culturally specific artifact designed to maintain a White supremacist master script" (Ladson-Billings, 1998, p. 18). The following is a perfect explanation of precisely what is happening with our school curriculum:

Master scripting is something that silences multiple voices and perspectives, primarily legitimizing dominant, white, upper-class, male voicings as the "standard" knowledge students need to know. All other accounts and perspectives are omitted from the master script unless they can be disempowered through misrepresentation. Thus, content that does not reflect the dominant voice must be brought under control, mastered, and then reshaped before it can become a part of the master script (Ladson-Billings, p. 18).

Thus, the type of curriculum found in our public schools is yet another powerful means by which the educational system enables America's hidden racist agenda to be perpetuated, thus guaranteeing the maintenance of the status quo for yet another generation of young people. 
When it comes to our children's education, then, rather than continuing to "do business as usual," what we must do is bring what is lacking in it into the light, so that it can be seen for what it is - a perpetuation of racism, a means of making sure that our Black children will always feel "less than." Only then will we have any hope of bringing about a degree of social justice, which will then bring about at least the beginning of a transformation of our society, which is something that we need desperately.

There are a number of strategies we can utilize to improve the quality of education for future teachers. One of those is to introduce open discussions about the impact that race has on learning, teaching, and assessment into the education classroom. We also need to train and/or re-train teachers to be more knowledgeable about poor urban areas and the needs of the youth who grow up in them, so that Black students will no longer be characterized as deficient and in need of some kind of remediation. Therefore, we need to devise a conscious strategy by which to weave issues of race into teacher education, so that our future educators will be able to teach racial and ethnic minority students in our inner-city schools effectively, leaving behind any and all attitudes and biases toward them which they may have.

In the meantime, until we can facilitate those kinds of deep reforms, enrichment centers for inner-city Black youth like OYC should be the perfect venues for introducing such topics to the students. Unfortunately, however, I have found that OYC is not doing nearly enough to educate the students about a subject that is so crucial to their development and thus so important for them to be aware of.

As a matter of fact, most of the people at OYC seem hesitant to talk about race or racial issues; and more often than not, they either skirt the issue or just avoid it altogether. 
I perceive that as being a serious problem and something that may well be slowing down the progress that the Center would otherwise be making when it comes to helping its young people to develop self-esteem, self-respect, and strength of character. Rather than avoid the issue, the Center should make the existence of racism very explicit to them, so that they will be able to recognize it, and more importantly, struggle against that particular form of oppression. The leaders at the Center should not hesitate to remind the students that mainstream society expects them to be failures and then should encourage them to succeed as a form of "counterinsurgency." A few of the students I interviewed, most notably, Reginald and Deborah, expressed that very same way of thinking, but knowing them as I do, I tend to believe that such knowledge came from within them rather than from something they learned at the Center.

It is my contention that the mere fact that the Center's leadership shies away from talking about or educating the youth about race serves to further racism rather than rebel against it. I have begun to think that they are embracing some kind of warped support for their own particular brand of "colorblindness," a construct that is utterly rejected by CRT theorists as both a totally irrational idea and as yet another concept used to perpetuate rather than eliminate racism in our society. What I would like to say to the administration of OYC in response to the colorblindness it is unknowingly (I believe) espousing, is that simply ignoring a subject like race/racism, does not make it cease to exist, and it certainly does not make it go away. The only thing that failing to expose the pernicious presence of racism to the young people they claim to want to empower and enrich will do is keep it alive and enable it become even more embedded in our culture than it already is (if that is possible). 
One of the most important contributions that CRT has made to the education field is its exposing of all the ways in which racism is still very much alive in the United States today. If the Center wants to be really successful at empowering the youth, what it needs to do is learn something from CRT and follow its lead. That is, rather than allow the students to ignore its existence, which will ultimately do nothing other than further its deleterious effects on them, the Center needs to bring it into the light, to expose it, and by doing that, help the youth by empowering them with the truth. Allowing those youth to believe that racism does not exist for them is just another way of keeping them oppressed.

There are a great many ways in which the Overtown Youth Center has succeeded admirably in its goal of empowering its youth. However, neither it nor any other program for Black inner-city youth can be totally successful if it does not teach them to understand and appreciate where they came from (their heritage). Only until they are fully cognizant of their roots will they be able to formulate a viable plan for their future.

Because of that understanding, I have taken it upon myself to educate the youth at OYC as much as possible about Black history and culture. The fact that the OYC staff and administration have been supportive of my efforts to do so is an indication that they (a) do have some degree of awareness of the students' needs in that area, and (b) are at least willing to allow those needs to be addressed, albeit by someone outside their immediate circle. Therefore, whenever the opportunity presents itself, I take full advantage of the chance to speak to them about such subjects as the transatlantic slave trade, the Civil Rights movement, the Haitian Revolution, the Black Nationalist Movement, and so on. And when I do, I find that the students are very interested, and become engaged in listening, discussing, and asking questions. 
One final area also related to race that the Center could improve upon substantially is its tendency to surround the youth with primarily Black staff, teachers, and administrators. In all the years I have been connected with the Center, I have seen only one or two White people working there; and of those, not one was an administrator, coordinator, or teacher. In addition, of the myriad times I have visited the center, $99 \%$ of the time I have been the only White person there. That one-dimensional aspect of the Center is something that has made me wonder what kind of message it is sending to the students. Are they being surrounded almost exclusively by Black adults so they will have role models they can relate to easily? Or, by doing that, is the Center unintentionally teaching them to discriminate against people who do not look like them? Or, are they simply trying to insulate or protect them against possibly negative confrontations with White society? Those and other related questions are ones that I have been unable to answer for myself satisfactorily at this juncture, although I have had the feeling that they are engaging in their own form of racism. However, having been unable to find any satisfactory answers to those questions, I would strongly suggest that further research in this area is necessary.

Whatever the answers to the questions above are, the fact remains that between the schools they attend, the neighborhood they live in, and the Center, these students are so segregated from White society that they do not seem to have any idea of what it is like to be out in the world and be the only person who looks different from everyone else. Therefore, it is incumbent upon the Overtown Youth Center - and upon all such centers whose goal it is to enrich and empower the lives of inner-city Black youth - to fill that very significant void in their educational and cultural field. Perhaps one way in which 
they can accomplish that is by instituting the same kind of additional training I suggested previously for K-12 teachers. Although the staff is trained continually on how to replicate the relationship model and create that family culture that the Center espouses, that is obviously not enough. They should also be trained on compassionate but realitybased ways in which to discuss the problems of race and racism with the students in a non-confrontational, professional manner. This, too, suggests an area in which further research would be most beneficial to OYC.

\section{Some Additional Challenges for OYC}

Another problematic issue I found with the Overtown Youth Center is that of staff turnover, and particularly, the way in which it affects the OYC students. Almost every one of the students I spoke with expressed concern - and often dismay - about what they perceived as the frequent turnover in the staff at the Center. Given the importance the Center places on the building of close, trusting relationships with adults, I am astonished that it does not do more to limit such turnover, as it obviously presents real challenges for the youth there.

One of the reasons I have found for this turnover is something that almost everyone I spoke with at the Center pointed to when I asked them what they thought was the biggest obstacle to the success of the program. That is, they all named what they called "internal issues" as the biggest obstacle. What they meant by internal issues is that it is the relationships among the different staff members and administrators that cause the greatest problems. Such things as jealousies, favoritism, family members employed just because they are family, church members working there just because they go to the same 
church as an administrator, and so on, are the sources of most of the staff/administrator problems and of much of the staff turnover.

In one of my interviews with him, Fred Rosario, the high-school coordinator at the Center, told me that, "the staff and administration are very cliquey," which, he explained, is simply what happens when you have family members and people who are in relationships with one another working in the same place. It is easy to see how that kind of situation could serve to create serious conflicts of interest.

The problem of turnover, then, should be seen as a challenge, not only for OYC, but also for the broader youth development programming field to address. Aside from causing emotional upheavals among the participating youth, it also relates to many other problematic issues. Some of those are professional credentialing; the limited salary structure for community nonprofit work; and the youthfulness of many staff members, who are still figuring out their careers and who may well be working in the field, not because they care about helping youth, but rather, because they need a paycheck. I have learned that those types of constraints present challenges for just about all communitybased programs and are frequently the reason why some students attend them irregularly or not at all. Therefore, as the after-school field develops, greater attention will need to be paid to developing and retaining talented and caring youth workers, especially those who grew up in the community that a particular program serves.

Another related challenge that needs to be addressed at OYC and other programs similar to it is the lack of consistency on the part of the students in regard to their attendance at the Center. In my own interactions with the students, I have found that lack of consistency to be not only frustrating for me - and for those youth who do attend 
regularly - but also counterproductive to what I am trying to accomplish with them. For example, when I have tried to have a group continue with a particular reading we are working on, I can never count on the same students being in attendance at the sessions from one week to the next. Therefore, for example, in trying to read an entire book with a group, rather than being able to progress, I end up having to repeat the same material over again every time we meet, in a constant attempt to bring the students who were not present the week before up to speed. Needless to say, that inconsistency makes progress on any given project extremely slow.

Moreover, for those students who are truly engaged in learning, that kind of repetition can make them so frustrated that they may lose interest in the learning process altogether. It is my contention, then, that this is the main reason the academic portion of the program is, as some of the staff and administrators - and even some of the students at the Center have told me, its weakest link. It is also one of the main reasons, along with frequent staff turnover, why many students lose interest in the Center and simply stop attending it.

My contention is supported by the findings of a majority of the studies I have reviewed. While they have all established that structured after-school programs are significant contexts for youth development, many of them, including some of the recent evaluations of large-scale after-school initiatives (Granger \& Kane, 2004) have yielded mixed results. That is, they found that while the programs have had some impact on students' attitudes toward school, the impact on their academic performance has been limited. 
Another problem that many of the students, staff, and administrators have spoken to me about is the fact that the Center is often inconsistent when it comes to adhering to the classes or activities that the students are scheduled for, which makes the Center often chaotic and hectic. For example, Carla Penn told me that during the summer, the Center schedules an education component in the mornings from 9 a.m. until noon to help with the students' retention of what they learned during the school year. However, if a donor decides that $\mathrm{s} / \mathrm{he}$ wants to introduce an arts program during that time period or to give the kids a pizza party, the Center will defer to the wishes or dictates of the donor rather than maintain its original schedule of events.

The above is another reason for the weakness of the Center's academic program. However, it could be remedied, or at least ameliorated, if the Center were to be more cognizant of how important keeping to its schedule actually is to the youth as well as to the volunteers who go there to work with them. Not only would doing so create a less chaotic atmosphere at the Center, but it would also serve to show the students, by its own example, how important it is for one to take responsibility for one's actions. When dealing with young people, especially, the importance of structure and the need to make and honor commitments cannot be emphasized enough. There can be no structure when a schedule is so readily subject to change.

One clear conclusion of all the negatives pointed to above in regard to attendance at the Center is that, how often and for how long young people spend time in these afterschool settings has a great deal to do with the outcomes of the programs. In other words, no program can make a difference if it does not change the daily experiences of the participants, and it cannot do that if attendance is poor. Although that finding may seem 
obvious - and is certainly not surprising - it does underscore the importance of knowing what aspects of after-school settings young people find engaging.

\section{Some Additional Areas of Success for OYC}

One issue that many youth centers have struggled with is how to maintain the interest of youth as they move into adolescence. In the course of this research, I have learned how much older students are drawn to programs that are geared specifically for their particular age group. OYC's programming demonstrates a high level of cognizance of that fact, and thus, time and space are set aside on a daily basis to allow for informal community building among peers. The high-school students are allowed significant time to interact among themselves for both informal and formal activities. Opportunities of that nature combined with the myriad exposure opportunities they are provided with are among the most significant reasons for the Center's ability to maintain the interest of the adolescents in its program.

Another extremely attractive aspect of the Center for the high-school students, in particular, is the fact that it offers them an abundance of programs that enable them to develop the kinds of career and academic skills they will need to become successful citizens. More than any other age group, this group is motivated by instrumental, futureoriented goals, such as gaining job skills and building their resumes, both of which types of activities are available in abundance at OYC.

The findings of this study suggest that OYC does serve as a unique developmental niche for its youth. It meets many of their needs, needs that are not often met in their schools and are never met in their neighborhoods. My findings suggest that, overall, OYC has been able to make a difference in the lives of these Black youth, who have been 
described as at-risk, because it has served to fill many critical gaps in their emotional, social, and academic needs. The niche metaphor also underscores the interrelationships between themes that were reported by many of the youth I interviewed and observed. As an example of such interrelationships, I have shown the way in which the kinds of supportive relationships formed with peers and adults at OYC contribute to the students' sense of safety; which in turn, cultivates a caring, motivating space in which they can express their emotions, try on new identities, and learn new skills.

Finally, youths' descriptions of their experiences at OYC suggest that, as researchers and evaluators, we should broaden our ideas of "success" and "impact" in evaluating after-school programs. For inner-city Black youth in particular, the benefits of comprehensive empowerment programs like OYC are far from being related solely to academically-oriented outcomes. Rather, participation fulfills more of their fundamental developmental needs. That is, benefits of participation stem from the very qualities that are rare in school and in the neighborhood, such as informal relationships with adults and opportunities for open-ended inquiry.

As my interviews with the students and staff have indicated, meeting young peoples' broad developmental needs and engaging them in creative and productive activities are important precursors to academic success. In addition, the fact that the Center is aware that not every child is capable of being a college student and therefore works within the parameters of each individual student's capabilities and passions is another one of the more positive things that the Center does. That kind of awareness is one of the strongest qualities of the Center and one of the reasons for the Center's overall success. 
As stated previously, OYC is not a typical after-school program. It is not simply an extension of the school day. What it does is provide a core developmental context that must be assessed according to the full spectrum of the developmental needs of the young people it services. Moreover, the wide range of exposure opportunities the Center provides are invaluable to the growth of the whole individual and could rarely if ever be experienced by most of the students if it were not for the intervention of the Center.

\section{Limitations of the Study}

While the findings of this study do provide critical perspectives about the importance of centers like OYC, we must always be careful about generalizing from individual case studies; and certain of the design features of this study could limit its generalizability to other settings and contexts. For example, the sample of youth who participated in the research was primarily those who enjoyed spending time at the Center and participating in its activities. Some of them were recommended to me by Fred, the high-school coordinator, as good subjects. Although I also spoke with and/or observed several youth who attended the Center less frequently than my main informants, my conclusions might have been stronger if I had interviewed more young people who attended the Center with less frequency. In spite of that, I still believe that my focus on the descriptions of the experiences and feelings provided by the youth I interviewed and observed have helpful implications for further practice and research, and I contend that the field can learn a great deal from both this study and the cumulative weight of multiple studies comparable to it. 


\section{Some Final Thoughts}

When I first began the partnership I initiated with the Overtown Youth Center and FIU almost 5 years ago, I had no idea that it would come to mean as much to me as it has, or that it would become the subject matter for this dissertation. While I was really excited about the many possibilities that embarking on a path that was so new to me would open up, I could not have imagined how integral a part of my life it would become. But after working with the OYC kids, watching them grow, and watching them become more and more engaged in learning and in expanding their once very limited horizons, I realized that I had truly found my passion in life, a passion that will continue to grow and has already given a whole new meaning to my life. And for that, I am very grateful. It is really true that nothing feels better than making a difference in someone's life - and in the course of my work with the OYC kids, I know that I have, indeed, made a difference.

Most change comes about very slowly, very gradually, but by working patiently and persistently with one child at a time, the change one aims for will eventually be realized. The hope here is that initiatives like the Overtown Youth Center will gather a momentum around them, a momentum that will eventually sweep more and more people of vision along with it until it becomes a veritable movement. The statement made many years ago by Hillary Clinton that "it takes a village" is so true, and a village is precisely what the Overtown Youth Center is trying to provide for the hundreds of underprivileged youth it serves in the neighborhood of Overtown.

We, as the privileged members of an academic community, have so much to offer to this effort, but many of us are simply not interested in doing so. We have to become 
more caring, more compassionate, more willing to give of our time, effort and knowledge. We must recognize that we cannot afford to allow the children - all the children - who represent the future of our entire world fall by the wayside, to be forgotten, to go to waste. We need to help every one of them to fulfill their potential, to tap into all the possibilities that exist for them, if we are to have any hope of creating a future worth living for. And to do that, we need everyone in our privileged little community to show them that we care about them.

One of the primary goals of the partnership I forged with OYC, which is also among the central goals of the Overtown Youth Center, is to encourage the OYC youth to want to go to college and to believe that they are capable of doing so. After long-term observation and the conducting of numerous interviews of OYC administrators, staff members, and students, it is evident to me that this youth enrichment program has made very definite progress toward accomplishing that goal. The Center provides its youth with supportive relationships, warmth and affection, constant exposure to cultural and intellectual experiences, and a consistent, repeated exposure to the college environment, all of which work together to help these underprivileged, underserved young boys and girls reach their full potential.

Those of us in academia here at FIU - and at all institutions of higher education, for that matter - are in a unique position to be at the forefront of the kind of transformative change that I envision. We certainly have all of the tools that are needed to facilitate the kinds of changes of which our inner-city youth are so desperately in need. But, before we can utilize those tools for such a lofty purpose, we must first become more sensitive to their needs; we must become more caring, more compassionate human 
beings. We can no longer afford to remain insulated from the pressing needs of all our youth, rich and poor, Black and White. We must shift our primary emphasis from doing research for its own sake, and focus, instead, on the kind of applied research that can bring about a total transformation of our educational system. It is through compassion and unity - joining together as one - that we will be able to succeed in uplifting our youth. My ultimate vision is to help facilitate just such a united effort. Unfortunately, Overtown is far from being the only neighborhood of its kind in our community or in South Florida - or for that matter, in our nation. And, while the kind of transformative change I envision may come relatively slowly; with patience, persistence, and the help and cooperation of other capable, caring individuals, it will come. We can make it happen. Therefore, it is my hope that recognition of the accomplishments of this individual initiative will provide a momentum capable of inspiring others and of sweeping them along with me in a river of change that flows from an ocean of compassion. 


\section{LIST OF REFERENCES}

Adler, P.A., \& Adler, P. (1994). Observational Techniques. In Denzin, N.K., \& Lincoln, Y.S. (Eds.), Handbook of qualitative research. Thousand Oaks, CA: Sage.

Allen, W.R. (1998). And who shall control their minds?: Race consciousness and collective commitments among African American students. In K. Freeman (Ed.), African American culture and heritage in higher education research and practice. Westport, CT: Praeger.

Allen, W. R., \& Jewel, J. (1995). The mis-education of Black America. Daedalus, 124(1), 77-100.

Allen, W. R., \& Jewel, J. (2002). A backward glance forward: Past, present and future perspectives on historically Black colleges and universities. The Review of Higher Education, 25(3), 241-261.

Anderson, J. (1988). The Education of Blacks in the South, 1860-1935. Chapel Hill: University of North Carolina Press.

Arroyo, A.A., Rhoad, R., \& Drew, P. (1999). Meeting diverse student needs in urban schools: Research-based recommendations for school personnel. Preventing School Failure, 43(4), 145-153.

Artiles, A.J. (1998). The dilemma of difference: Enriching the disproportionalitry discourse with theory and context. The Journal of Special Education, 32(1), 3236 .

Atkinson, P., \& Hammersley, M. (1994). Ethnography and participant observation. In Baker, P. (2005). The impact of cultural biases on African American students' education: A review of research literature regarding race-based schooling. Education and Urban Society, 37(3), 243-256.

Beck, E. L. (1999). Prevention and intervention programming: Lessons from an after-school program. The Urban Review, 31(1), 107-124.

Bergin, D., Hudson, L., Chryst, C., \& Resetar, M. (1992). An afterschool intervention program for educationally disadvantaged young people. The Urban Review, 24, 203-217.

Berliner, D.C., \& Biddle, B.J. (1995). The manufactured crisis. New York, NY: Longman.

Bogdan, R.C., \& Biklen, S.K. (1982). Qualitative research for education: An introduction to theory and methods. Boston, MA: Allyn \& Bacon. 
Bolvin, J.O. (1995). The Manchester youth development center. Unpublished.

Bourdieu, P. (1977a). The cultural transmission of social inequality. Harvard Educational Review, 47, 545-555.

Bourdieu, P. (1977b). Cultural reproduction and social reproduction. In J. Karabel \& A.H. Halsey (Eds.), Power and ideology in education. New York, NY: Oxford University Press.

Bowen, W.G., \& Bok, D. (1998). The shape of the river: Long-term consequences of considering race in college and university admissions. Princeton, NJ: Princeton University Press.

Brice-Heath, S. (1983). Ways with words: Language, life and work in communities and classrooms. New York, NY: Cambridge University Press.

Brown, Elaine (2002). The condemnation of Little B: New age racism in America. Boston, MA: Beacon Press.

Brown, M. C. (1999). The politics of industrial education: Booker T. Washington and Tuskegee State Normal School, 1880-1915. The Negro Educational Review, 50(34), 123-128.

Brown v. Board of Education, 347 U.S. 483. (1954). Retrieved December 6, 2005, from http://www.nationalcenter.org/brown.html

Bullock, H.A. (1967). A history of Negro education in the South: From 1619 to the present. Cambridge, MA: Harvard University Press.

Chang, M.J. (1999). Does racial diversity matter? The educational impact of a racially diverse undergraduate population. Journal of College Student Development, 40, 377-395.

Chang, M.J. (2000). Improving campus racial dynamics: A balancing act among competing interests. The Review of Higher Education, 23, 153-175.

Chang, M.J. (2002). Preservation or transformation: Where's the real educational discourse on diversity? The Review of Higher Education, 25, 125-140.

Children's Defense Fund (2000). Leave no child behind: The state of America's children. Washington, DC

Clark, M. (1991). Social identity, peer relations, and academic competence of AfricanAmerican adolescents. Education and Urban Society, 24(1), 41-52. 
Cochran, L.L., Feng, H., Cartledge, G., \& Hamilton, S. (1993). The effects of cross-age tutoring on the academic achievement, social behaviors and self-perceptions of low-achieving African American males with behavioral disorders. Behavioral Disorders, 18, 292-302.

Comer, J. (2004). Leave no child behind: Preparing today's youth for tomorrow's world. New Haven, CT: Yale University Press.

Cosden, M., Gutierrez, L., \& Morrison, G. (2004). The effects of homework programs and after-school activities on school success. Theory into Practice, 43(3), 220226.

Cosden, M., Morrison, G., Albanese, A.L., \& Macias, S. (2001). When homework is not homework: After-school programs for homework assistance. Educational Psychologist, 36, 211-221.

Crabtree, B.F., \& Miller, W.L. (Eds.). (1992). Doing qualitative research, $2^{\text {nd }}$ Ed. Thousand Oaks, CA: Sage.

Creswell, J.W. (1998). Qualitative inquiry and research design: Choosing among five traditions. Thousand Oaks, CA: Sage.

DeCuir, J.T., \& Dixson, A.D. (2004). So when it comes out, they aren't so surprised that it is there: Using critical race theory as a tool of analysis of race and racism in education. Educational Researcher, 33(5), 26-31.

Delgado, R. (1995). The Rodrigo chronicles: Conversations about America and race. New York, NY: New York University Press.

Delpit, L. (1995). Other people's children: Culture conflict in the classroom. New York, NY: New Press.

Demaine, J. (2003). Social reproduction and education policy. International Studies in Sociology of Education, 13(2), 125-140.

Denzin, N.K., \& Lincoln, Y.S. (Eds). (1994). Handbook of qualitative research. Thousand Oaks, CA: Sage.

Denzin, N.K., \& Lincoln, Y.S. (Eds.) (1998). The landscape of qualitative research: Theories and issues. Thousand Oaks, CA: Sage.

Denzin, N.K., \& Lincoln, Y.S. (Eds.) (2003). Strategies of qualitative inquiry, $2^{\text {nd }}$ Ed. Thousand Oaks, CA: Sage. 
Dyson, Michael E. (2005). Is Bill Cosby right?: Or has the Black middle class lost its mind? New York, NY: Basic Civitas Books.

Dyson, Michael E. (2008). April 4, 1968: Martin Luther King, Jr. 's death and how it changed America. New York, NY: Basic Civitas Books.

Ferrarotti, F. (1981). On the autonomy of the biographical method. In D. Bertaux (Ed.), Biography and society: The life history approach in the social sciences (pp. 1927). Beverly Hills, CA: Sage.

Freeman, K. (Ed.) (1998). African American culture and heritage in higher education research and practice. Westport, CT: Praeger.

Freeman, K. (1999). No services needed? The case for mentoring high achieving African-American students. Peabody Journal of Education, 74(2). Retrieved on June 8, 2007, from http://vnweb.com.ezproxy.fiu.edu/hww/results

Gardner, R., III; Cartledge, G.; Seidl, B.; Woolsey, G., Schley, S., \& Utley, C. (2000). Mt. Olivet after-school program: Peer-mediated interventions for at-risk students. Remedial and Special Education, 22(1), 22-33.

Gaining Early Awareness and Readiness for Undergraduate Programs (GEAR UP). Retrieved on April 9, 2008, from http://www.ed.gov/programs/gearup/.

Gelles, R. (1992). Poverty and violence toward children. American Behavioral Scientist, $35,258-274$.

Gold, R. (1958). Roles in sociological field observations. Social Forces, 36, 217-233.

Granger, R.C., \& Kane, T.J. (2004). Improving the quality of after-school programs. Education Week,14, 76.

Greenwood, C.R., Delquadri, J., \& Hall, R.V. (1989). Longitudinal effects of classwide peer tutoring. Journal of Educational Psychology, 86, 376-383.

Guba, E. (1978). Toward a method of naturalistic inquiry in educational evaluation. Los Angeles: Center for the Study of Evaluation.

Guiffrida, D. (2005). Othermothering as a framework for understanding AfricanAmerican' students' definitions of student-centered faculty. The Journal of Higher Education, 76(6), 701-723.

Halpern, R. (1992). The role of after-school programs for low-income children: Promise and challenges. The Future of Children, 9, 81-95. 
Halpern, R. (1999). After-school programs in the lives of inner city children: A study of the "urban-youth network." Child Welfare, 72, 215-230.

Hawkins, R.P., \& Mathews, J.R. (1999). Frequent monitoring of clinical outcomes: Research and Accountability for clinical practice. Education and Treatment of Children, 22, 117-135.

Henderson-Sparks, J. (2002). Student teacher preparation: A collaborative model to assist at-risk students. Preventing School Failure, 46(2).

Hernandez, T.K. (2003) Comparative judging of civil rights: A transnational critical race theory approach. Louisiana Law Review, 62(3), 875-886.

Hollister, R. (2003). The growth in after-school programs and their impact. Brookings Roundtable on Children. Paper commissioned by the Brooking's Institute for the Children's Roundtable, February, 2003.

Hurtado, S. (1996). The campus racial climate: Contexts for conflict. The Journal of Higher Education, 63, 539-569.

Jost, M., Whitfield, E.L., \& Jost, M. (2005). When the rules are fair but the game isn't. Multicultural Education, 13(1), 14-21.

Kagan, J. (1991). Etiologies of adolescents at risk. Journal of Adolescent Health, 12, 591-596.

Kim, M. M. (2002). Historically Black vs. White institutions: Academic development among Black students. The Review of Higher Education, 25(4), 385-407.

Kopp, C.B., \& Kopp, J.B. (1983). The developmentalist and the study of biological risk: A view of the past with an eye toward the future. Child Development, 54(5), 1086-1108.

Kuh, G. D., and Whitt, E. J. (1988). Culture in American colleges and universities. In Brown, M.C., Ed., Organization and governance in higher education, $5^{\text {th }}$ Ed. Boston, MA: Pearson Custom Publishing, 160-169.

Kvale, S. (1996). Inter Views: An introduction to qualitative research interviewing. Thousand Oaks, CA: Sage.

Ladson-Billings, G. (1996). "Your blues ain't like mine": Keeping issues of race and racism on the multicultural agenda. Theory into Practice, 35, 248-255.

Ladson-Billings, G. (1998). Just what is critical race theory and what's it doing in a nice field like education? Qualitative Studies in Education, 2 (1), 7-24. 
Lee, W. Y. (2002). Culture and institutional climate: Influences on diversity in higher education. The Review of Higher Education, 25(3), 359-368.

Lincoln, Y.S., \& Guba, E.G. (1985). Naturalistic inquiry. Beverly Hills, CA: Sage.

Lintner, T. (2004). The savage and the slave: Critical race theory, racial stereotyping and the teaching of American history. Journal of Social Studies Research, 28(1), 2732.

Magee-Andrews, R.V. (2003). Affirmative action after Grutter: Reflections on a tortured death, imagining a humanity-affirming reincarnation. Louisiana Law Review, 63(3), 705-716).

Marshall, C., \& Rossman, G.B. (1995). Designing qualitative research. Thousand Oaks, CA: Sage.

Marshall, N.L., Coll, C.G., Marx, F., McCartney, K., Keefe, N., \& Ruh, J. (1997). After school time and children's behavioral adjustment. Merrill-Palmer Quarterly, 43, 497-514.

Martin, D., Martin, M., Gibson, S.S., \& Wilkins, J. (2007). Increasing prosocial behavior and academic achievement among adolescent African American males. Adolescence, 42(168), 689-698.

Mayer, S., and Jencks, C. (1989). Growing up in poor neighborhoods: How much does it matter? Science, 17, 1441-1445.

Mayers, C.M., \& Schnorr, D.L. (2003). Getting it together: Effective strategies for university/school partnerships. Education, 124(1), 108-114.

McComb, E.M., \& Scotts-Little, C. (2003). After-school programs: Evaluations and outcomes. Greensboro, N.C.: The Regional Educational Laboratory at SERVE.

McWhirter, J.J., McWhirter, B.T., McWhirter, A.M., \& McWhirter, E.H. (1998). At-risk youth: A comprehensive response ( $2^{\text {nd }}$ Ed.). Belmont, CA: Brooks/Cole.

Merriam, S. B. (1998). Qualitative Research and case study applications in education. San Francisco: Jossey-Bass.

Miles, M.B., \& Huberman, A.M. (1994). Qualitative data analysis: A sourcebook of new methods $\left(2^{\text {nd }}\right.$ ed.). Thousand Oaks, CA: Sage.

Miller, B. (2001). The promise of after-school programs. Educational Leadership, 58(7), 6-12. 
Morris, J.E. (2002). African American students and gifted education: The politics of race and culture. Roeper Review, 24(2), 59-62.

Morris, M. (1992). The complex nature of intervention. In Goddard, Ed., AfricanAmerican youth at high risk work group: An African-American centered model of prevention for African-American youth at high risk. Rockville, MD: U.S. Department of Public Health and Human Services Administration Series Public Health Service Substance Abuse and Mental Health.

National Research Council (1993). Losing generations: Adolescents in high-risk settings/Panel on high-risk youth, Commission on Behavioral and Social Sciences Education. Washington, DC: National Academy Press.

Natriello, G., McDill, E.L., \& Pallas, M. (1990). Schooling of disadvantaged children: Racing against catastrophe. New York, NY: Teacher's College Press.

Noguera, P. (2001). Racial politics and the elusive quest for excellence and equity in education. Education and Urban Society, 34(1), 18-41.

Noguera, P. (2003). The trouble with black boys: The role and influence of environmental and cultural factors on the academic performance of African American males. Urban Education, 38(4), 431-459.

Ogbu, J. (1993). Origins of human competence: A cultural perspective. Child Development, 52, 413-429.

Ogbu, J. (1995). Cultural problems in minority education: Their interpretations and consequences. The Urban Review, 27, 189-205.

Ogbu, J. (2003). Origins of human competence: A cultural perspective. Child Development, 52, 413-429.

Outcalt, C. L., \& Skewes-Cox, T.E. (2002). Involvement, interaction, and satisfaction: The human environment at HBCUs. The Review of Higher Education, 25(3), 331-347.

Overtown Youth Center. Retrieved on April 18, 2007, from http://www.overtownyouth.org.

Pascarella, E.T., \& Terenzini, P.T. (2005). How college affects students: A third decade of research ( $2^{\text {nd }}$ ed.). San Francisco, CA: Jossey-Bass.

Patton, M. Q. (1990). Qualitative evaluation and research methods, 2nd Ed. Newbury Park, CA: Sage. 
Posner, J., \& Vandell, D. (1994). Low income children's after-school care: Are there beneficial effects of after school programs? Child Development, 65. 440-457.

Rhoads, R.A., Saenz, V., \& Carducci, R. (2004). Higher education reform as a social movement: The case of affirmative action. The Review of Higher Education, 28(2), 191-220.

Ross, M.J. (1998). Success factors of young African-American males at a historically black college. Westport, CT: Bergin \& Garvey.

Rossides, D.W. (2004). Knee-jerk formalism: Reforming American education. The Journal of Higher Education, 75(6), 667-703.

Rush, S., \& Vitale, P.A. (1994). Analysis for determining factors that place elementary students at risk. Journal of Educational Research, 87, 325-333.

Ruud, B. (2008). K-12: A whole university partnership. Proteus, 25(1), 3-4.

Saddler, C.A. (2005). The impact of Brown on African American students: A critical race theoretical perspective. Educational Studies (AESA), 37(1), 41-55.

Schuman, D. (1982). Policy analysis, education, and everyday life. Lexington, MA: Heath.

Schutz, A. (1967). The phenomenology of the social world (G. Walsh \& F. Lembert, Trans.). Chicago, IL: Northwestern University Press.

Schwartz, D.C., \& Pace, D. (2008). Students create art: Expanding an after-school program. Teaching Exceptional Children, 40(4). 50-54.

Seidman, I. (2006). Interviewing as qualitative research ( $3^{\text {rd }}$ ed.). New York, NY: Teacher's College Press.

Seidman, S. (1998). Contested knowledge: Social theory in the post-modern era. Oxford: Basil-Blackwell.

Seifert, T.A., Drummond, J., \& Pascarella, E.T. (2006). African-American students' experiences of good practices: A comparison of institutional type. Journal of College Student Development, 47(2), 185-205.

Self-Enhancement Incorporated. Retrieved on February 21, 2009, from http://www.selfenhancement.org.

Silverman, D. (2000). Doing qualitative research: A practical handbook. Thousand Oaks, CA. Sage. 
Smith, R.A. (2004). Saving black boys. The American Prospect, 15(2).

Solorzano, D.G. (1998). Critical race theory, racial stereotyping, and teacher education. Teacher Education Quarterly, 24(3), 5-19.

Solorzano, D.G., \& Yosso, T.J. (2001). From racial stereotyping and deficit discourse toward a critical race theory in teacher education. Multicultural Education, 9(1), $2-8$.

Somers, C., \& Piliawsky, M. (2004). Drop-out prevention among urban African American adolescents: Program evaluation and practical implications. Preventing School Failure, 48(3), 17-22.

Spradley, J.P. (1997). Participant observation. New York, NY: Holt, Rinehart \& Winston.

Steele, C. (1992). Race and school of black Americans. Atlantic Monthly, April, 68-78.

Stovall, D. (2004). School leader as negotiator: Critical theory praxis and the creation of productive space. Multicultural Education, 12(2), 8-12.

Thurlow, R., Ledoux, M., McHenry, N., \& Burns, M. (2007). University and community partnerships: A full circle program. Essays in Education, 22, 113-121.

Townsend, B. (2000). The disproportionate discipline of African American learners: Reducing school suspensions and expulsions. Exceptional Children, 66, 381-391.

U.S. Census Bureau (2000). Census 2000, Summary File 3.

U.S. Department of Education, National Center for Education Statistics (NCES). (2003). National household education survey. Washington, DC: Office of Educational Research and Improvement.

U.S. Department of Education (2008). http://www.ed.gov/programs/gearup/index.html

Watson, L.W. (1998). The college experience: A conceptual framework to consider for enhancing students' educational gains. In K. Freeman (Ed.), African American culture and heritage in higher education research and practice. Westport, CT: Praeger.

Weis, L., \& Fine, M. (2000). Speed bumps: A student-friendly guide to qualitative research. New York, NY: Teacher's College Press. 
Williams, J.B. (1988). Title VI regulation of higher education. In J.B. Williams (Ed.), Desegregating America's colleges and universities. New York, NY: Teacher's College Press.

Wilson, R. (1998). African American participation in higher education. In K. Freeman (Ed.), African American culture and heritage in higher education research and practice. Westport, CT: Praeger.

Woodson, C.G. (1933). The mis-education of the Negro. Trenton, NJ: First Africa World Press, Inc. 
APPENDICES 


\section{Appendix A \\ Semi-Structured Interview Guide \\ Interview Questions for OYC Students - First Interview}

1. Where were you born?

2. How long have you lived in Overtown?

3. Can you describe what living in Overtown is like for you - how it makes you feel?

4. If you have brothers and/or sisters, how many do you have? Are they younger or older than you? Are they currently living with you?

5. Can you describe the kind of relationship you have with them?

6. Who is raising you (mother, father, mother and father, grandparent $[\mathrm{s}]$ )?

7. How did you first hear about the Overtown Youth Center (i.e., from a friend, your mother/father/guardian, etc.)?

8. Whose idea was it for you to go to the center?

9. How long have you been going there?

10. What are your favorite kinds of activities at the center?

11. Would you describe one particular activity that has had the strongest positive effect on you?

12. What are your least favorite activities? Why?

13. What do you envision yourself doing after high school?

14. What kinds of things are you doing at OYC that you think are helping you to prepare yourself for life after high school? 
15. If you had not thought about going to college before but are thinking about it now, in what ways has the center influenced your desire to go to college?

16. Before you started going to the center, what were your experiences at school like (i.e., in terms of your relationships with your peers, your teachers, your attitude toward school)?

17. What kinds of things did you do after school before you started attending the center?

18. How do they differ from what you do now?

\section{Second Interview Questions for OYC Students}

Sample - Deborah Breedlove

1. How old were you when you started living with your grandparents?

2. How did you come to be living with your grandparents? What happened to your mother? Your father?

3. Do you have any contact with your birth mother/father?

4. The other day you talked about someone being shot right in front of your house. How did that make you feel?

5. Have you had other experiences like that one?

6. Would you explain what you meant when you told me that "sometimes the scheduling can get a little crazy?"

7. Before you were going to the Center and you were "just hanging out," what, if anything were you getting in to that you were not supposed to (i.e., drugs, gangs, etc.)?

8. Before you started going to the Center, what kind of grades did you get in school? 
9. Did you have any behavioral problems like fighting?

10. What kinds of relationships did you have with your teachers before the Center, and have those relationships changed? 


\section{Appendix B \\ Semi-Structured Interview Questions \\ Fred Rosario, High-School Coordinator - First Interview}

1. What were you doing professionally before working at OYC?

2. How did you first become involved with OYC?

3. Could you provide me with an overview of your basic responsibilities as the highand post-high school coordinator?

4. Which of your responsibilities do you consider to be your biggest challenge(s)?

5. Please describe the kind of training you receive, particularly as it relates to the replication of SEI culture and policy?

6. Carla talked about the importance of "moving toward fidelity of replicating the SEI model." What is your opinion on that, i.e., how closely should it be replicated?

7. What are some of the specific outcomes for your students that you are tasked with (i.e., graduating from high school, getting into college, on-time promotion, student's grades, student conduct)?

8. How would you describe the "culture" of the center (as it relates to the "OYC standards")?

9. What would you consider to be the greatest obstacle(s) these kids face in regard to adapting to or accepting the OYC culture?

10. What do you see as some of the most significant differences between the culture at the center and the culture in the environment surrounding the center? 
11. What are some of the outside groups that work with your students, and how do they contribute to their educational aspirations?

12. Carla Penn talked about a recruitment selection process called the " $10,30,60$." First, is that really the way students are recruited to the center; and second, what do you think of that formula?

13. To what extent, and in what ways, are the peers in the $10 \%$ she described encouraged/utilized to assist the others?

14. What is your view of the extent to which the parents buy into the center's culture, and how much of a commitment do you think they have to the overall picture?

15. How much do you see the culture of the center running over into the home life of the kids?

16. In what behavioral and educational areas do you think OYC has had the most success, in terms of instilling that culture in the youth there? The least success?

17. What were your initial expectations of the center, in terms of the overall impact its programs would have on the youth there?

a. In what ways, if any, have your expectations been met?

b. In what ways, if any, have they not been met?

c. In what ways, if any, have your expectations been exceeded?

18. If you have a personal vision for the center and its youth, what is it?

19. How much awareness do you think the students have of Black/White relationships in the U.S. and in Overtown - both historically and at present?

20. How do you feel about educating them on the subject? 
21. What role does education play in the overall structure of the center's daily activities?

22. What are some of the specific things the Center does to increase the aspirations of its youth to attend college?

23. What role, if any, does religion or spirituality play in the culture of the center?

24. What role, if any, does it play in the student's aspirations to attend college?

25. Could you describe a "typical" day at the center (if there is such a thing)?

26. Could you tell me a "story" about one or two of the students there in whom you have noted a particularly major change since he/she began participating in the center's activities?

27. How would you rate the overall success of the center?

28. In your opinion, what aspect(s) of the program need to be improved upon? Eliminated? Expanded upon?

29. What, if anything, would you like to see added to the center's programming?

\section{Second Interview Questions for Fred Rosario}

1. Can you tell me the total number of kids who have graduated from high school so far?

2. Of those, how many went to college?

3. What kinds of things do you do with/for the post-high-school kids?

4. Can you tell me something about the Job Corps and how it works?

5. Questions 9, 10, 11, 17, 18, 21, 22 from the original interview were not asked, so they need to be asked this time. 
6. In what ways do you think that the academic portion of the program could be improved upon? Content? Delivery? Teachers? Subject matter?

7. I was talking to one of the university administrators the other day who has done a lot of work with community organizations and told me that the inconsistencies I have noted at OYC as being one of its down sides is simply "the nature of the beast." That is, one of the only things that has bothered me about working with the Center is the fact that our plans get canceled frequently, because the students suddenly have something else they have to do or someplace else they have to be, which takes priority. I had gotten the feeling that stuff like that made it more difficult for them to understand the importance of making a commitment to doing something or for taking responsibility, both of which are things that they definitely need to learn to be successful in the outside world. Now I'm not so sure about it being a detriment of the program. What do you think?

8. Also, I have seen that there are many very major "pros" to having a celebrity heading up a charity organization like OYC. The most significant of the pro's is that, because so many groups and individuals want to get involved with something the celebrity is doing, the kids have an opportunity to get exposed to a lot of things they might ordinarily not get exposed to (such as putting together an entire magazine under the tutteledge of a professional magazine staff). On the other hand, I sometimes get the impression that at least some of them begin to develop a false sense of entitlement by being given all sorts of opportunities to do things, whether they truly deserve them or not. They know that they can do almost whatever they want and get away with it. However, that feeling is basic 
human nature, and perhaps rather than being the kids' fault, it is simply an essential weakness of the program. (This is mostly in reference to the kids not having to attend the center on a regular basis.) I know that you told me that SEI works the same way, but what I want to know now is whether or not you think that is a weakness of the program. Also, is there anything they have to do to "qualify" to participate in a special program or trip? 
Appendix C

Semi-Structured Interview Questions

\section{Interview Questions for OYC Coordinators/Parents (Williams \& Jackson)}

1. What is your educational background?

2. What were you doing professionally before working at OYC?

3. How did you first become involved with OYC?

4. What kind of special training, if any, did you need to have to be a coordinator?

5. What kind of training do you get at the center?

6. How long have you been with OYC?

7. Would you please describe some of the details of your home life for me (i.e., are you a single mother? How many children do you have? How old are they? Etc.)

8. How much importance, if any, do you place on religion or spirituality in your family life?

9. What role, if any, does it play in your children's aspirations to attend college?

10. How much of a role - if any - do you think religion, God, etc., should play at the center?

11. What made you decide to have your child (children) go to OYC?

12. What do you see as the greatest benefit(s) of the center for your child?

13. In what ways, if any, has the culture of the center positively influenced your home life?

14. What is the most important thing that you want your child to get from his/her participation in the center (i.e., a love for education, the aspiration to go to college, the ability to be a leader, etc.)? 
15. What positive changes, if any, have you seen in your child since he/she first began going to OYC?

16. Could you provide me with an overview of your basic responsibilities as a coordinator?

17. What are some of the specific outcomes for your group of students that you are tasked with (i.e., on-time promotion, improved grades, improved attitude and conduct)?

18. Which of those do you consider to be the biggest challenge(s)?

19. As a coordinator, who is also a parent, to what extent do you see the other parents buying into the center's culture, and how much of a commitment do you think they have to the overall picture?

20. In what behavioral and educational areas do you think OYC has had the most success, in terms of instilling its culture in the youth there? The least success?

21. To what extent, and in what ways, do the older kids at the center help to mentor the younger ones?

22. In what ways, if any, have your initial expectations of the center, in terms of the overall impact its programs would have on the youth there, been met?

23. How much awareness do you think the students have of Black/White relationships in the U.S. and in Overtown - both historically and at present?

24. How do you feel about educating them on the subject?

25. What role does education play in the overall structure of the center's daily activities? Do you think it plays enough of a role? If not, how would you change things? 
26. Could you describe a "typical" day at the center (if there is such a thing)?

27. Could you tell me a "story" about one or two of the students there in whom you have noted a particularly major change since he/she began participating in the center's activities?

28. How would you rate the overall success of the center?

29. In your opinion, what aspect(s) of the program need to be improved upon? Eliminated? Expanded upon? 


\section{Second Interview Questions for Coordinators/Parents}

1. In what ways, if any, has the culture of the center positively influenced your home life?

2. What is the most important thing that you want your child to get from his/her participation in the center (i.e., a love for education, the aspiration to go to college, the ability to be a leader, etc.)?

3. What do you see as the greatest benefit(s) of the center for your child?

4. What are some of the specific outcomes for your group of students that you are tasked with (i.e., on-time promotion, improved grades, improved attitude and conduct)?

5. In what behavioral and educational areas do you think OYC has had the most success, in terms of instilling its culture in the youth there? The least success?

6. To what extent, and in what ways, do the older kids at the center help to mentor the younger ones?

7. In what ways, if any, have your initial expectations of the center, in terms of the overall impact its programs would have on the youth there, been met?

8. How do you feel about educating them on the subject of black/white relationships in the U.S.?

9. What role does education play in the overall structure of the center's 0 daily activities? Do you think it plays enough of a role? If not, how would you change things?

10. Could you describe a "typical" day at the center (if there is such a thing)? 
11. Could you tell me a "story" about one or two of the students there in whom you have noted a particularly major change since he/she began participating in the center's activities?

12. How would you rate the overall success of the center?

13. I was reading something about SEI that said the kids participate in anti-violence campaigns, and that some of the things they do is take trips to juvenile detention facilities and/or hospital trauma centers. Do they do things like that at OYC as well? 


\section{Appendix D \\ Semi-Structured Interview Questions \\ First Interview Questions for Carla Penn}

1. Where were you living before you came to OYC?

2. What were you doing professionally before OYC?

3. How did you first become involved with OYC?

4. Could you provide me with an overview of your basic responsibilities as Executive Director of the Center?

5. As an OYC administrator, which of those responsibilities do you consider to be your biggest challenge(s)?

6. What kind of selection process is there for the center's youth?

7. How would you describe the "culture" of the center?

8. In what areas do you think OYC has had the most success, in terms of instilling that culture in the youth there?

9. What would you consider to be among the greatest obstacles these kids face in regard to adapting to the OYC culture?

10. What were your initial expectations of the center, in terms of the impact it would have on its students?

11. In what ways, if any, have those expectations been met?

12. In what ways, if any, have they not been met?

13. In what ways, if any, have they been exceeded?

14. What is your personal vision for the center and its youth? 
15. How much awareness do you think the students have of Black/White relationships in the U.S. and in Overtown - both historically and at present?

16. How do you feel about educating them on the subject?

17. What are some of the things the Center does to increase the aspirations of its youth to attend college?

18. What role, if any, do you think spirituality plays in student aspirations?

19. Could you describe a "typical" day at the center (if there is such a thing)?

20. Could you tell me a "story" about one or two of the students there in whom you have noted a particularly major change since he/she began participating in the center's activities?

21. How would you rate the overall success of the center?

22. What measures does the center use to evaluate its success?

23. In your opinion, what aspect(s) of the program, if any, need to be improved upon and/or eliminated?

24. What, if anything, would you like to see added to the center's programming? 


\section{Second Interview Questions for Carla Penn}

1. Would you please explain what you mean by the program "functioning with high integrity?"

2. What are some of the specific outcomes of the Center's programs thus far?

3. How have those outcomes been measured (i.e., can you provide statistical information?)?

4. What means do you use to "insure that the agency is operating at its optimal effort?"

5. In the question I asked you regarding your basic responsibilities, you did not mention fundraising, but then, in answer to the next question, you said that fundraising is your biggest challenge. What, specifically, do you do in the area of fund raising? (i.e., do you plan/organize fund raisers? Do you go to see prospective donors yourself?)

6. How does the Center determine which students fit into which category of the 1060-30? Do you have a questionnaire? Do interviews?

7. Since I am familiar with most of the high school kids, could you give me an example of one of them that fit into the " 10 " category before even starting here? [I would guess Reginald and DeAndre]

8. What kinds of things do you do to try to engage a parent who is reticent in taking an interest in his/her child's education and growth?

9. What do you think is among the greatest obstacles that the kids face in attempting to adapt themselves to the OYC culture? 
10. When I asked you what your initial expectations of the center were, in terms of the impact it would have on the kids, you said "quality," but you also said that you were "clearly not there yet." What do you think is still missing? What are some of the things you would like to see improvement in? What are some of the "great outcomes" you mentioned? [See my original questions 11, 12, 13]

11. Is there some written document you could give me that describes the SEI model?

12. On a scale of $1-5$, you rated the success of the Center as " 3 ." Could you give me some examples of areas in which you consider there to be "much room for improvement?"

13. Could you describe a "typical day at the Center" for me?

14. Could you tell me a brief story about 1 or 2 of the students there in whom you have noted a particularly major change?

15. How do household income and kids getting free lunch or not figure in as measures of outcome?

16. What are some of the things you would do to improve the parent programs and the post-high follow up?

17. Have you had any "wrong partnerships," and if so, how were they "wrong?"

18. Why do you think there is such a large turnover in OYC staff? 


\section{Appendix E \\ Semi-Structured Interview Questions \\ Interview questions for Alonzo Mourning}

1. Why did you choose to build your first center in Overtown rather than, say, in Opa Locka, Carroll City, Miami Gardens, Little Haiti, or even somewhere in Broward County?

2. What would you say are the major obstacles that the youth growing up in inner city neighborhoods like Overtown face today?

3. How do you envision the Center helping them to deal with those obstacles?

4. What are your short- and long-term goals/visions for the future in regard to assisting inner city youth?

5. What is the current status of your proposed center in Miami Gardens?

6. What is your point of view regarding the importance of educating Black youth about African and African-American culture and history?

7. What are your feelings on educating them about the history of racism in America? That is, do you think such knowledge would benefit them, or might it be detrimental to them? 


\section{Appendix F \\ Semi-Structured Interview Questions \\ Interview with Parent Coordinator}

1. How did you first get involved with the Center?

2. Will you give me an overview of the program itself? Its components, how it is organized, etc.

3. So, if they don't come, their kids can't attend the Center?

4. But you don't go to the schools yourself?

5. When the parents come here for meetings, is there a specific subject you talk about?

6. What I mean is the meetings are just more instructional classes and things like that?

7. does the Center set any specific goals that you have to meet?

8. How easy or difficult would you say it is to get the parents to buy into the culture?

9. What are some of the obstacle you think the parents face when it comes to getting involved with the center?

10. What are some of the challenges that you have when you're trying to get certain parents involved?

11. What do you think is the $\%$ of parents who participate actively is?

12. Is there anything you can think of that could improve the program that you aren't able to do at this point, or do you think that your part of the program is as good as it could be right now? 
13. Do you think that the kids are at a big disadvantage if their parents aren't really involved?

14. I was just thinking in terms of psychologically for the kids. I mean if their parents are not involved if they are still going to be able to succeed, because of all the other things they are getting from the Center. 
VITA

JAYNE A. KLEIN

Born, New York, New York

B.A., French Literature

Hunter College, City University of New York

New York, New York

2004

M.A., Religious Studies

Florida International University

Miami, Florida

Graduate Certificate, African New World Studies

Florida International University

Miami, Florida

2005-2011

Program Coordinator, Honors College

Florida International University

Miami, Florida

Instructor, Honors College

Florida International University

Miami, Florida

Adjunct Instructor, Religious Studies

Florida International University

Miami, Florida

Doctoral Candidate

Florida International University

Miami, Florida

2008

Adjunct Faculty Award for Excellence in Teaching

Florida International University

Miami, Florida

2011

Martin Luther King, Jr., Service Award

Florida International University

Miami, Florida

PUBLICATIONS AND PRESENTATIONS

Klein, J. (2004). The Religion of Vodou in Haiti and Miami. Paper presented at the $16^{\text {th }}$ Annual Conference of the Haitian Studies Association, Old San Juan, Puerto Rico. 
Klein, J. (2005). The United States Occupations of Haiti. Paper presented at the $17^{\text {th }}$ Annual Conference of the Haitian Studies Association, Boston University, Boston, Massachusetts.

Klein, J. (2006). The First United States Occupation of Haiti. Paper presented at the $30^{\text {th }}$ Annual Conference of the Caribbean Studies Association, Santo Domingo, Dominican Republic. 